\title{
WestVirginiaUniversity
}

THE RESEARCH REPOSITORY @ WVU

Graduate Theses, Dissertations, and Problem Reports

2016

\section{A computational model for thermal management of battery storage systems}

\author{
Mehmet Aygun
}

Follow this and additional works at: https://researchrepository.wvu.edu/etd

\section{Recommended Citation}

Aygun, Mehmet, "A computational model for thermal management of battery storage systems" (2016). Graduate Theses, Dissertations, and Problem Reports. 5134.

https://researchrepository.wvu.edu/etd/5134

This Thesis is protected by copyright and/or related rights. It has been brought to you by the The Research Repository @ WVU with permission from the rights-holder(s). You are free to use this Thesis in any way that is permitted by the copyright and related rights legislation that applies to your use. For other uses you must obtain permission from the rights-holder(s) directly, unless additional rights are indicated by a Creative Commons license in the record and/ or on the work itself. This Thesis has been accepted for inclusion in WVU Graduate Theses, Dissertations, and Problem Reports collection by an authorized administrator of The Research Repository @ WVU. For more information, please contact researchrepository@mail.wvu.edu. 


\title{
A Computational Model for Thermal Management of Battery Storage Systems
}

\author{
Mehmet Aygun \\ Thesis submitted \\ to the Benjamin M. Statler College Engineering \& Mineral Resources \\ at West Virginia University \\ in partial fulfillment of the requirements for the degree of \\ Master of Science in \\ Mechanical Engineering
}

Ismail B. Celik, Ph.D., Chair

Terence Musho, Ph.D.

Xingbo Liu, Ph.D.

Department of Mechanical and Aerospace Engineering

Morgantown, West Virginia

2016

Keywords: NaS Battery, 3D Model, Numerical Modelling, Heat Transfer, Electrochemistry, Lumped Model

Copyright 2016 Mehmet Aygun 


\section{Abstract \\ A Computational Model for Thermal Management of Battery Storage Systems}

\section{Mehmet Aygun}

Fossil fuel based power generation causes air pollution and climate change. The consequences of these two factors are of at most importance for future generations. Thus, renewable energy sources can play a significant role by reducing the dependence on fossil fuels. However, if the energy storage problem is not solved renewable sources will not be useful. Sodium sulfur battery $(\mathrm{NaS})$ is one of the practical solutions to store wind and solar energy. A $\mathrm{NaS}$ battery is comprised of two liquid electrodes and one solid electrolyte which operate between $300-350{ }^{\circ} \mathrm{C}$. The molten sodium is in anode electrode, the molten sulfur and sodiumpolysulfide are in cathode electrode, and solid electrolyte, which is made out of beta-alumina or Nasicon material is between anode and cathode.

The purpose of this study is to develop a computational model for a NaS battery block which includes multiple cells and to predict the temperature inside the block during the operation cycles. The temperature distributions are calculated using a newly developed threedimensional thermal model which takes cell temperatures as input from a lumped electrochemistry model. The properties required for solving governing equations are calculated and updated as a function of time and temperature based on the composition of each control volume. The lumped model is validated against experimental results from the literature. The 3D thermal model is used to perform a parametric study on key stack properties. The newly developed algorithm is robust and can be used for stack design analysis and improvement. 


\section{Acknowledgements}

My deepest gratitude goes first to my advisor, Dr. Celik, for his patience and for supporting and helping me succeed. Without his knowledge, wisdom and leadership this research could not have reached its present form. Also, beyond being an advisor he has been like a father to me in my private life.

I would also like to thank Dr. Hayri Sezer. He has been a great colleague at work and great friend in social life. He rendered me with his assistance anytime I needed and contributed greatly to this study. I must also acknowledge other members of my graduate committee: Dr. Xingbo Liu for providing funding through his research group - the Center for Electrochemical Energy Storage (CEES) and Dr. Musho for the courses he has taught and for lighting my way for a better research.

Finally, I owe my sincere gratitude to my family and my girlfriend Thaina F. Deolindo. They have supported me morally in any condition during my education. Also, I would like to thank my friends; Deniz and Meltem Ozgulbas, Eren and Meltem Alay, Zekiye Yagmur, Ugur Magat, Ozgun Ezgi Onen and friends in Computational Fluid Dynamics and Applied MultiPhysics (CFD\&AMP) Center, especially Hunter Mason, Jose Escobar, Sergio Escobar, Albio Gutierrez, Satish Guda and Vicente Carpio. They have all been helpful and enjoyable people during the time I have spent in the office with them. 


\section{Table of Contents}

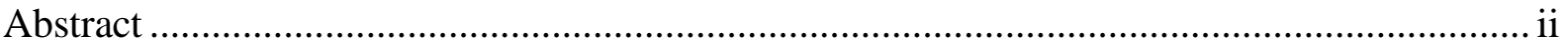

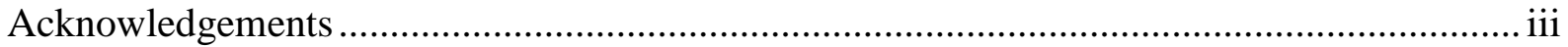

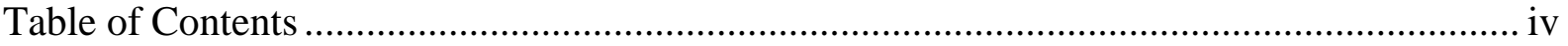

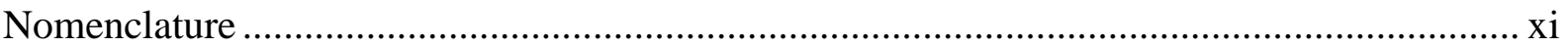

Chapter 1: Introduction ............................................................................................. 1

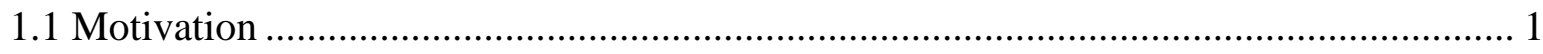

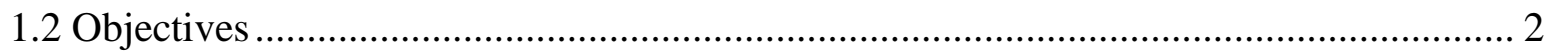

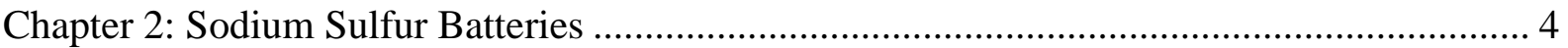

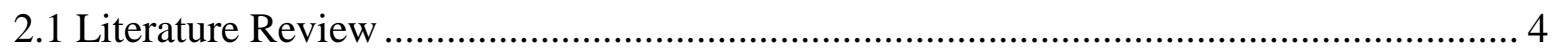

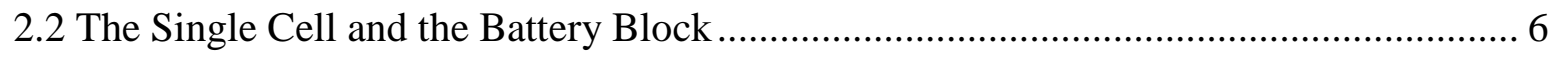

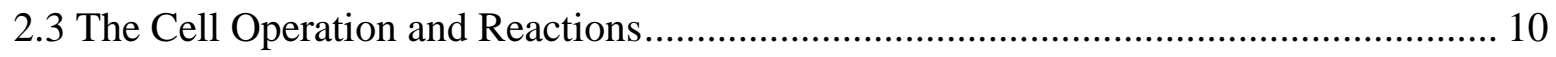

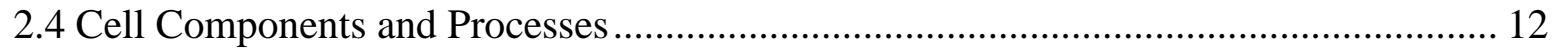

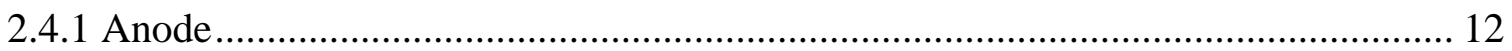

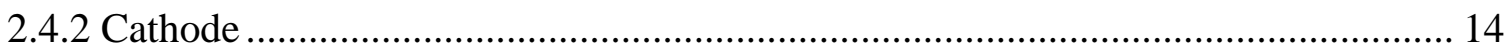

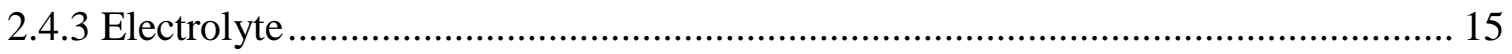

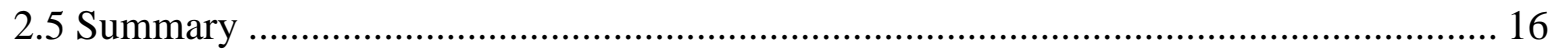

Chapter 3: Lumped Mathematical Model ............................................................................ 17

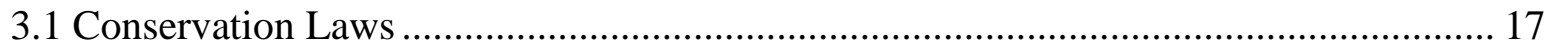

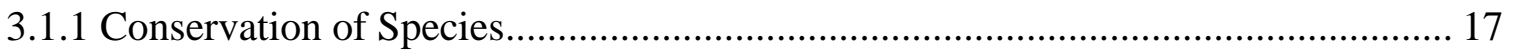




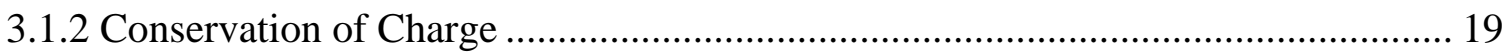

3.1.3 Conservation of Energy ………………………............................................. 20

3.2 Gibbs Free Energy and Open Circuit Voltage............................................................ 22

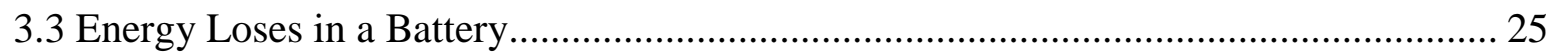

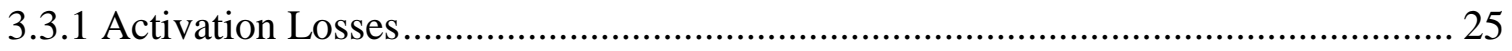

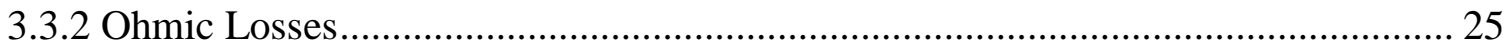

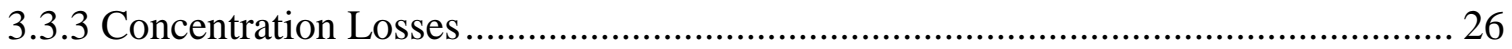

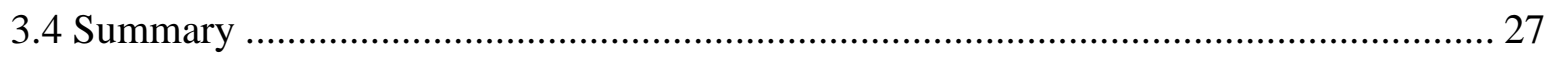

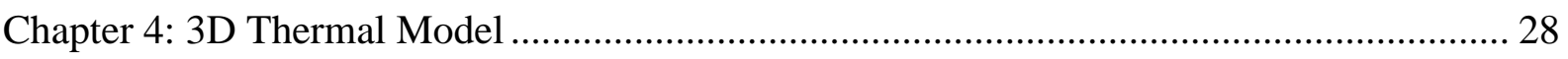

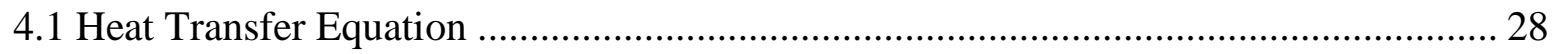

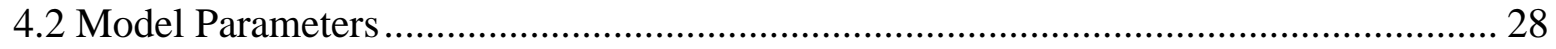

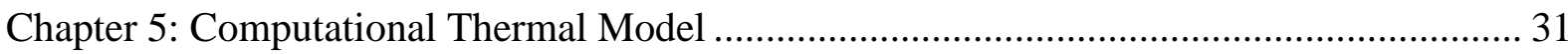

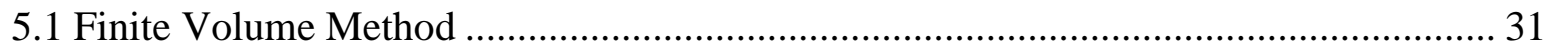

5.2 Discretization of the Heat Transfer Equation .............................................................. 32

5.3 Computational Domain and Boundary Conditions ………....................................... 32

5.4 Numerical Method................................................................................................ 34

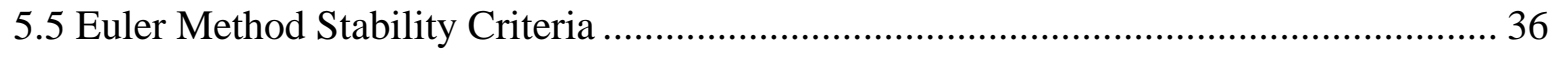

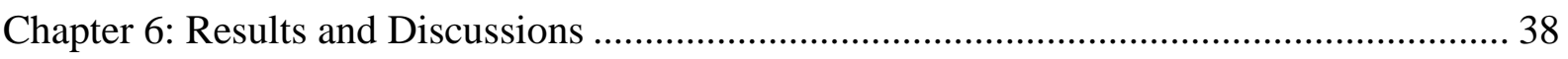

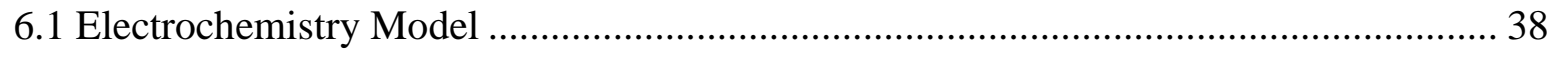

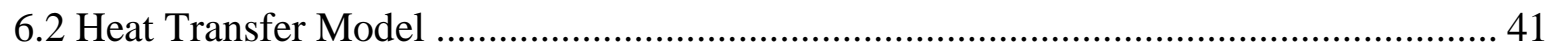


6.3 Mesh Convergence Analysis

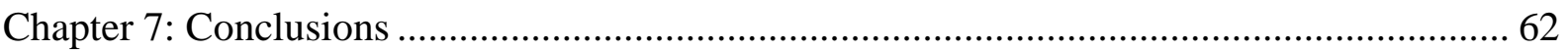

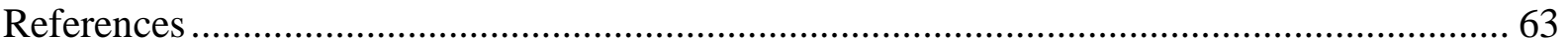

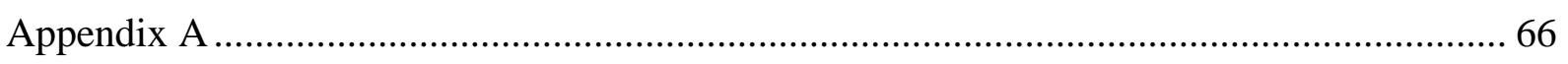

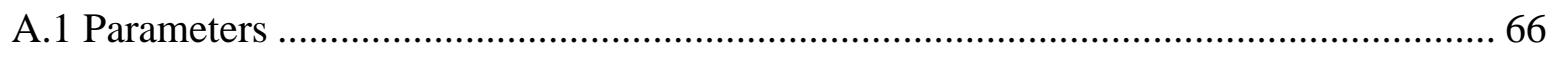

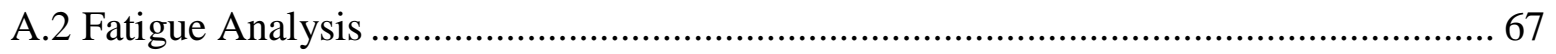




\section{List of Figures}

Figure 1 - Representation of NaS battery for (a) planar cell [19] (b) cylindrical cell [4]........ 7

Figure 2 - Cell configuration in a battery module [11] ............................................. 9

Figure 3 - Representation of the thermal enclosure for a battery module.......................... 10

Figure 4 - NaS cell voltage vs. state of discharge [23]. ............................................ 11

Figure 5 - Schematic of three anode designs; (a) reservoir feeding (b) sodium wicking (c)

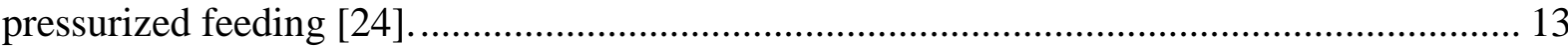

Figure 6 - Control volume for the two-dimensional heat conduction equation. ................... 31

Figure 7 - Computational domain of battery module for $3 \times 3$ cell arrangement. ................ 33

Figure 8 - Computational domain of battery module for a single cell. .............................. 33

Figure 9 - The flow chart of the model..................................................................... 35

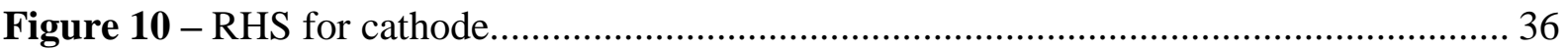

Figure 11 - RHS for electrolyte............................................................................ 36

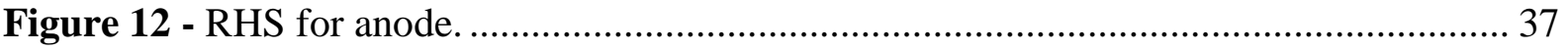

Figure 13 - (a) Temperature (b) Voltage \& Depth of discharge (DoD) for .......................... 38

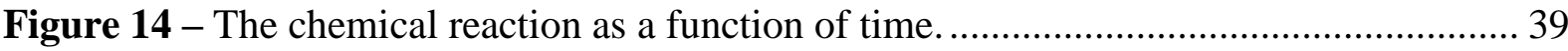

Figure 15 - (a) Temperature (b) Voltage \& Depth of discharge for $i=195 / 260 \mathrm{~mA} / \mathrm{cm} 2.40$

Figure 16 - Average temperature of surrounding points of the cell inside the battery block (a)

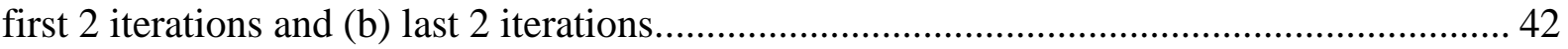

Figure 17 - Cell temperature difference inside the battery block a) first 2 iterations b) last 2

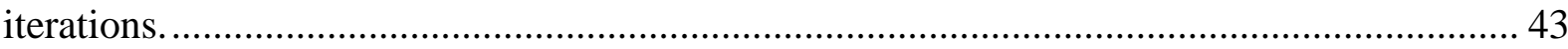

Figure 18 - Temperature contour in 2 hrs. of charging cycle (a) full scale (b) small scale. ... 43

Figure 19 - Temperature contour in 2 hrs. of discharging cycle. ..................................... 44 
Figure 20 - Temperature of the thermal enclosure with air convection at south and north boundaries. 45

Figure 21 - The battery voltage and DoD when $T=200{ }^{\circ} \mathrm{C}$ 45

Figure 22 - Temperature contour in 2 hrs. of charging cycle when the gaps filled with sand

(a) full scale (b) small scale.

Figure 23 - Temperature contour in 2 hrs. of discharging cycle when the gaps filled with sand. 47

Figure 24 - Voltage and DoD for larger cell model. 48

Figure 25 - Temperature profile for larger cell model. 48

Figure 26 - Temperature contour in 2 hrs. of charging cycle for uniform boundary condition

(a) full scale (b) small scale. 50

Figure 27 - Temperature contour in 2 hrs. of discharging cycle for uniform boundary condition (a) whole module (b) 4 cells in the bottom left-hand corner. 51

Figure 28 - Temperature profile along the x-axis for uniform boundary condition. 52

Figure 29 - Temperature profile in 2 hrs. of charging cycle for non-uniform boundary condition (a) full scale (b) small scale. 53

Figure 30 - Temperature contour in 2 hrs. of discharging cycle for non-uniform boundary condition (a) whole module (b) 4 cells in the bottom left-hand corner. 54 Figure 31 - Temperature profile along the x-axis with non-uniform boundary condition...... 55 Figure 32 - Temperature profile in 2 hrs. of charging cycle for $8 \times 5$ battery module (a) full scale (b) small scale. 57

Figure 33 - Temperature profile in 2 hrs. of charging cycle for the 4 cells in bottom left-hand corner. 57 
Figure 34 - Temperature profile in 2 hrs of discharging cycle for $8 \times 5$ battery module

Figure 35 - Temperature profile of the middle row along the $\mathrm{x}$-axis for $8 \times 5$ cell

configuration.

Figure 36 - Temperature profiles along the $\mathrm{x}$-axis for the grid numbers defined in Table 7 at the end of the discharge cycle.

Figure 37 - Temperature profiles along the $\mathrm{x}$-axis for the grid numbers defined in Table 7 at the end of the discharge cycle for larger cell model. 61

Figure A.2 Temperature profile of the electrolyte during the 5 full cycles 


\section{List of Tables}

Table 1 - Comparison of battery performances [20] [21] ................................................ 8

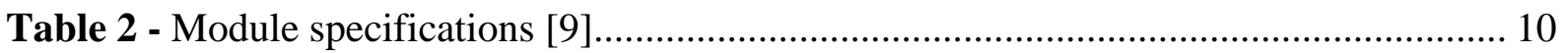

Table 3 - Thermal conductivity values and empirical equations [22]............................... 29

Table 4 - Electrical and ionic conductivity values and empirical equations [22]................. 29

Table 5 - Heat capacity values and empirical equations [22] ......................................... 30

Table 6 - Material density values and empirical equations [22]...................................... 30

Table 7 - Grid numbers for mesh convergence analysis. ............................................. 59

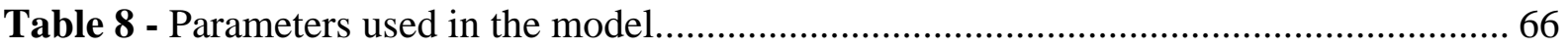




\section{Nomenclature}

\section{Symbol Description}

\begin{tabular}{|c|c|}
\hline A & Ampere \\
\hline$A^{\text {cond }}$ & Conduction area \\
\hline$A^{\text {conv }}$ & Convection area \\
\hline$A_{\text {eff }}$ & Effective cross-sectional area \\
\hline $\mathrm{CV}$ & Control volume \\
\hline $\mathrm{C}_{\mathrm{p}}$ & Heat capacity \\
\hline DoD & Depth of discharge \\
\hline $\mathrm{E}$ & Voltage \\
\hline $\mathrm{E}^{0}$ & Electrochemical cell voltage \\
\hline e & Electron \\
\hline $\mathrm{F}$ & Faraday Constant \\
\hline $\mathrm{G}$ & Gibbs free energy \\
\hline g & Gram \\
\hline $\mathrm{H}$ & Enthalpy \\
\hline $\mathrm{h}$ & Hour \\
\hline I & Faradaic current \\
\hline $\mathrm{I}_{\mathrm{e}}$ & Electronic current \\
\hline $\mathrm{I}_{i}$ & Ionic current \\
\hline$i$ & Current density \\
\hline$i_{0}$ & Exchange current density \\
\hline
\end{tabular}




\begin{tabular}{ll} 
Symbol & Description \\
$\mathrm{J}$ & Joule \\
$\mathrm{K}$ & Kelvin \\
$\mathrm{k}$ & Thermal conductivity \\
$l_{\text {eff }}$ & Effective conductor length \\
$\mathrm{m}$ & Mass \\
$\dot{\mathrm{m}}$ & Mass flow rate \\
$\mathrm{N}$ & Avogadro number \\
$\mathrm{n}$ & Number of moles \\
$\mathrm{OCV}$ & Open circuit voltage \\
$\mathrm{Q}$ & Heat \\
$\mathrm{q}$ & Charge \\
$\mathrm{R}$ & Universal gas constant \\
$\mathrm{t}$ & Electrical resistance \\
$R_{0}$ & Source term \\
$S_{T}$ & Molar entropy \\
$\bar{s}$ & Temperature \\
$\mathrm{T}$ & Ambient temperature \\
\hline & \\
\hline & Time \\
\hline & \\
\hline &
\end{tabular}




$\begin{array}{ll}\varepsilon & \text { Porosity } \\ \eta & \text { Activation loss } \\ \rho & \text { Density } \\ \sigma & \text { Electrical conductivity }\end{array}$

\section{Superscriptions}

$\begin{array}{ll}\text { o } & \text { Old numerical step } \\ \text { prod } & \text { Produced } \\ \mathrm{S} & \text { Species } \\ \text { used } & \text { Consumed } \\ + & \text { Ion } \\ - & \text { Electron }\end{array}$

\section{Subscriptions}

\begin{tabular}{ll} 
A & Anode \\
E & Cathode \\
$\mathrm{e}$ & Electrolyte \\
$\mathrm{j}$ & East \\
$\mathrm{n}$ & Neighbor point \\
$\mathrm{P}$ & North \\
$\mathrm{s}$ & Center point \\
$\mathrm{w}$ & South \\
\hline
\end{tabular}




\section{Chapter 1: Introduction}

\subsection{Motivation}

The energy demand has been rapidly increasing worldwide as the planet runs out of non-renewable energy resources such as coal, petroleum and natural gas. Thus, it has become necessary to find sustainable energy sources. Due to the need of a reliable and secure energy supply, renewable energy sources such as wind and solar energy can be used to meet the energy need. On the other hand, fossil fuels effect the nature adversely such as air pollution and change the climate which is a serious problem for the future of the world. Whereas, clean energy can be obtained from renewable energy sources which do not have greenhouse gasses such as $\mathrm{CO}$, $\mathrm{CO}_{2}$ and $\mathrm{NO}_{\mathrm{x}}$. However, the electricity that is obtained from renewable resources varies with the natural conditions. The wind does not blow and the sun does not always shine at the expected time and point. Thus, solar and wind energy might not be always available when needed. These variations cause fluctuations on generating electricity which can cause several problems. In order to avoid fluctuations, new solutions have been developed and one of them is storing the electricity for some time. Storing the electricity is possible with rechargeable batteries. One solution is to use the generated electricity when the demand is high and to store electricity at night times when the demand is low. Rechargeable batteries are good candidates for energy storage and they can be a reliable power supply for industrial facilities [1].

A rechargeable battery is a type of electrical battery which is also called as secondary battery. Basically, the battery consists of one or more reversible chemical reactions. There are several different secondary batteries such as lithium-ion (Li-ion), sodium-sulfur ( $\mathrm{NaS}$ ), vanadium redox (VR), polysulfide-bromide (PSB), lead-acid, and nickel-cadmium (NiCd) and they provide various functions [2]. Secondary battery technologies that use sodium are 
attractive candidates for the use of large-scale energy scale applications including electric vehicles, utility generation and distribution, and aerospace. Most promising and well-known sodium beta battery is sodium sulfur battery which has been developed for 25 years. The NaS battery system was initially designed as an energy management device for load leveling and peak shaving applications. Later, with the new improvements NaS battery was redesigned to respond to power quality demands. Today's NaS batteries are unique multiple function storage devices that can satisfy a variety of energy and power requirements from load leveling. Another feature of the NaS battery that makes it very desirable is its relatively high energy density that giving it a size advantage over some other battery technologies. Basically, NaS battery is low in cost since it has inexpensive raw materials and due to the liquid electrodes it has high life cycle. Also, NaS battery is a high temperature battery system which is insensitive to ambient conditions. These features make the sodium/sulfur battery useful and applicable [3]. However, Na-S battery technology comes with the disadvantages of high temperature operating conditions, brittle insulator and safety concern with regarded to temperature management. Especially, temperature changes during charging and discharging states cause a fatigue in the solid electrolyte. After several repeatedly applied cycles the solid electrolyte becomes weak and does not function as expected. Therefore, many experimental and computational research have been done on sodium sulfur battery to improve its performance such as trying to reduce the operation temperature and fatigue effects.

\subsection{Objectives}

The objective of this study is to develop a three-dimensional computational NaS battery block model which includes multiple cells in different configuration and to predict the temperature inside the block during the operation cycles. The 3D thermal model takes cell 
temperatures as input from a lumped (or zero dimensional) electrochemistry model which is derived from the integral analysis of the mass, energy and charge transport throughout the battery. The thermal properties such as electrical conductivity, thermal conductivity, density and heat capacity change with time, temperature, phase and specie concentrations. The lumped model is integrated into the 3D thermal model which, in turn, is used to perform a parametric study on key stack properties. The specific tasks to achieve the stated objectives are:

1. Describe the cell components, the chemical reactions inside the battery and operating principles.

2. Develop the mathematical and thermal model equations for the lumped electrochemistry model.

3. Develop the 3D thermal model and integrate the lumped model into the 3D model.

4. Apply different cell configurations, boundary conditions and numerical method.

5. Validate the results against the numerical and experimental results that are found in the literature.

6. Perform mesh convergence analysis.

7. Perform the parametric studies relevant to industrial applications.

8. Make suggestions for the future experimental and numerical studies based on the obtained results. 


\section{Chapter 2: Sodium Sulfur Batteries}

\subsection{Literature Review}

Sodium-sulfur battery technology development began developing with vehicular applications in the 1960's. More details of it were first released in 1966 by Ford Motor Company. The main developments have been made during the early 1980's and significant achievements have been made, especially by TEPCO and NGK Insulators, Ltd. companies. During the early 1980 's the energy demand increased rapidly, while the load factor was relatively low. Thus, the electric storage devices have started to take their places. In 1984, the Tokyo Electric Power Company (TEPCO) and NGK used the sodium-sulfur batteries to load levelling and to provide stable and uninterruptible electricity. After successful developments, TEPCO and NGK established the technology which has the brand name "NaS" battery in Japan since April 2002 [2] [4] [5].

In the US, the first NaS battery project was done by the American Electric Power Company (AEP) in September 2002 in Sandia National Laboratories, and their project partners were TEPCO, NGK, ABB, EPRI and DOE. In late 2004, over 100 projects were installed including early demonstration projects dates back to 1992. During 2004, the Tokyo Electric Power Company installed the largest battery energy storage project in the world [4].

In China, the research work on sodium sulfur battery dates back to 1970 's, but since 1980, Shanghai Institute of Ceramics (SICCAS) have been the only Chinese institution which does research on sodium sulfur battery. Besides, several heat transfer modeling works have been done for NaS batteries [6]. 
In 1989, Kawamoto and Kusakabe [7] derived a model for single cell and compared the results of the numerical study with the experimental results. According to the study the temperature during the discharge operation is higher than that in the charging operation. Also the calculated results from the model are in good agreement with measured results.

In 2006 Iba, Ideta and Suziki [8] did some experimental measurements on NaS battery system which has been used to provide one third of electricity demand of a university. Measurements are made daily, weekly, monthly and long term. The total power, the demanded power and charge/discharge power for the NaS system are measured. Also temperature measurements have been made from bottom and side for each module in the whole system to check the heater and the system temperature operations. Based on the experimental results;

- $\quad$ Bottom temperature is higher than side temperature.

- Temperatures change slowly according to the charge/discharge operation.

- Heaters heat up each module to keep the temperature above $300{ }^{\circ} \mathrm{C}$.

- Temperature increases in discharging and it tends to decrease during charge operation.

- Joule loss may cause heat-up during charge and discharge.

In 2007, Hussein, Cheung, Siam and Ismail [9] developed a single NaS battery cell model and validated the voltage-current behavior and characteristics of the cell against the experimental data. Later on, the model was extended to represent a NAS battery module since the NaS battery is usually used in this form where a number of NAS cells are connected together to give higher power and energy capacity. The module is simulated to perform a peak shaving operation. It has been seen that the temperature of the battery module increases at a steady rate 
of about $7{ }^{\circ} \mathrm{C}$ per hour during the $50 \mathrm{~kW}$ discharging operation and in practice, the allowable upper limit of the temperature of the battery module is set at $360^{\circ} \mathrm{C}$.

In 2010, Sarasua, Molina, Pontoriero, Mercado [10] developed a NaS battery model which is suitable to analyze the thermal behavior. It takes into account non-linear battery element characteristic during charging and discharging. Also, the internal resistance of the cell depend on temperature and depth of discharge. As a result, this study shows the effectiveness of the developed $\mathrm{NaS}$ model in a small testing power system.

In 2012, Min and Lee [11] did a numerical study on the thermal management system of $\mathrm{NaS}$ battery. Three-dimensional temperature distribution inside the module was predicted by solving conservation of the thermal energy equation. At the end of the study, authors obtained that the equivalent thermal conductivity of the cell has larger value in vertical direction than in the horizontal direction. Also, module efficiency was predicted for various heater operation and insulation materials and module efficiency is obtained clearly by using variable insulation thickness model. Moreover, temperature distribution inside the module for various operating conditions and cell arrangements were predicted using 3D analysis.

On the other hand, some other types of modelling studies have been done to obtain charge-discharge characteristics, potential distribution, distribution of electrochemical reaction rates, distribution of sodium polysulfide in electrode, the conductivities of the liquids and electrolyte etc. [12] [13] [14] [15] [16].

\subsection{The Single Cell and the Battery Block}

A rechargeable sodium sulfur battery basically contains liquid sodium in anode (or negative electrode), liquid sulfur in cathode (or positive electrode) and a ceramic or glass solid electrolyte between anode and cathode. Both anode and cathode materials are chemically active 
and the electrolyte is electrically non-conductive. Since the active materials are liquid there is no life limitation to the battery. In a sodium sulfur battery, no side reaction occurring in both charging and discharging states. Thus, charging quantity of electricity can be the same with discharging quantity of electricity. The battery is a sealed type so there is no need for a maintenance. However, it comes with some problems. If the solid electrolyte is damaged by a mechanical or thermal shock, there might be a rapid reaction between anode and cathode and there is no solution for this problem. In addition, since the molten sulfur has a high activity and operation temperature, it causes the corrosion in metallic case. The other con is that when the purity of sodium and sulfur decrease, battery life becomes shorter [17] [18].

There are two type of construction for sodium sulfur battery. One type includes a cylindrical metal outer housing which is cathode and circular electrolyte is in the outer housing. The liquid sodium is placed on the first chamber and sulfur is placed on the second chamber. The other type is planar cell. It is called "planar" because the lateral extent is bigger than its height compared to the cylindrical cell.

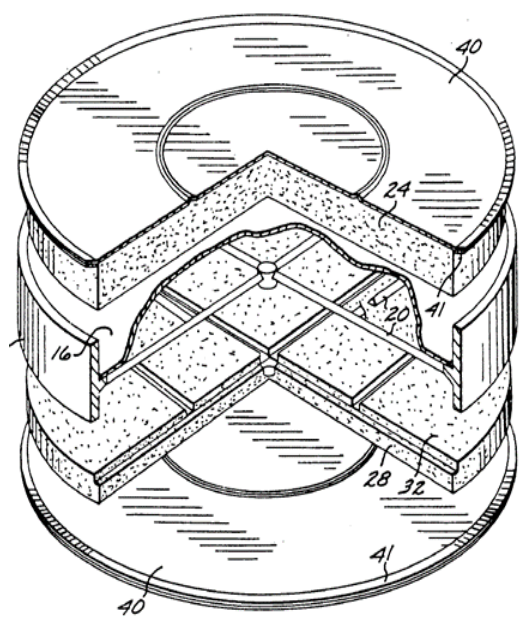

(a)

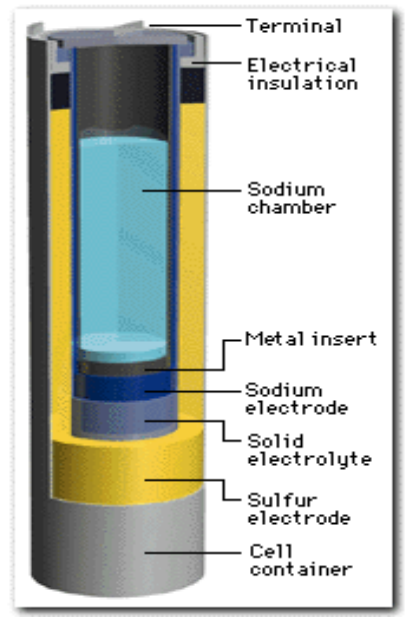

(b)

Figure 1 - Representation of NaS battery for (a) planar cell [19] (b) cylindrical cell [4]. 
Both types of cells are considered depending on applications. One of them is to use the cells in the electrically powered vehicles. However, it has not been manufactured in the market because of some engineering problems related to the operating temperature of the cell. On the other hand, the spacecraft area is another application field for NaS battery to use it as a storage device such as communication with satellites. Some satellites are created by solar cells to power the systems on their boards which means they need solar energy. However, satellites rotates around the world and they plunge into the world's shadow for a periodic of time. Therefore, satellites cannot produce the solar energy. In this case, $\mathrm{NaS}$ battery is good candidate for storing the electricity while the solar cells are generating the energy during day time. The electricity can be used when the sun light is not available. However, both type of cells are not in use in spacecraft yet because of some problems such as reliability and failure mechanisms [19].

On the other hand, $\mathrm{NaS}$ is not the only battery used in marketing field. Some other types of storage batteries are available as well. The common battery types are listed in Table 1 .

Table 1 - Comparison of battery performances [20] [21].

\begin{tabular}{|c|c|c|c|c|c|}
\hline Battery Type & $\begin{array}{c}\text { Energy } \\
\text { Efficiency }\end{array}$ & $\begin{array}{c}\text { Manufacturing } \\
\text { Cost }\end{array}$ & Cycle & $\begin{array}{c}\text { Operation } \\
\text { Temperature }\end{array}$ & $\begin{array}{c}\text { Self- } \\
\text { discharge }\end{array}$ \\
\hline- & - & (MJ/Wh) & - & ${ }^{\circ} \mathrm{C}$ & $\% /$ month \\
\hline Lead acid & $0.72-0.78$ & - & $1000-2000$ & -5 to 40 & $2-5$ \\
\hline $\begin{array}{c}\text { Nickel- } \\
\text { Cadmium(NiCd) }\end{array}$ & $0.72-0.78$ & 2.1 & $300-500$ & -40 to 50 & $5-20$ \\
\hline $\begin{array}{c}\text { Sodium } \\
\text { Sulfur(NaS) }\end{array}$ & $0.75-0.83$ & 0.6 & $2300-2500$ & 300 to 350 & 0 \\
\hline Lithium ion & $0.85-0.95$ & 1.2 & $3000-5000$ & -30 to 60 & 1 \\
\hline $\begin{array}{c}\text { Vanadium } \\
\text { Redox(VRB) }\end{array}$ & $0.6-0.8$ & 2.1 & $2800-3000$ & 0 to 40 & negligible \\
\hline Zinc Bromine & 0.75 & 1.2 & $1500-2500$ & 0 to 40 & negligible \\
\hline
\end{tabular}

As seen, in Table 1 in several perspectives $\mathrm{NaS}$ batteries are more attractive than the other batteries. These advantages make the NaS battery a good candidate for future applications. 
The sodium sulfur battery is not a type of battery that can be used by itself. It is usually used in the form of a battery module in where cells are collected and housed in a thermal enclosure. The battery module is generally equipped with an electrical heater to raise and maintain cell temperature as NaS battery operates at an optimal temperature of nearly $300-$ $350{ }^{\circ} \mathrm{C}$. Cells inside the module are anchored in place by filling and solidifying them with sand to prevent fires. Also, each $\mathrm{NaS}$ cell is configured in series/parallel arrays to provide the specified voltage and energy storage capability. The aim of this study is to predict the temperature inside the enclosure with regard to the cell numbers, cell configurations (parallel and series), heater operations and the insulation materials between cells (dry sand or air) and insulation on the enclosure walls. The parametric study has been done under different conditions and results are discussed in future chapters.

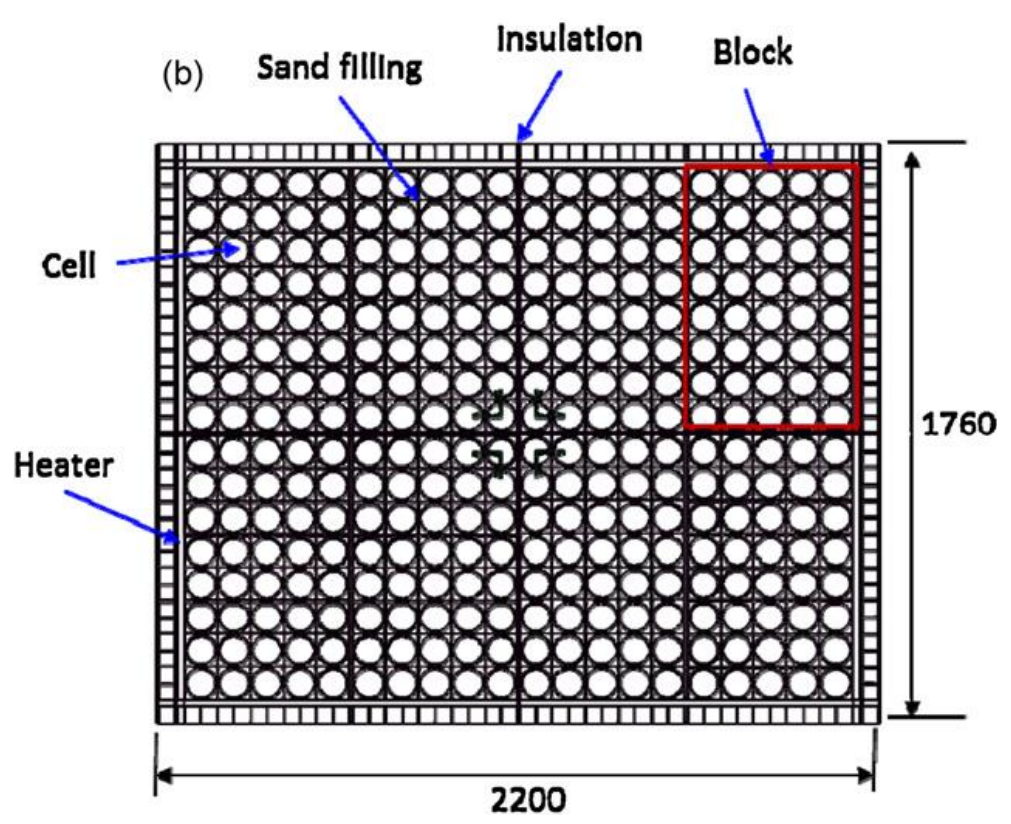

Figure 2 - Cell configuration in a battery module [11]. 


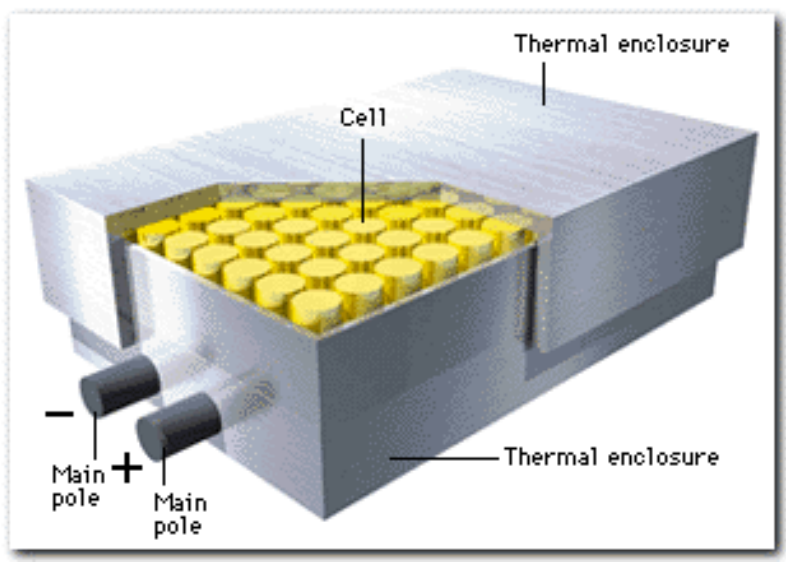

Figure 3 - Representation of the thermal enclosure for a battery module.

A NaS battery module can contain different numbers of blocks depending on the power need. In Figure 2, the module has 8 blocks and the module specifications list is in the Table 2.

Table 2 - Module specifications [9].

\begin{tabular}{|c|c|}
\hline Power Output & $50 \mathrm{~kW}$ \\
\hline Voltage & $58 \mathrm{~V} / 116 \mathrm{~V}$ \\
\hline Current & $726 \mathrm{~A} / 363 \mathrm{~A}$ \\
\hline Capacity & $375 \mathrm{kWh}$ \\
\hline Efficiency & $>83 \%$ \\
\hline Weight & $3.5 \mathrm{ton}$ \\
\hline Energy density & $160 \mathrm{kWh} / \mathrm{m}^{3}$ \\
\hline Number of cells & 320 \\
\hline
\end{tabular}

\subsection{The Cell Operation and Reactions}

The sodium sulfur battery uses molten sodium and sulfur in anode and cathode respectively and it operates at a temperature of about $300-350{ }^{\circ} \mathrm{C}$ to keep the sodium and sulfur molten. During charging and discharging a reversible reaction occurs. When the cell is discharged the sodium is oxidized at the beta alumina interface and formed sodium ions. These 
sodium ions move to the cathode through the electrolyte and react with sulfur and form sodiumpolysulfide. The overall reaction in the cell is;

$$
2 N a+x S \rightarrow N a_{2} S_{x}
$$

In the overall reaction the composition of $\mathrm{Na}_{2} \mathrm{~S}_{x}$ changes with state of discharge (Figure 4). For the further discharge process, the composition converts to $\mathrm{Na}_{2} \mathrm{~S}_{2}$ which has a high melting point and at this state, in the cathode, the resistance increases and prevents further discharges [18] [22].

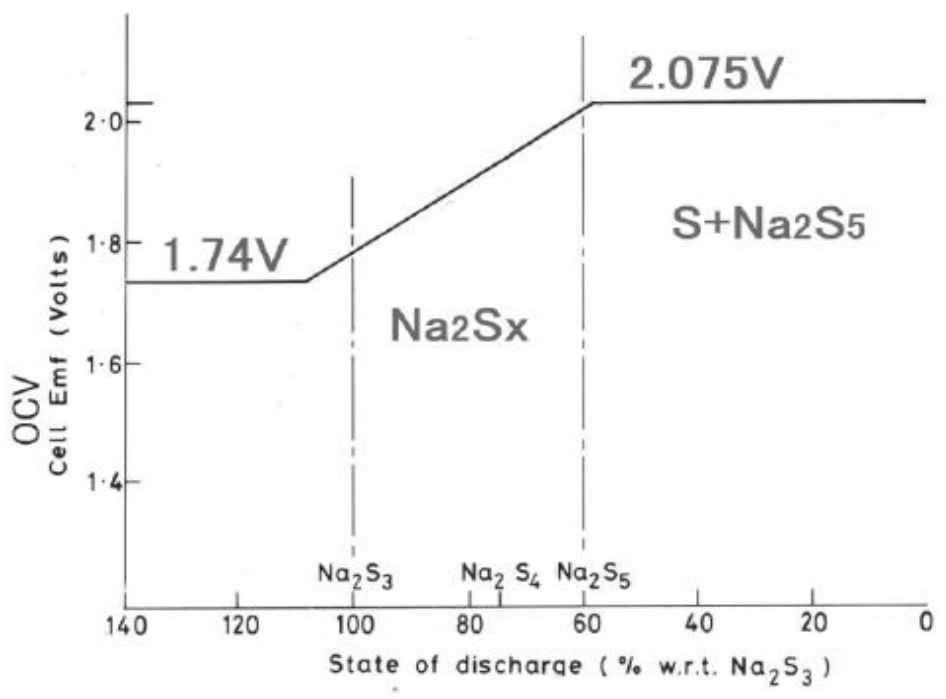

Figure 4 - NaS cell voltage vs. state of discharge [23]. 


\subsection{Cell Components and Processes}

\subsubsection{Anode}

This component of the battery contains the active molten sodium where the sodium is oxidized and formed sodium ions during the discharge operation. The reaction for discharge state is;

$$
2 \mathrm{Na} \rightarrow 2 \mathrm{Na}^{+}+2 e^{-}
$$

In order to obtain a high efficiency from the sodium anode, the sodium should be in good contact with beta-alumina electrolyte during the cell operation and also the interfacial polarization between sodium and the beta electrolyte must be minimum during the cell life. Polarization between sodium and electrolyte surface shows itself in different ways such as nonlinear I-V curve, asymmetry of resistance i.e., lower resistance on charge state rather than discharge state, high transient resistance at the beginning of discharge or a rapid increase in the cell resistance during cycling. Thus, many ways are developed to keep the sodium in good contact with the beta alumina. The first one is feeding the sodium from the top reservoir (Figure 4a). This method is the most straight forward one which means that it comes with some problems. Most common problem of this application is sealing. Molten sodium contacts the seals and possible reactions might occur. Also, it requires lower sodium utilization rate since the redundant sodium has to be kept in the electrolyte tube even if the cell is fully discharged. Moreover, it needs more space for the sodium reservoir. 


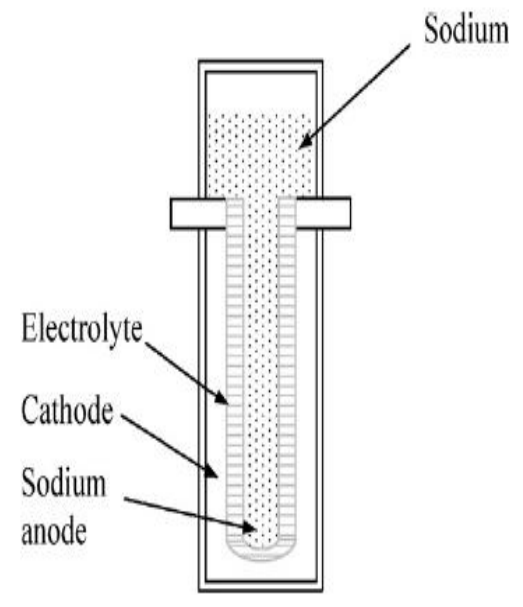

(a)

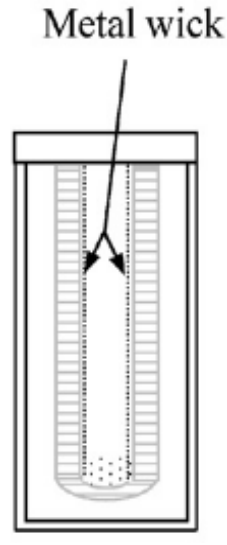

(b)

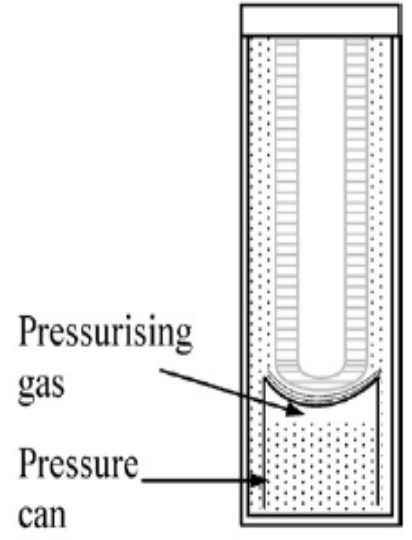

(c)

Figure 5 - Schematic of three anode designs; (a) reservoir feeding (b) sodium wicking (c) pressurized feeding [24].

The other method is wicking the sodium to the electrolyte surface with a capillary force (Figure $4 \mathrm{~b}$ ). In that way sodium makes the electrolyte surface wet. Here, the sodium is almost independent from the amount of sodium in the anode. Thus, wicking method costs less, does not require complex sealing methods since there is no contact between molten sodium and the seals if the cell operates vertically. Also it is available for higher sodium utilization so there is no additional need for additional sodium and possible to make more compact cell designs. The last common method is pressurizing the sodium with an inert gas (Figure 4c). It gives a simple resolution of cell assembly with a small reduction in specific energy and is more suitable for large vertical cells [3] [22] [24]. 


\subsubsection{Cathode}

This component of the battery contains the molten sulfur and molten polysulfide. During the discharge the sulfur is reduced to sodium polysulfide and during charge state it reverses. The reaction in cathode during the discharge state is:

$$
x S+2 e^{-} \rightarrow S_{x}^{2-}
$$

and

$$
2 N a^{+}+x S+2 e^{-} \rightarrow N a_{2} S_{x}
$$

Cathode is more challenging part of the battery since the sulfide melts are corrosive. Thus, selection of the materials is an important matter. Using of metals, alloys, inexpensive materials such as stainless steel are limited. In cells with beta alumina electrolyte, aluminum can be used as a cathode material however it requires a coating process for a good sustainability. This method generally is suitable for central sulfur cells since the current collector has smaller diameter and it is easy to coat the collector. On the other side, for the central sodium cells, the cell case is also a current collector and the aluminum is less suitable for this type of cells because of its relatively low melting point. Also, coating inside surface of collector is harder than coating outside of it and aluminum case is not a desirable structure for cases. For these reasons aluminum has not been used widely in central sodium cells. Usually steel cases which have a protective coating as well are used.

In cells with beta alumina electrolyte, the distance between electrolyte and the current collector is much greater than the distance between anode and electrolyte. Therefore, the volume of the electrode must be filled with a material which is electrically conductive. Due to 
both sulfur and polysulfide being electrically non-conductive, carbon felt or mat is used as a matrix material and this process has a high cost.

On the other hand, cell failure mode is another issue in the cathode side. If sulfur contacts with sodium under a failure condition, it causes a rapid reaction between them and might cause a fire or explosion. Also, in failure mode the resistance increases and all cells becomes open-circuit [3] [22] [24].

\subsubsection{Electrolyte}

Beta-alumina electrolyte is a ceramic that is used as an electrical insulator and sodium ion conductor between anode and cathode in a $\mathrm{NaS}$ cell. Two crucial functions expected from the beta-alumina electrolyte to perform are to show low ionic resistance during the transfer of sodium ions between anode and cathode and be a good electrical insulator as a separator in the cell. While doing these functions beta-alumina electrolyte also must have high efficiency, high reliability, high mechanical strength, high density without porosity, long term durability of battery operation (Example: low corrosion rate due to the sodium and sulfur) and low cost [3] [6] [23] [24].

On the other hand, Nasicon crystal structure was discovered recently being a very important improvement in solid electrolyte development due to the high ionic conductivity at lower temperatures. Even though, Nasicon structure seems very convenient for the battery applications it is still under development at the current stage. Thus, it is not in use widely [25] [26] [27]. 


\subsection{Summary}

Cell temperature is a critical parameter for the $\mathrm{NaS}$ battery due to having a limited range of operation temperature. Thus, many numerical and experimental model has been developed since early 1970s to predict the cell temperature. These models are generally one or two dimensional and recently three-dimensional models have also been developed. On the other hand, several modellings have been done in literature to obtain charge-discharge characteristics, and potential distribution etc.

The surveyed literature shows that the NaS batteries are very promising for the future applications as secondary storage devices. The $\mathrm{NaS}$ batteries are generally used as multiple cells in a battery module instead of being used as a single cell. Thus, the battery module and cell arrangements should also be understood. In this chapter some module specifications such as current, capacity, voltage, energy density, number of the cells etc. were explained and the module was illustrated with figures.

In order to perform and appropriate analysis the electrochemistry of the NaS must be understood well. The chemical reactions that occur in each component are discussed and the working principle of the battery is explained. 


\section{Chapter 3: Lumped Mathematical Model}

\subsection{Conservation Laws}

Mathematical equations are the key of the modeling work so that it has to be well understood. For the lumped model, each component of NaS battery which are anode, electrolyte and cathode is taken as the control volume and conservation laws are applied to each control volume. In what follows, the governing equations for each component within a cell are presented.

\subsubsection{Conservation of Species}

The general conservation of species equation is written as below:

$$
\frac{d m_{s}}{d t}=\dot{m}_{s}^{\text {in }}-\dot{m}_{s}^{\text {out }}+\dot{m}_{s}^{\text {prod }}-\dot{m}_{s}^{\text {used }}
$$

Here, the left side of the equation represents the rate change of the mass with time. The mass flow rate is represented by $\dot{m}$, which enters in and leaves out the control volume. The subscript $s$ represents different species. This equation is applied to the reactants that move to the anode and the cathode through the electrolyte and plays a role in chemical reactions inside the control volumes. Since, electrons have little effect on mass balance, it has not been considered in this study. The chemical reaction during the discharging state in anode is

$$
2 N a \leftrightarrow 2 N a^{+}+2 e
$$

According to this reaction the law of conservation of mass can be applied as below:

$$
\left(\frac{d m_{N a}}{d t}\right)_{\text {anode }}=-\left(\dot{m}_{N a}^{\text {used }}\right)_{\text {anode }}
$$


Between $300-350{ }^{\circ} \mathrm{C}$ temperature ranges, all sodium can be considered as sodium ion since there is no metallic bond in molten sodium. Thus, the rearranged equation in anode is

$$
\left(\frac{d m_{N a^{+}}}{d t}\right)_{\text {anode }}=-\left(\dot{m}_{N a^{+}}^{o u t}\right)_{\text {anode }}
$$

In electrolyte, no reaction occurs. It only transfers the sodium ions between anode and cathode. Thus, the sodium ion balance in electrolyte is

$$
\left(\dot{m}_{N a^{+}}^{\text {in }}\right)_{\text {electrolyte }}=\left(\dot{m}_{N a^{+}}^{\text {out }}\right)_{\text {electrolyte }}
$$

In cathode, during charge and discharge cycles only sodium ions enter and leave the control volume. The half reaction in anode during the discharge state is

$$
2 N a^{+}+x S+2 e \leftrightarrow N a_{2} x S
$$

The law conservation of mass for each species of cathode is

$$
\left(\frac{d m_{S}}{d t}\right)_{\text {cathode }}=\left(\dot{m}_{S}^{\text {in }}\right)_{\text {cathode }}-\left(\dot{m}_{S}^{\text {used }}\right)_{\text {cathode }}
$$

For sulfur the equation reduces to

$$
\left(\frac{d m_{S}}{d t}\right)_{\text {cathode }}=-\left(\dot{m}_{S}^{u s e d}\right)_{\text {cathode }}
$$

For the sodium ions:

$$
\left(\frac{d m_{N a^{+}}}{d t}\right)_{\text {cathode }}=\left(\dot{m}_{N a^{+}}^{\text {in }}\right)_{\text {cathode }}-\left(\dot{m}_{N a^{+}}^{\text {used }}\right)_{\text {cathode }}
$$

Since all sodium ions react with sulfur, the rate change of ions is zero. Thus, it can be written as 


$$
\left(\dot{m}_{N a^{+}}^{\text {in }}\right)_{\text {cathode }}=\left(\dot{m}_{N a^{+}}^{\text {used }}\right)_{\text {cathode }}
$$

The law of conservation of species for the sodium-polysulfide is

$$
\left(\frac{d m_{N a_{2} x S}}{d t}\right)_{\text {cathode }}=\left(\dot{m}_{\mathrm{Na}_{2} x S}^{\text {prod }}\right)_{\text {cathode }}
$$

Within the same manner, the law of conservation of species can be applied to the other reactions that occur in charging state.

\subsubsection{Conservation of Charge}

Similar to thermodynamics first law, electric charge can neither be created nor destroyed. The net amount of electric charge is always conserved. If this rule is applied to our control volumes, the law of conservation of charge during the discharging state becomes as follows for each control volume.

In the anode, sodium ions and electrons leave the control volume and move towards to the cathode. Thus, ionic current becomes negative since ions leaves the control volume, however the current due to the electrons becomes positive since the electron and current flow in opposite directions.

$$
\left(\frac{d q}{d t}\right)_{\text {anode }}=\left(I_{e}\right)_{\text {anode }}-\left(I_{i}\right)_{\text {anode }}
$$

Here, $I_{e}$ is the current due to the electron flow and $I_{i}$ is the current due to the ion flow.

In electrolyte, electrons are not allowed to pass through the electrolyte, only sodium ions can pass inside the electrolyte. Thus, the amount of ionic current that enters the control 
volume of electrolyte leaves the control volume with the same amount of current. Current balance can be shown as below:

$$
\begin{aligned}
& -\left(I_{i}\right)_{\text {anode }}=\left(I_{i}\right)_{\text {electrolyte }} \\
& -\left(I_{i}\right)_{\text {electrolyte }}=\left(I_{i}\right)_{\text {cathode }}
\end{aligned}
$$

In the cathode, unlike anode the current which is carried by electrons move outward of cathode since the electron flow direction is into the cathode and ionic current flows into the cathode control volume. Thus, the equation can be shown as:

$$
\left(\frac{d q}{d t}\right)_{\text {cathode }}=-\left(I_{e}\right)_{\text {cathode }}+\left(I_{i}\right)_{\text {cathode }}
$$

Overall, it can be assumed that the quantity of electrons and ions which leave a control volume are the same. Therefore, the rate of current change can be assumed zero for simpler calculations [28].

$$
\left(\frac{d q}{d t}\right)_{C V}=0
$$

\subsubsection{Conservation of Energy}

In a battery, the chemical energy converts to thermal energy. Overall, the total energy is conserved. For a general control volume, the equation for conservation of energy can be written as

$$
\frac{d E}{d t}=\left(\dot{m} c_{p}\right)^{i n} \mathrm{~T}^{\text {in }}-\left(\dot{m} c_{p}\right)^{\text {out }} \mathrm{T}^{\text {out }}+\dot{Q}^{\text {net }}+\dot{Q}^{\text {source }}
$$

In Eq. (20), E is the total energy, $\mathrm{c}_{\mathrm{p}}$ is the specific heat capacity, $\left(\dot{m} c_{p}\right)^{\text {in }}$ and $\left(\dot{m} c_{p}\right)^{\text {out }}$ are the energies come in and going out of the control volume by mass flow, $\dot{Q}^{\text {net }}$ is the net heat 
change from surroundings by convection or conduction, $\dot{Q}^{\text {source }}$ is the summation of heat change during chemical reactions and the heat due to the ohmic losses.

$$
\begin{gathered}
\dot{Q}_{n e t}=\sum_{i=n e i g h b o r} \frac{k A^{\text {cond }}}{l}\left(T_{j}-T_{P}\right)+h A^{\text {conv }}\left(T_{\infty}-T_{P}\right) \\
\dot{Q}_{\text {source }}=\dot{Q}_{\text {ohmic }}+\dot{Q}_{\text {reaction }} \\
\dot{Q}_{\text {ohmic }}=\frac{I_{F}^{2} * l_{\text {eff }}}{\sigma * A_{\text {eff }}}
\end{gathered}
$$

Here $k$ is the thermal conductivity, $A$ is effective contact area, $l$ is conduction length, $T_{j}$ and $T_{P}$ represent the temperature of the neighbor space and local temperature of the control volume. $I_{F}$ is faradaic current, $l_{e f f}$ is effective length of conductor, $\sigma$ electrical conductivity and $A$ is effective cross sectional area of the conductor.

Although the ohmic heat source occurs all over the battery, the source from chemical reaction occurs only in the cathode side. Because, in the anode it is assumed that all sodium is molten and there are no metallic bonds in molten state. However, in the cathode side sodium ions react with sulfur and composed sodium polysulfide and release heat during discharge process.

$$
\dot{Q}_{\text {reaction }}=-\frac{I}{2 F} T_{C}\left(\bar{s}_{s_{x}^{2-}}-2 \bar{s}_{e^{-}}-x \bar{s}_{S}\right)
$$

In Eq. (24) $\bar{S}$ donates the molar entropy of each species, $T_{C}$ is the cathode temperature, and $F$ is the Faraday constant. 


\subsection{Gibbs Free Energy and Open Circuit Voltage}

The Nernst equation is an important equation for systems where electrochemical reactions occur. It gives the electrochemical cell potential in terms of reactants and products of the reaction. It can be derived by using Gibbs free energy criteria for chemical reactions. The Gibbs free energy is the way to determine the energy which is released in a chemical reaction process. Gibbs free energy of a system at any moment in time is defined as the enthalpy of the system minus the product of the temperature times the entropy of the system.

$$
G=H-T S
$$

Also, Gibbs free energy can be defined in term of electrical work. The maximum amounts of electrical energy that can be delivered, by a battery in a given state, depend on the change in Gibbs free energy.

$$
\Delta G=-n F E
$$

Here, $n$ is the number of moles of electrons released, $F$ is the Faraday constant and $E$ is the cell potential. In standard state the Gibbs free energy is

$$
\Delta G^{o}=-n F E^{o}
$$

Where, $E^{o}$ is the electrochemical cell potential and $\Delta G^{o}$ is the Gibbs free energy changes in standard state. According to this for a general chemical equation the Gibbs free energy is;

$$
\Delta G-\Delta G^{o}=R T \ln \left[\frac{a_{\text {product }}}{a_{\text {reactants }}}\right]
$$

or 


$$
\Delta G-\Delta G^{o}=2.303 * R T \ln \left[\frac{a_{\text {product }}}{a_{\text {reactants }}}\right]
$$

In Eq. (29) $\Delta G$ and $\Delta G^{o}$ are the changes in free energy of products and reactants in standard and non-standard states, $R$ is the gas constant, $T$ is the absolute temperature, $a_{\text {product }}$ and $a_{\text {reactants }}$ are the activities (effective concentrations) of products and reactants, respectively. These equations create the Nernst equation which is related to the cell potential in any state [29] [30].

$$
E-E^{o}=-\left[\frac{2.303 R T}{n F}\right] \ln \left[\frac{a_{\text {product }}}{a_{\text {reactants }}}\right]
$$

or

$$
\begin{gathered}
E=E^{o}-\left[\frac{2.303 R T}{n F}\right] \ln \left[\frac{a_{\text {product }}}{a_{\text {reactants }}}\right] \\
a A+b B \rightarrow c C+d D
\end{gathered}
$$

For a chemical reaction, if the chemical activities are shown as in the Eq. (32) the reaction quotient can be defined as below.

$$
Q=\frac{\{C\}^{c}\{D\}^{d}}{\{A\}^{a}\{B\}^{b}}
$$

In the above equation, capital letters denote the chemical activities and lower case letters denote the number of moles. Similarly, in a sodium sulfur battery the overall reaction is;

$$
2 N a^{+}+x S+2 e^{-} \rightarrow N a_{2} S_{x}
$$


Thus, the Gibbs free energy is given by;

$$
\Delta G-\Delta G^{o}=2.303 * R T \ln \left[\frac{\left(a_{N a_{2} S_{x}}\right)}{\left(a_{N a}\right)^{2}\left(a_{S}\right)^{x}}\right]
$$

In the same manner the equation for the Nernst potential becomes;

$$
E=E^{o}-\left[\frac{2.303 R T}{n F}\right] \ln \left[\frac{\left(a_{N a_{2} S_{x}}\right)}{\left(a_{N a}\right)^{2}\left(a_{S}\right)^{x}}\right]
$$

As it is mentioned above, Gibbs free energy can be converted to electrical energy. Therefore;

$$
\Delta G^{o}=-2 F E^{o}
$$

and the electrochemical cell potential in standard state becomes;

$$
E^{o}=-\frac{\Delta G^{o}}{2 F}
$$

If Eq. (37) is substituted into the Eq. (35) Nernst potential equation can be written as;

$$
E=-\frac{\Delta G^{o}}{2 F}-\left[\frac{2.303 R T}{n F}\right] \ln \left[\frac{\left(a_{N a_{2} S_{x}}\right)}{\left(a_{N a}\right)^{2}\left(a_{S}\right)^{x}}\right]
$$

or

$$
E=E^{o}-\left[\frac{2.303 R T}{n F}\right] \ln \left[\frac{\left(a_{N a_{2} S_{x}}\right)}{\left(a_{N a}\right)^{2}\left(a_{S}\right)^{x}}\right]
$$




\subsection{Energy Loses in a Battery}

\subsubsection{Activation Losses}

During charge and discharge states a battery voltage is different from its open circuit voltage $(\mathrm{OCV})$. The difference between OCV and the voltage during current-flow conditions called as activation loss. In another words, it is referred as over-potential. Due to this overpotential the battery voltage during charge is higher than OCV and during discharge it is lower than OCV. The over-potential basically depends on the charge/discharge current value, temperature, state of charge, battery chemistry and aging.

The activation loss can be determined for anode and cathode using the Butler-Volmer equation.

$$
i=i_{0}\left\{e^{(1-\beta) n F \eta / R T}-e^{-\beta n F \eta / R T}\right\}
$$

Here, $i$ is current density, $i_{0}$ is exchange current density which is the current in the absence of net electrolysis and at zero overpotential, $\beta$ is the transfer coefficient which leads to change in reaction rate constant, $F$ is Faraday constant and $T$ is absolute temperature [28] [31]. Commonly, $\beta$ is assumed to be 0.5 . Thus, Eq. (40) can be written as;

$$
\eta_{a c t}=\frac{2 R T}{n F} \sinh ^{-1}\left[\frac{i}{2 i_{0}}\right]
$$

\subsubsection{Ohmic Losses}

All electronic devices have ohmic losses and $\mathrm{NaS}$ battery have no difference compared to others. An ohmic loss occurs due to the resistance to electron flow in battery components. It is usually defined in terms of current density and area of resistance. 
In a battery the voltage is

$$
V=i . R
$$

Here, $i$ is the current density and $R$ is the area specific resistance. A single battery cell is a low voltage power source so that small losses can play a crucial role in the electrical characteristic of the battery. In contrast to other components, ohmic resistance is highest in the electrolyte because electrolyte must be electrically insulated. Therefore, for liquid electrodes in order to reduce the effect of ohmic loss, high conductive electrodes can be used. Also, the distance which electrons travel should be reduced because resistance is proportional to distance [32].

\subsubsection{Concentration Losses}

Concentration losses represent restrictions in the current caused by concentration changes of the species on the electrode surface. Because the reduction in concentration is the result of a failure to transport sufficient reactant to the electrode surface, this type of loss is also called mass transport loss.

In this study, the concentration loss is calculates using the formula below.

$$
\eta_{c}=-\frac{|i|}{i} \frac{R T}{n F} \ln (1-M F-D)
$$

Here, $M F$ is the mass fraction of sulfur, and $D$ is diffusion loss term.

$$
D=8.64 * 10^{-5} * i-9.54 * 10^{-3}
$$

Diffusion loss term is calculated by calibrating the model for a range of currents [32]. 


\subsection{Summary}

In this chapter three main factors which are conservation of species, Gibbs free energy and the losses in the battery are considered. The final form of activation loss using ButlerVolmer equation is defined and used in the code as shown;

$$
\eta_{\text {act }}=\frac{2 R T}{n F} \sinh ^{-1}\left[\frac{i}{2 i_{0}}\right]
$$

From Gibbs free energy and Nernst equation the final form OCV becomes;

$$
E=E^{o}-\left[\frac{2.303 R T}{n F}\right] \ln \left[\frac{\left(a_{N a_{2} s_{x}}\right)}{\left(a_{N a}\right)^{2}\left(a_{S}\right)^{x}}\right]
$$

On the other hand, mass transport loss is the potential loss which is calculated from

$$
\eta_{c}=-\frac{|i|}{i} \frac{R T}{n F} \ln (1-M F-D)
$$

Taking into account all of the losses as well, the cell potential can be deduced from,

$$
V_{\text {cell }}=O C V-I R_{o}-\eta_{a c t}-\eta_{c}
$$

Although there is other type of loses such as crossover/internal current loses which occurs when substance leaks through the electrode or electrons leak through the electrode, in this study these losses are not considered. 


\section{Chapter 4: 3D Thermal Model}

\subsection{Heat Transfer Equation}

Since sodium sulfur batteries work effectively in a range of relatively high temperature, changes in cell temperature can have significant effects on the components of the battery and the battery block. In this study, three-dimensional conduction heat transfer equation is used to analyze the temperature behavior in a battery module. Assuming a rectangular thermal enclosure, the heat transfer equation is solved in Cartesian coordinates.

$$
\rho C_{p} \frac{\partial T}{\partial t}=\frac{\partial}{\partial x}\left(k \frac{\partial T}{\partial x}\right)+\frac{\partial}{\partial y}\left(k \frac{\partial T}{\partial y}\right)+\frac{\partial}{\partial z}\left(k \frac{\partial T}{\partial z}\right)+S_{T}
$$

The source term in Eq. (48), $S_{T}$, is utilized to account for the heat generated by each cell within the enclosure. The thermal conductivities are used as a function of time and temperature.

\subsection{Model Parameters}

In order to solve the heat transfer equation, we need the thermal and physical properties such as heat capacity, density, electrical and thermal conductivities. Some of these properties depend on the temperature and volume fractions of each phase at each control volume. The equations that are used in this study are listed in the Tables 3, 4, 5, and 6. Sudworth's study [22] is used as a major reference in the present work. 
Table 3 - Thermal conductivity values and empirical equations [22].

\begin{tabular}{|c|c|}
\hline Phase/Species & Equation/Value $(\mathbf{W} / \mathbf{m}-\boldsymbol{K})$ \\
\hline Sodium & $k_{, N a}=\begin{array}{c}04.67-0.11381 T+5.5226 * 10^{-5} T^{2} \\
+1.1842 * 10^{-8} T^{3}\end{array}$ \\
\hline Sulfur & $k_{S}=0.0195-3 * 10^{-4} T$ \\
\hline Sodium polysulfide & $k_{N a s}=0.27$ \\
\hline Beta-alumina & $k_{\beta-A l}=3$ \\
\hline Stainless steel & $k_{\text {sol }}=20$ \\
\hline Inert gas (Argon) & $k_{g a s}=0.016$ \\
\hline Cathode mesh & $k_{\text {mesh }}=0.035$ \\
\hline
\end{tabular}

The temperature range $\left(300<T<350^{\circ} \mathrm{C}\right)$ during charge and discharge process is such that only thermal conductivities of sodium and sulfur are defined as a function of temperature (See Table 3). In the same manner, electrical conductivities are calculated as shown in Table 4.

Table 4 - Electrical and ionic conductivity values and empirical equations [22].

\begin{tabular}{|c|c|}
\hline Phase/Species & Equation/Value (1/ $\Omega-m)$ \\
\hline Sodium & $\begin{array}{c}\sigma_{N a}=10^{8}\left(6.87+2.44 * 10^{-2} T+2.67 * 10^{-5} T^{2}+1.07\right. \\
\left.* 10^{-7} T^{3}-2.67 * 10^{-10} T^{4}\right)^{-1}\end{array}$ \\
\hline Stainless steel & $\sigma_{\text {sol }}=93 * 10^{8}$ \\
\hline Cathode mesh & $\sigma_{m e s h}=50$ \\
\hline Sodium polysulfide & $\sigma_{N a S}=0$ \\
\hline Sulfur & $\sigma_{S}=0$ \\
\hline Beta-alumina (ionic) & $\begin{array}{l}\sigma_{\beta-A l}=0 \\
\sigma_{\beta-A l}^{i}=21\end{array}$ \\
\hline Inert gas (Argon) & $\sigma_{g a s}=0$ \\
\hline
\end{tabular}

Compared to the electrical conductivity of sodium, the sulfur and sodium polysulfide conductivities have small values. Although they are calculated in the present study, they can be 
neglected as well. On the other hand, since the beta alumina is an electrical insulator, its electrical conductivity is close to zero. Also, inert gas conductivity is taken zero and the stainless steel is assigned a constant value.

Table 5 - Heat capacity values and empirical equations [22].

\begin{tabular}{|c|c|}
\hline Phase/Species & Equation/Value $(\mathrm{J} / \mathbf{g}-\mathbf{K})$ \\
\hline Sodium & $C_{p, N a}=1.4378-5.8063 * 10^{-4} \mathrm{~T}+4.624 * 10^{-7} T^{2}$ \\
\hline Sulfur & $C_{p, S}=1.11$ \\
\hline Sodium polysulfide & $C_{p, N a s}=1.31$ \\
\hline Beta-alumina & $C_{p, \beta-A l}=1.2$ \\
\hline Stainless steel & $C_{p, \text { sol }}=0.55$ \\
\hline Inert gas (Argon) & $C_{p, \text { gas }}=0.52$ \\
\hline Cathode mesh & $C_{p, \text { mesh }}=1.6$ \\
\hline
\end{tabular}

Table 6 - Material density values and empirical equations [22].

\begin{tabular}{|c|c|}
\hline Phase/Species & Equation/Value $\left(\boldsymbol{g} / \mathbf{m}^{\mathbf{3}}\right)$ \\
\hline Sodium & $\rho_{N a}=10^{6}\left(0.952-2.45 * 10^{-4} \mathrm{~T}\right)$ \\
\hline Sulfur & $\rho_{S}=2.0445 * 10^{6}-610 T$ \\
\hline Sodium polysulfide & $\rho_{N a S}=2.3112 * 10^{6}-660 T$ \\
\hline Beta-alumina & $\rho_{\beta-A l}=3.76 * 10^{6}$ \\
\hline Stainless steel & $\rho_{\text {sol }}=10^{5}$ \\
\hline Cathode mesh & $\rho_{\text {mesh }}=10^{6}$ \\
\hline Inert gas (Argon) & $\rho_{g a s}=P M_{A r} / R T$ \\
\hline
\end{tabular}

Similarly, equations for heat capacities and densities are shown in Table 5 and Table 6. Equations for some other related parameters can be found in the Appendix A. 


\section{Chapter 5: Computational Thermal Model}

\subsection{Finite Volume Method}

The finite volume method discretizes the integral form of the conservation equations directly in physical space. In this method, the computational domain is subdivided into a finite number of contiguous control volumes. At the centroid of the each control volume, the variable values are calculated. Interpolation is used to express variable values at control volume surface in terms of the center values.

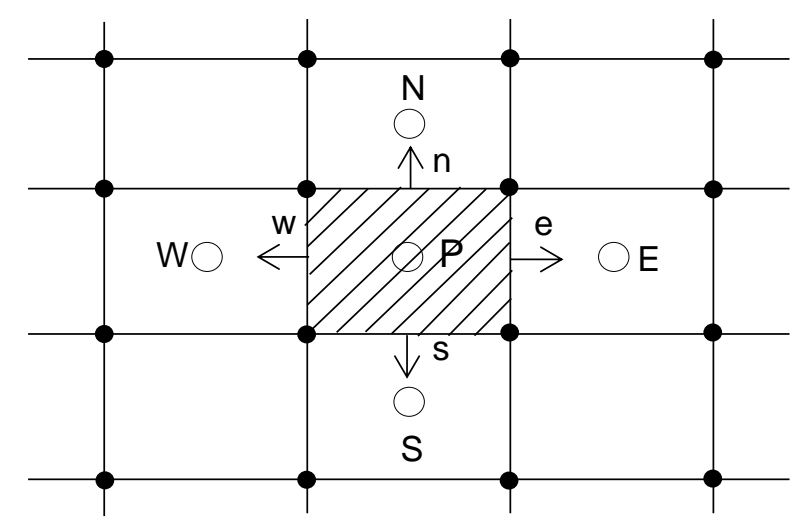

Figure 6 - Control volume for the two-dimensional heat conduction equation.

As the finite volume method works with control volumes and not the grid intersection points, it has the capacity to accommodate any type of grid. Instead of the structure grids, unstructured grids can be employed that allow a large number of options for the definition of the shape and location of the control volumes. Since the grid defines only the control volume boundaries, the method is conservative so long as the surface integrals that are applied at these boundaries are the same as the control volumes sharing the boundary [33]. 


\subsection{Discretization of the Heat Transfer Equation}

If we recall the $3 \mathrm{D}$ heat transfer equation and take the integral from west to east, south to north and bottom to top [34];

$$
\int_{b}^{\mathrm{t}} \int_{\mathrm{s}}^{\mathrm{n}} \int_{\mathrm{w}}^{\mathrm{e}}\left(\rho \mathrm{C}_{\mathrm{p}} \frac{\partial \mathrm{T}}{\partial \mathrm{t}}\right) \mathrm{dV}=\int_{\mathrm{b}}^{\mathrm{t}} \int_{\mathrm{s}}^{\mathrm{n}} \int_{\mathrm{w}}^{\mathrm{e}} \frac{\partial}{\partial \mathrm{x}}\left(\mathrm{k} \frac{\partial \mathrm{T}}{\partial \mathrm{x}}\right) \mathrm{dV}+\int_{\mathrm{b}}^{\mathrm{t}} \int_{\mathrm{s}}^{\mathrm{n}} \int_{\mathrm{w}}^{\mathrm{e}} \frac{\partial}{\partial \mathrm{y}}\left(\mathrm{k} \frac{\partial \mathrm{T}}{\partial \mathrm{y}}\right) \mathrm{dV}+\int_{\mathrm{b}}^{\mathrm{t}} \int_{\mathrm{s}}^{\mathrm{n}} \int_{\mathrm{w}}^{\mathrm{e}} \frac{\partial}{\partial \mathrm{z}}\left(\mathrm{k} \frac{\partial \mathrm{T}}{\partial \mathrm{z}}\right) \mathrm{dV}+\mathrm{S}_{\mathrm{T}}(49)
$$

Therefore

$$
a_{P} T_{P}=a_{E} T_{E}+a_{W} T_{W}+a_{N} T_{N}+a_{S} T_{S}+a_{T} T_{T}+a_{B} T_{B}+\text { const }
$$

where

$$
\begin{gathered}
\mathrm{a}_{\mathrm{P}}=\mathrm{a}_{\mathrm{W}}+\mathrm{a}_{\mathrm{E}}+\mathrm{a}_{\mathrm{S}}+\mathrm{a}_{\mathrm{N}}+\mathrm{a}_{\mathrm{B}}+\mathrm{a}_{\mathrm{T}}+\mathrm{a}_{\mathrm{p}}^{\mathrm{o}} \\
\mathrm{a}_{\mathrm{W}}=\frac{\mathrm{k}_{\mathrm{w}}}{\Delta \mathrm{x}} \Delta \mathrm{y} \Delta \mathrm{z}, \quad \mathrm{a}_{\mathrm{E}}=\frac{\mathrm{k}_{\mathrm{e}}}{\Delta \mathrm{x}} \Delta \mathrm{y} \Delta \mathrm{z}, \quad \mathrm{a}_{\mathrm{S}}=\frac{\mathrm{k}_{\mathrm{s}}}{\Delta \mathrm{y}} \Delta \mathrm{x} \Delta \mathrm{z}, \quad \mathrm{a}_{\mathrm{N}}=\frac{\mathrm{k}_{\mathrm{n}}}{\Delta \mathrm{y}} \Delta \mathrm{x} \Delta \mathrm{z} \\
\mathrm{a}_{\mathrm{B}}=\frac{\mathrm{k}_{b}}{\Delta \mathrm{z}} \Delta \mathrm{x} \Delta \mathrm{y}, \quad \mathrm{a}_{\mathrm{T}}=\frac{\mathrm{k}_{t}}{\Delta \mathrm{z}} \Delta \mathrm{x} \Delta \mathrm{y}, \quad \mathrm{a}_{\mathrm{p}}^{\mathrm{o}}=\frac{\rho \mathrm{C}_{\mathrm{p}}}{\mathrm{dt}} * \text { volume }, \quad \text { const }=\mathrm{a}_{\mathrm{p}}^{\mathrm{o}} \mathrm{T}_{\mathrm{p}}^{\mathrm{o}}+\text { source }
\end{gathered}
$$

\subsection{Computational Domain and Boundary Conditions}

The figures that shown (Figures 7 and 8) represent the computational domain of the $\mathrm{NaS}$ battery block. The number of the cells are user defined and can be changed to any kind of cell configuration. In this study, three cases are considered: one with a single cell, one with 9 cells, and the last one is with 40 cells. The main work has been done assuming that the battery module contains only one single cell. Based on the literature and experiments, various boundary conditions such as insulating the top and bottom walls, heating the side walls with an electrical heater etc. are applied. 


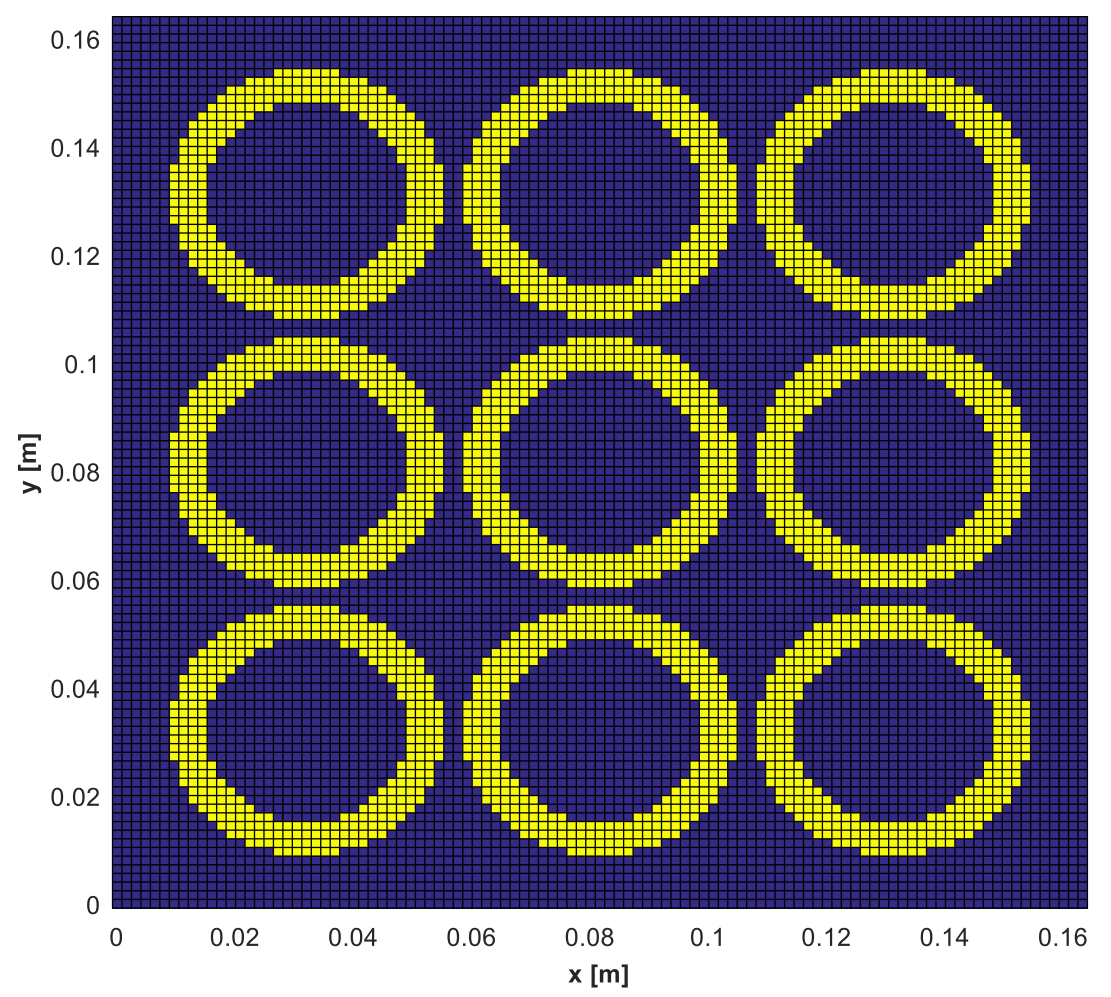

Figure 7 - Computational domain of battery module for $3 \times 3$ cell arrangement.

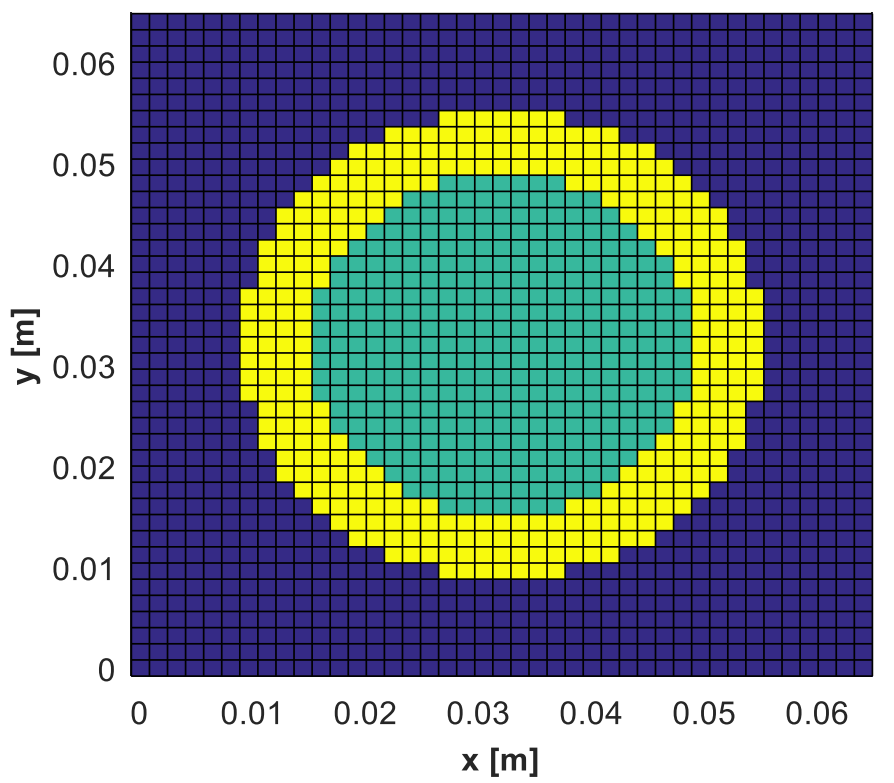

Figure 8 - Computational domain of battery module for a single cell. 


\subsection{Numerical Method}

For the lumped electrochemistry model, the first order Euler method has been used explicitly to solve the energy equation. Euler Method is one of the simplest numerical method for solving ordinary differential equations with a given initial value. A time marching method where the time dependent energy equation is integrated forward with time is used. The governing energy equation for the lumped model is;

$$
m c_{p} \frac{d T}{d t}=\dot{m} c_{p} \Delta T+\dot{Q}
$$

Euler Method gives;

$$
\left(m c_{p}\right)^{n} \frac{\left(T^{n+1}-T^{n}\right)}{\Delta t}=\left(\dot{m} c_{p}\right)^{n}\left(T_{b 1}-T_{b 2}\right)^{n}+\dot{Q}^{n}
$$

On the other hand, a fully implicit method has been used for solving 3D unsteady conduction heat transfer equation. The numerical methods solve the discretized equations using Conjugate Gradient Method (CGM). The CGM is the most prominent iterative method for solving sparse systems of linear equations [35].

A first order discretization in time for both lumped and 3D model and a second order discretization in space for the conduction term has been used in this study. The lumped model has been solved for each iteration. Time and temperature data obtained from the lumped model is stored and used in the 3D model by modifying the source term (see Eq. 48). The cubic spline function is used to interpolate the stored data on to time used in the 3D model. The flow chart of the model is depicted in Figure 9; 


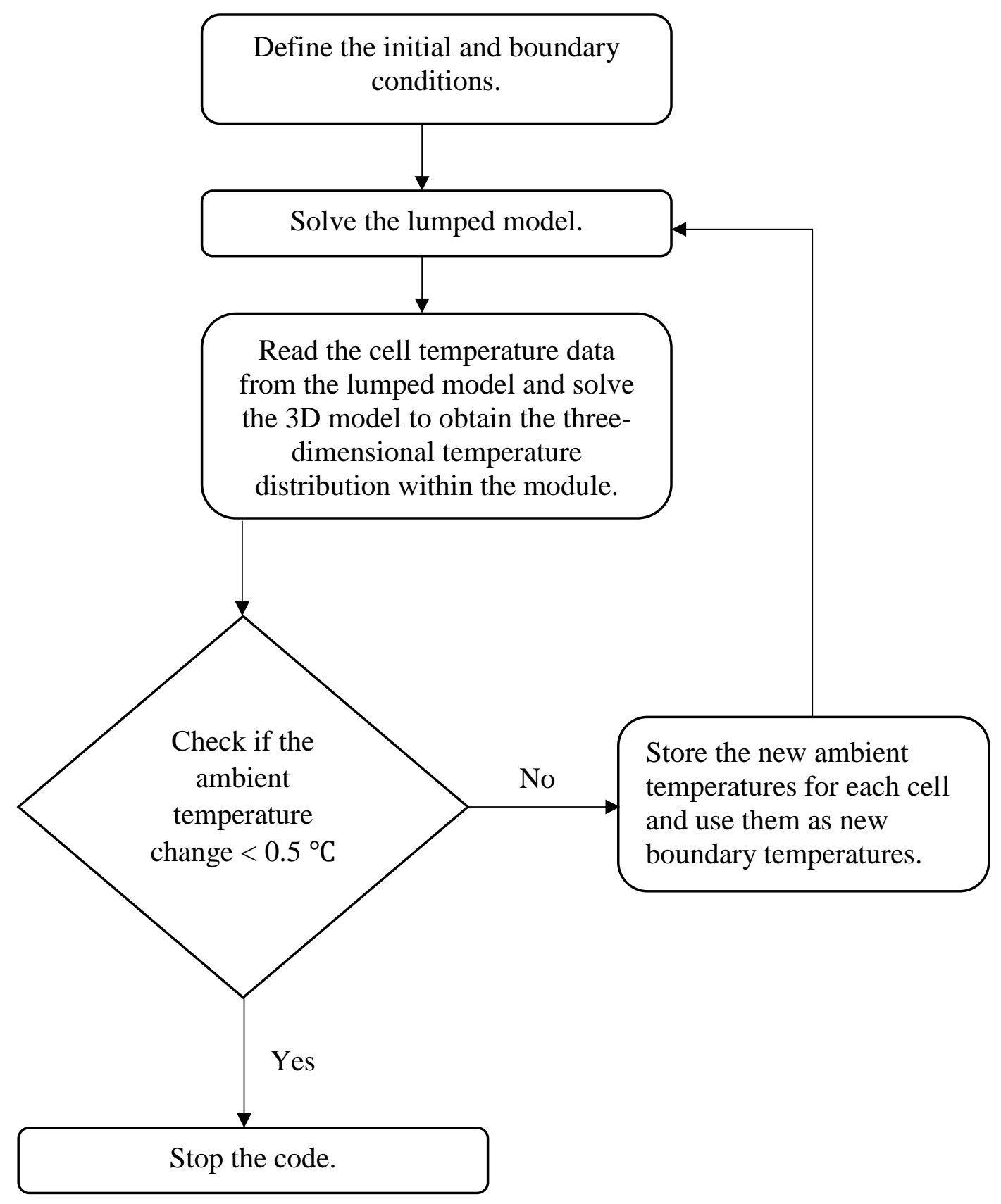

Figure 9 - The flow chart of the model. 


\subsection{Euler Method Stability Criteria}

A simple differential equation of the from $\frac{d T}{d t}=a T$ gives rise to an exponential solution if $a>0$, which in turn leads to instability in numerical solutions using Euler's method. As it can be seen in the figures 10,11 and 12 the r.h.s (right hand side) becomes aT $>0$ in several places. This may be the root cause of the instability problem in the lump model.

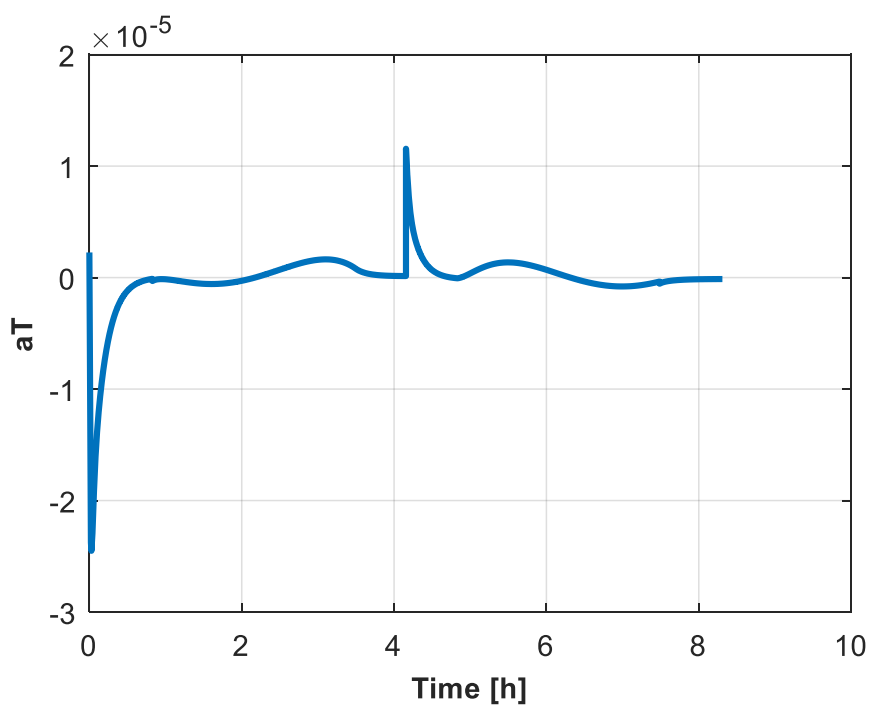

Figure 10 - RHS for cathode.

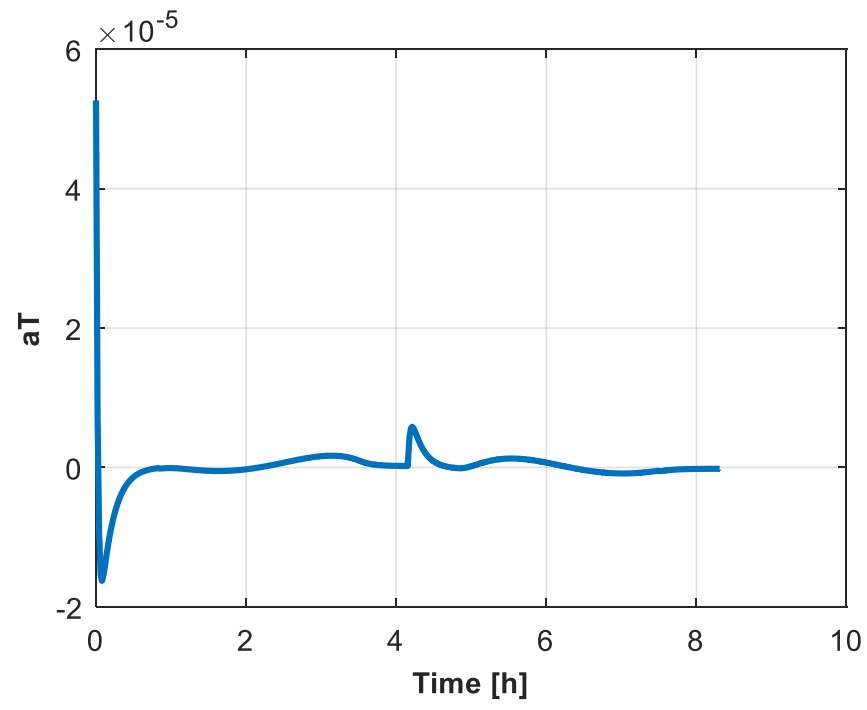

Figure 11 - RHS for electrolyte. 


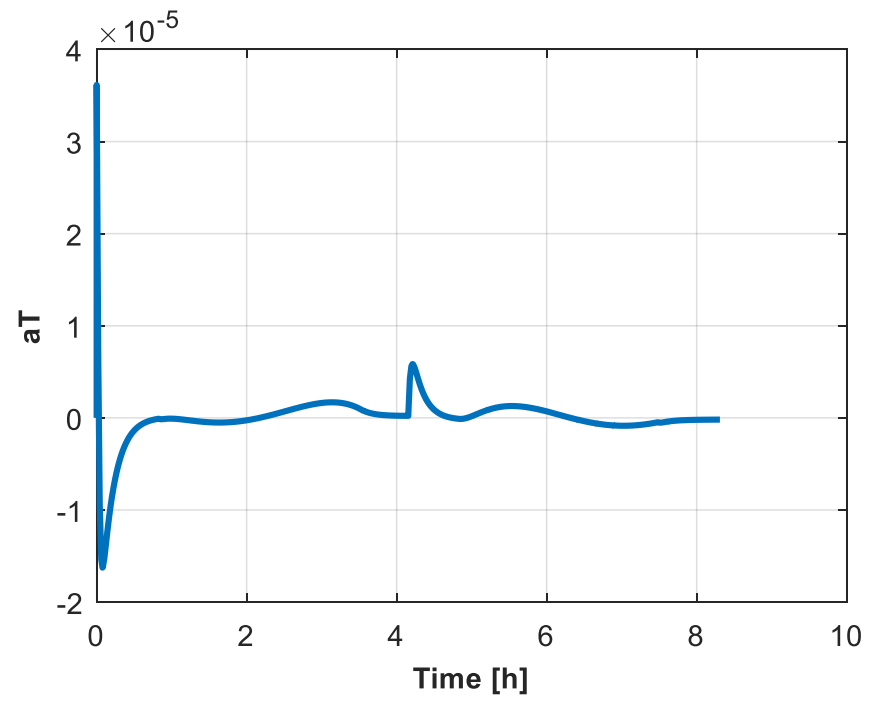

Figure 12 - RHS for anode. 


\section{Chapter 6: Results and Discussions}

\subsection{Electrochemistry Model}

In order to validate the lumped electrochemistry model, the results are compared to experimental and numerical results obtained from in the literature. In 1989, Kawamoto and Kusakabe [7] did some experimental studies on a single NaS battery cell. During the cell operation they measured the wall temperature and predicted the anode temperature at different currents. The initial conditions are applied to lumped model and the results are shown below.

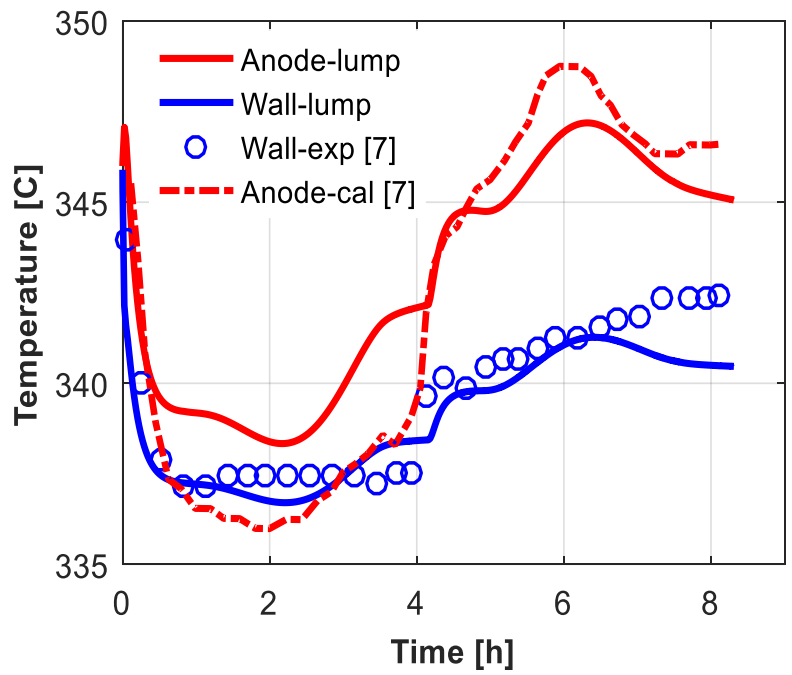

(a)

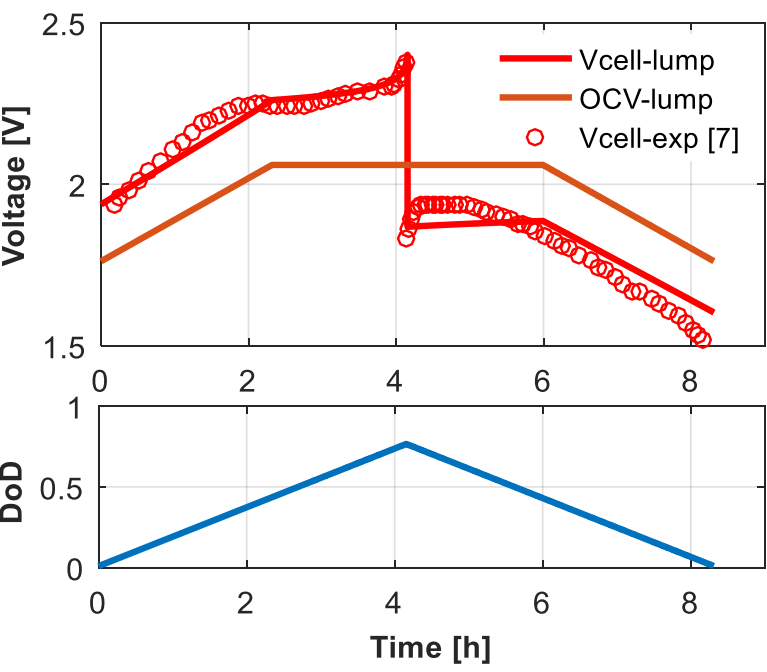

(b)

Figure 13 - (a) Temperature (b) Voltage \& Depth of discharge (DoD) for $i=130 / 130 \mathrm{~mA} / \mathrm{cm}^{2}$. Here, anode-lump and wall-lump are the temperatures of anode and wall which are calculated from the lumped model, wall-exp is the temperature of the wall from experimental data, anode-cal is the temperature of anode which is calculated numerically in the literature, Vcell-lump and OCV-lump are the cell voltage and open circuit voltage which are calculated from the lumped model respectively, Vcell-exp is the cell voltage measured from experiments [7]. 
In Figure 13a, it is seen that temperature decreases from initial temperature to around ambient temperature which is $335^{\circ} \mathrm{C}$ during the charging cycle. The reason that temperature decreases is the chemical reaction is an endothermic reaction. On the other side, the chemical reaction produces heat during the discharging cycle and temperature increases. However, the temperature start decreasing after the 5 hours of operation. The reason the temperature decreases is because the chemical reaction becomes endothermic (see Figure 14). The predicted temperatures both during charge and discharge cycle are in good agreement with experiments and calculations of Kawamoto and Kusakabe [7].

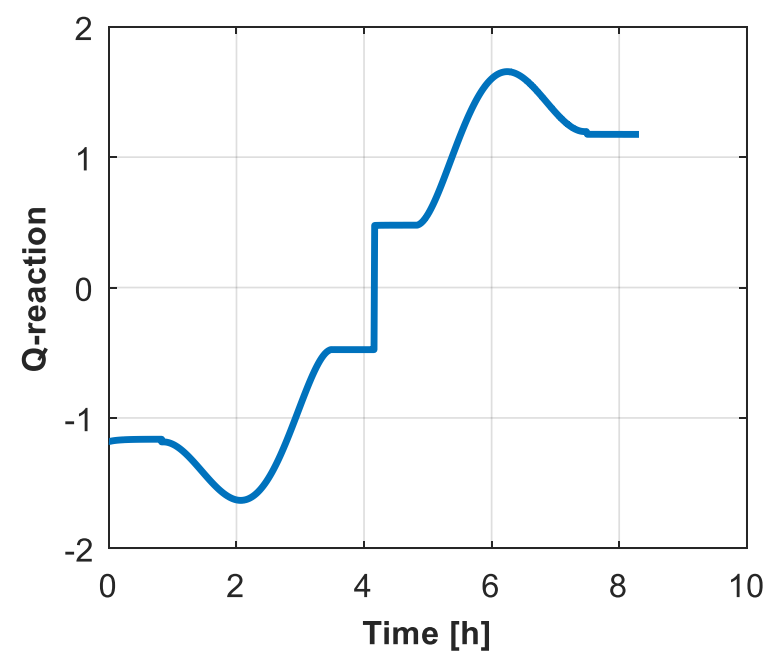

Figure 14 - The chemical reaction as a function of time.

Also, the cell voltage is in good agreement with experimental data in Figure 10b. The voltage increases rapidly at the end of the charging state due to the formation of atomic sulfur at the interface between sulfur electrode and solid electrolyte. At this interface is sodium polysulfide is decomposed to sodium and sulfur ions and sodium ions move to the anode through the electrolyte. Towards to end of charging the sodium polysulfide concentration decreases in cathode electrode and sulfur ions accumulate at the interface. Since the sulfur is an 
insulator there is significant loss; this causes the cell voltage increase rapidly at the end of the charge cycle.

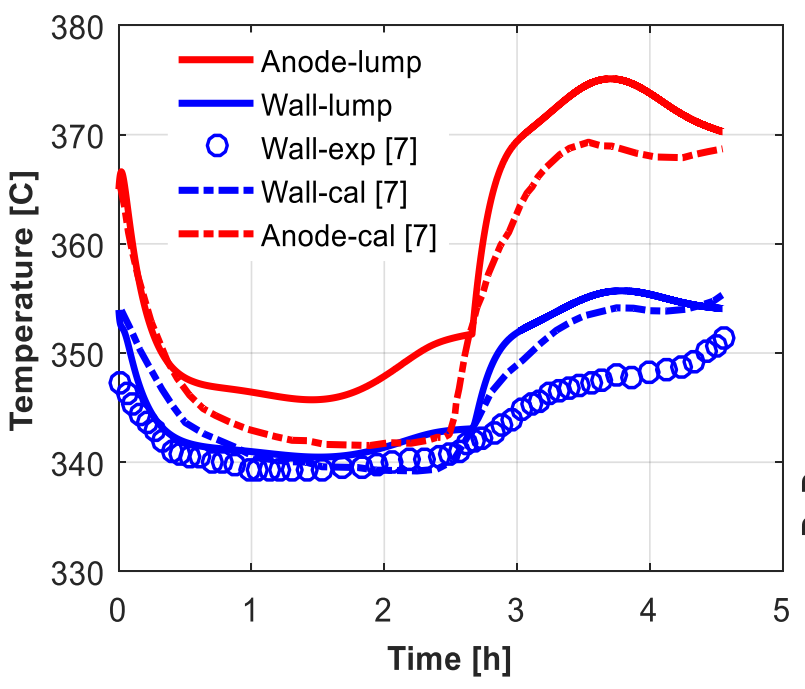

(a)

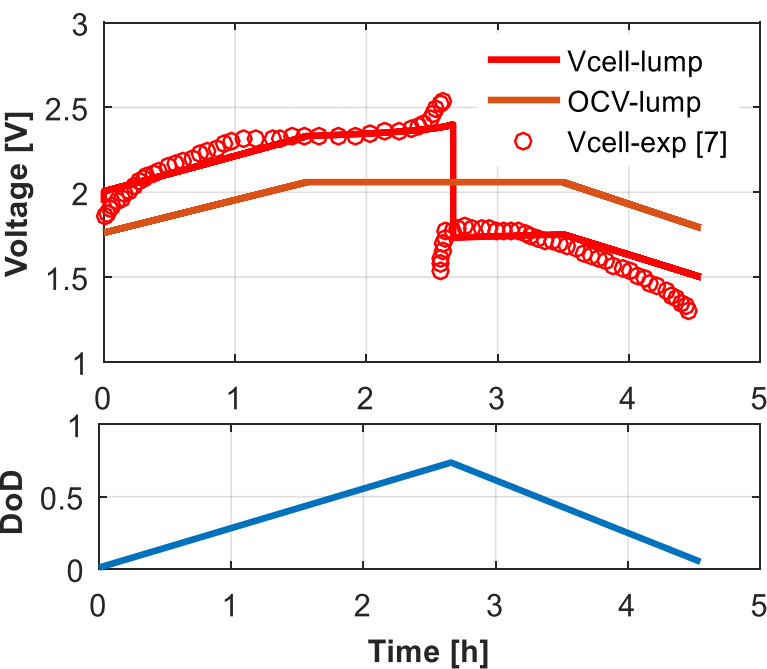

(b)

Figure 15 - (a) Temperature (b) Voltage \& Depth of discharge for $i=195 / 260 \mathrm{~mA} / \mathrm{cm}^{2}$.

Here, anode-lump and wall-lump are the temperatures of anode and wall which are calculated from the lumped model, wall-exp is the temperature of the wall from experimental data, anode-cal and wall-cal are the temperature of anode and wall which are calculated numerically in the literature, Vcell-lump and OCV-lump are the cell voltage and open circuit voltage which are calculated from the lumped model respectively and Vcellexp is the cell voltage measured from experiments [7].

In Figure 15, the lumped model results are compared to experiments and calculations at different charge and discharge currents [7]. It can be seen that the discharging takes less time than charging at higher currents as expected. Also, the losses are higher in charging state. 


\subsection{Heat Transfer Model}

Based on the validated lumped model, the temperature inside a battery module can be predicted. In order to gain computational time first it is assumed that the battery module contains only one single cell. After it is proved that the results converge for the single cell, multiple cell configurations are also applied.

The results shown in Figure 16 and Figure 17 are for a battery module which is insulated from bottom and top walls. Due to the operation temperature being between 300 and $350^{\circ} \mathrm{C}$, Drichlet boundary conditions are applied to the side walls and set to $330^{\circ} \mathrm{C}$. After 10 iterations, the temperature inside the battery module converged and remained in the range of operation temperature. The module takes the cell temperature from the lumped model. The environment temperature for the lumped model is calculated by taking the average temperature around the cell. The cell temperature and the environment temperature inside the battery block affect each other during the cell operations. After several iterations the cell and the environment temperature converge and do not change. In order to see that difference, the average temperature and the cell temperature are observed during the iterations. 


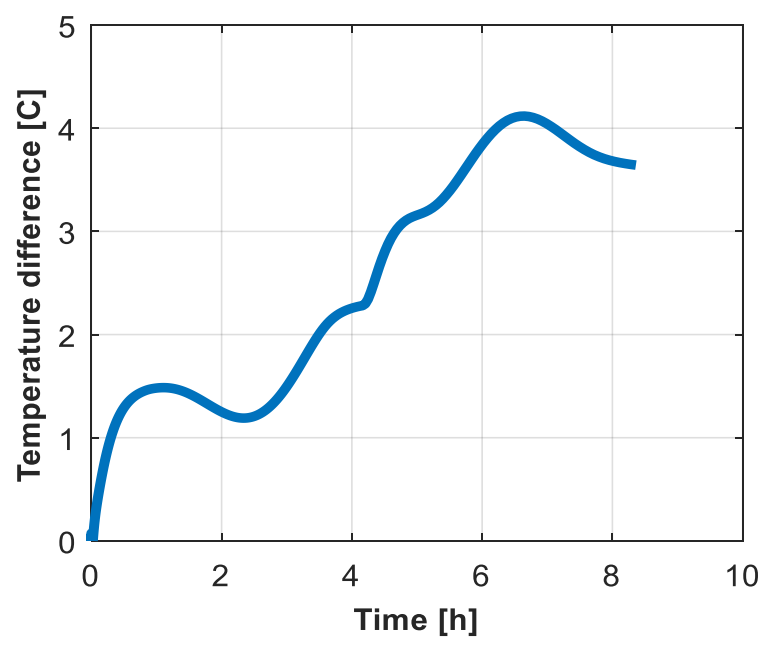

(a)

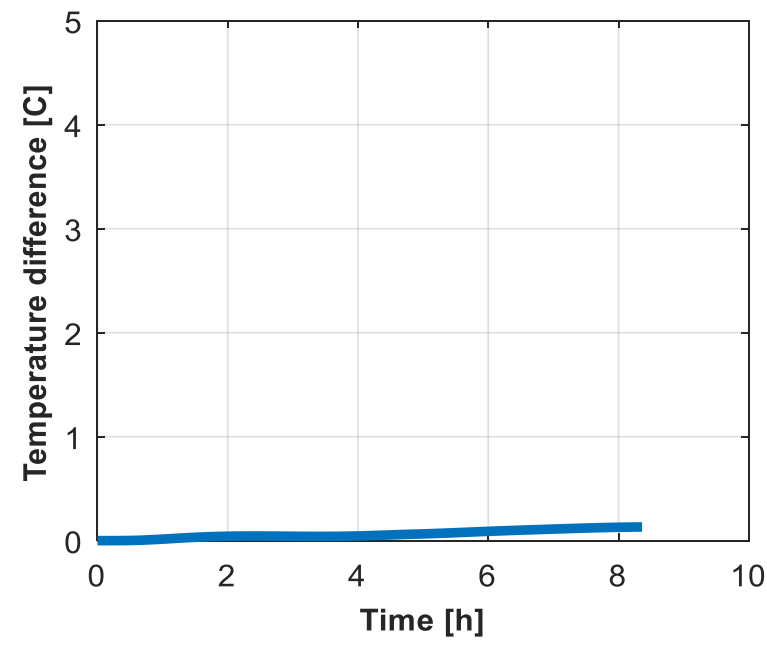

(b)

Figure 16 - Average temperature of surrounding points of the cell inside the battery block (a) first 2 iterations and (b) last 2 iterations.

The temperature difference between the iteration 1 and 2 is significantly high (Figure 16a). This shows that the cell heats up the environment. On the other hand, the temperature difference between the iteration 9 and 10 is less than $1{ }^{\circ} \mathrm{C}$ and the ambient temperature converges (Figure 16b). Similar to ambient temperature, the cell temperature is also expected to converge. In the same manner, same number of iterations are observed and following results were obtained for the cell temperature (Figure 17). 


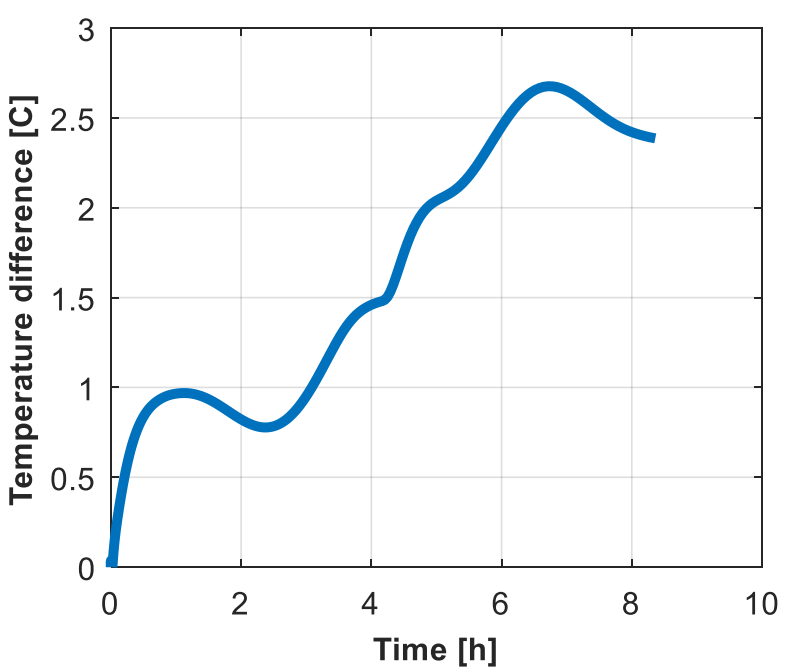

(a)

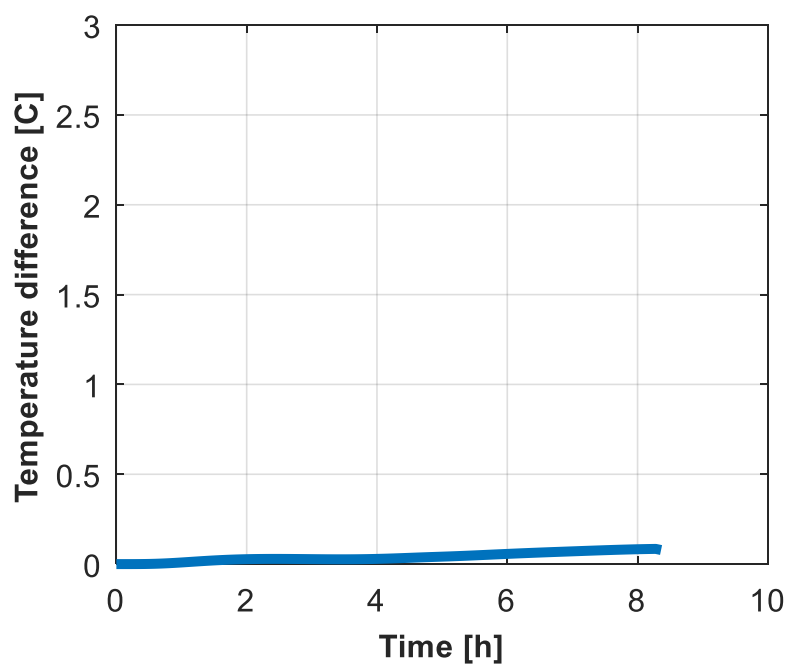

(b)

Figure 17 - Cell temperature difference inside the battery block a) first 2 iterations b) last 2 iterations.

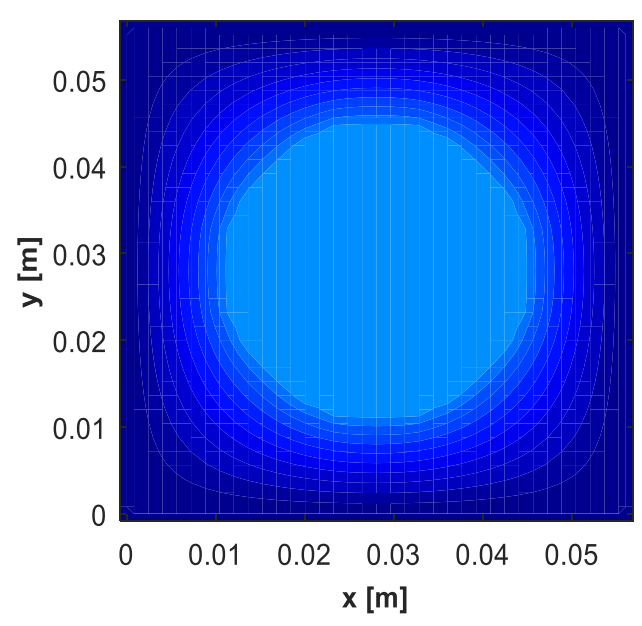

(a)
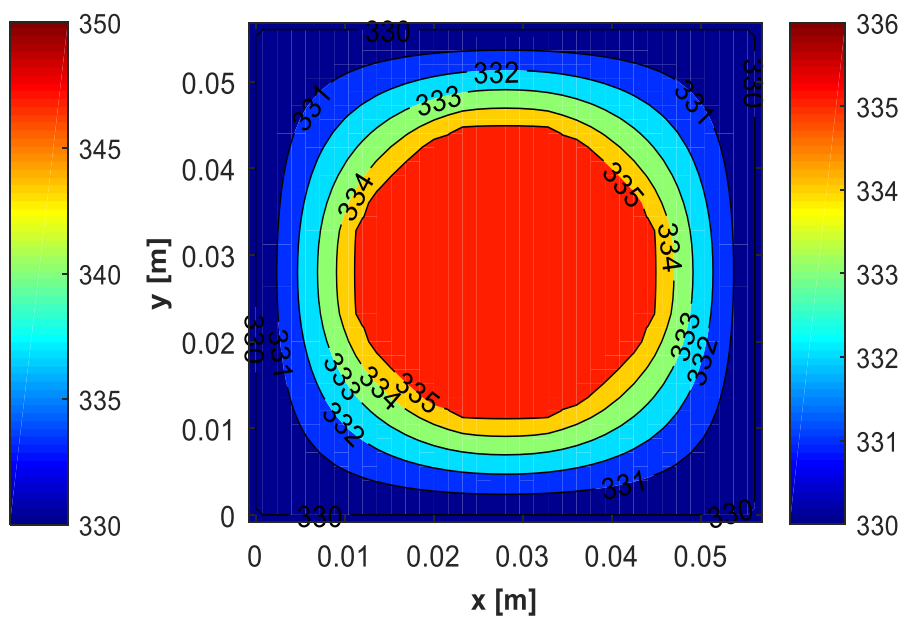

(b)

Figure 18 - Temperature contour in 2 hrs. of charging cycle (a) full scale (b) small scale. 


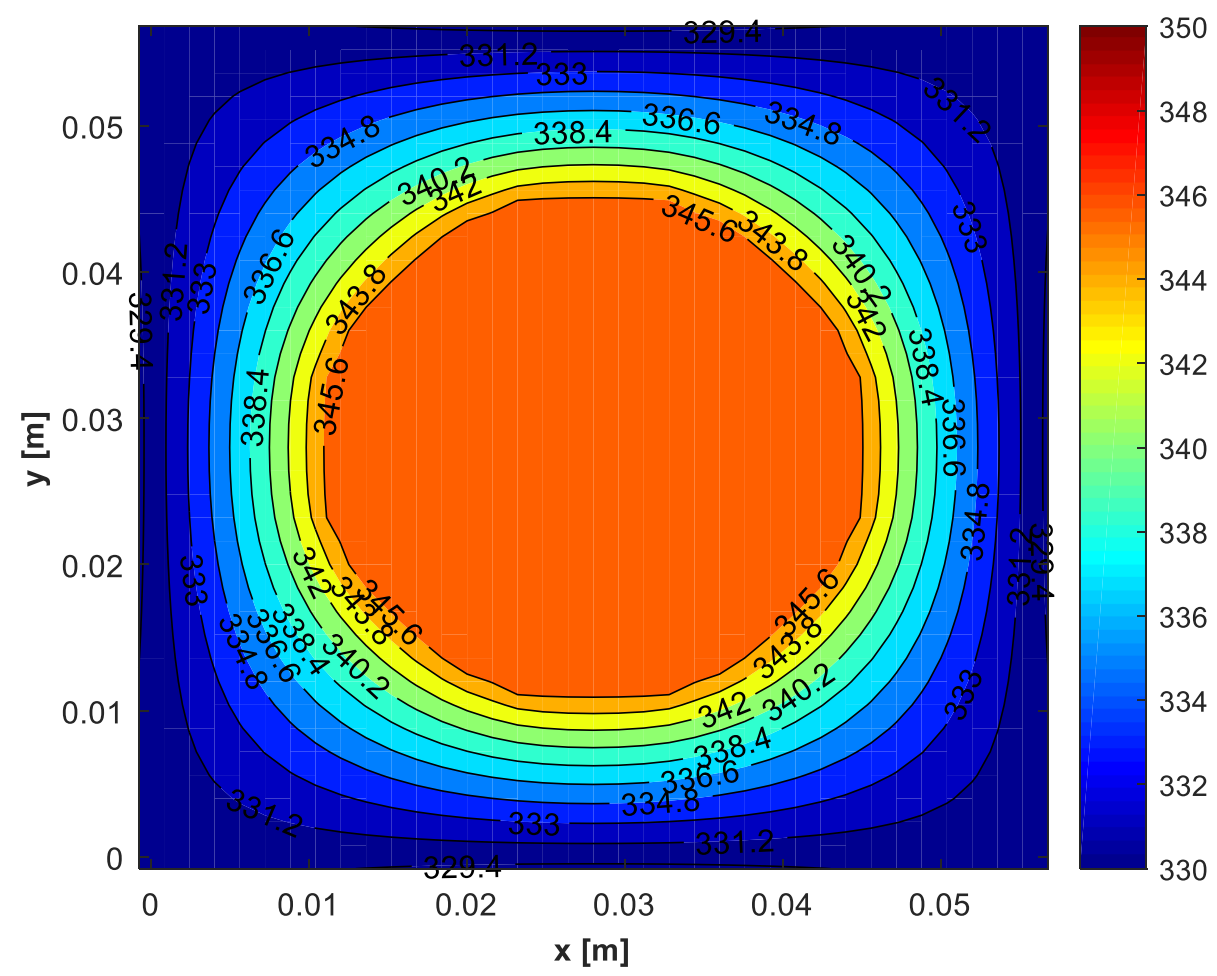

Figure 19 - Temperature contour in 2 hrs. of discharging cycle.

As it is mentioned in previous sections, the operation temperature is a critical for $\mathrm{NaS}$ battery. In order to have high ionic transfer through the electrolyte, the temperature should be greater than $300{ }^{\circ} \mathrm{C}$. Otherwise, the battery might fail to operate or the battery efficiency might decrease. In order to see the effect of the temperature on the battery, it is assumed that two of the electrical heaters which are at north and south walls have broken down and the thermal enclosure starts losing heat from walls to ambient where the air temperature is $0{ }^{\circ} \mathrm{C}$ and the air convective heat transfer coefficient is $150 \mathrm{~W} / \mathrm{m}^{2} \mathrm{~K}$ [36]. Therefore, the temperature inside the battery block decrease to around $200{ }^{\circ} \mathrm{C}$ during the operation cycles. Thus, the electrolyte's ionic conductivity decreases to approximately $5 \mathrm{ohm}^{-1} \mathrm{~m}^{-1}$ [37]. Low ionic conductivity 
means high resistivity so that potential losses increase inside the battery during the charge and discharge operation.

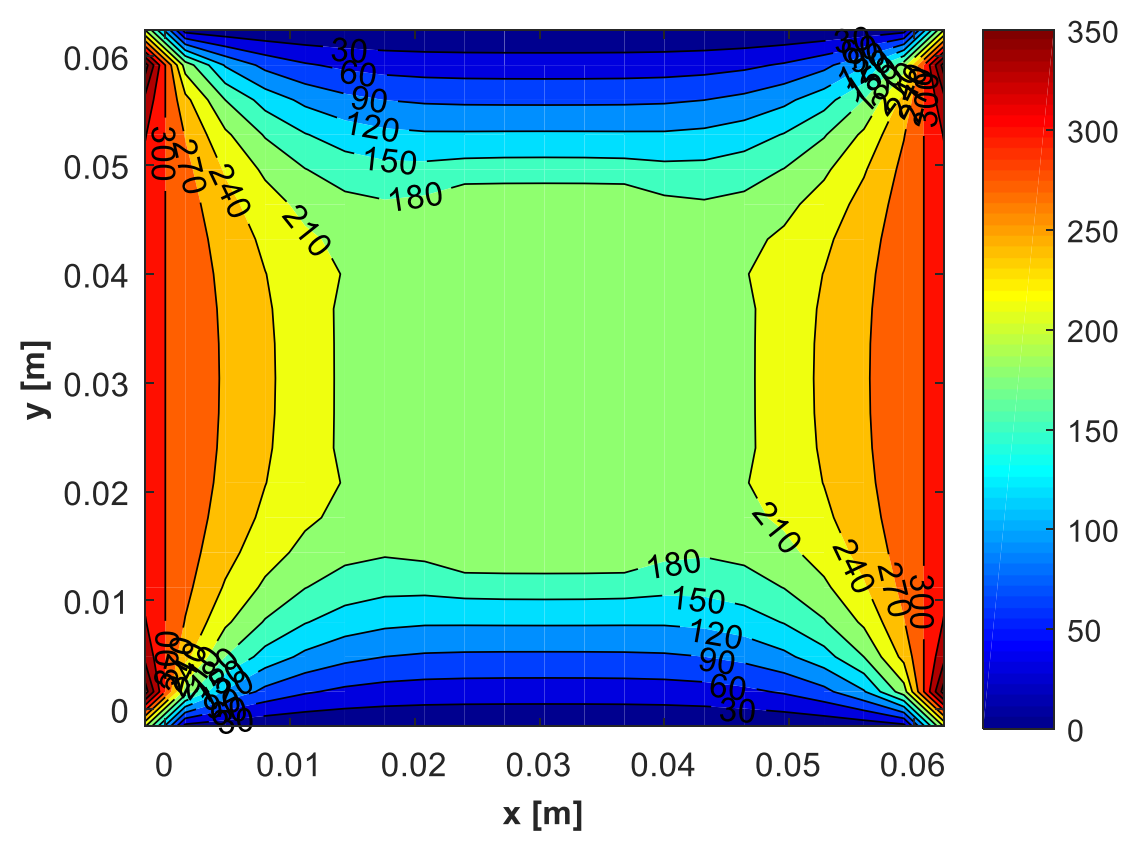

Figure 20 - Temperature of the thermal enclosure with air convection at south and north boundaries.
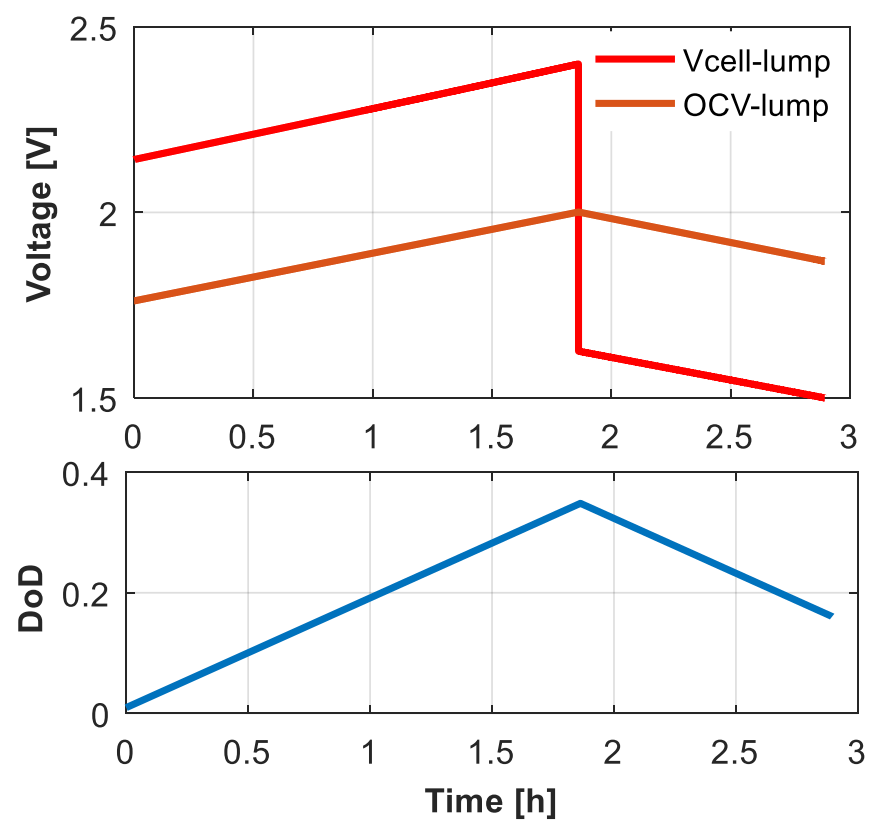

Figure 21 - The battery voltage and DoD when $T=200^{\circ} \mathrm{C}$. 
The battery is charged only less than $40 \%$ in about two hours and discharged about in an hour (Figure 21). Compare to normal operation results (Figure 13b), discharging time of the battery decreases to one-forth of it and the battery efficiency decreases as well. On the other hand, it can be calculated using convection heat transfer equation that the electrical heater must provide 594 Watt power in order to keep the wall at $330{ }^{\circ} \mathrm{C}$.

For another case study it is assumed that the surroundings around the single cell inside the thermal enclosure is air. However, for the real applications in the market, the gaps inside the battery block (between the cells) are filled by sand for packing stability, to limit the potential for oxidation in cells and to prevent the fire. Therefore, the computational model has been run based on the assumption that sand fills the gaps inside the block. The thermal properties of the air has been changed with thermal properties of the sand. The temperature results are obtained below.

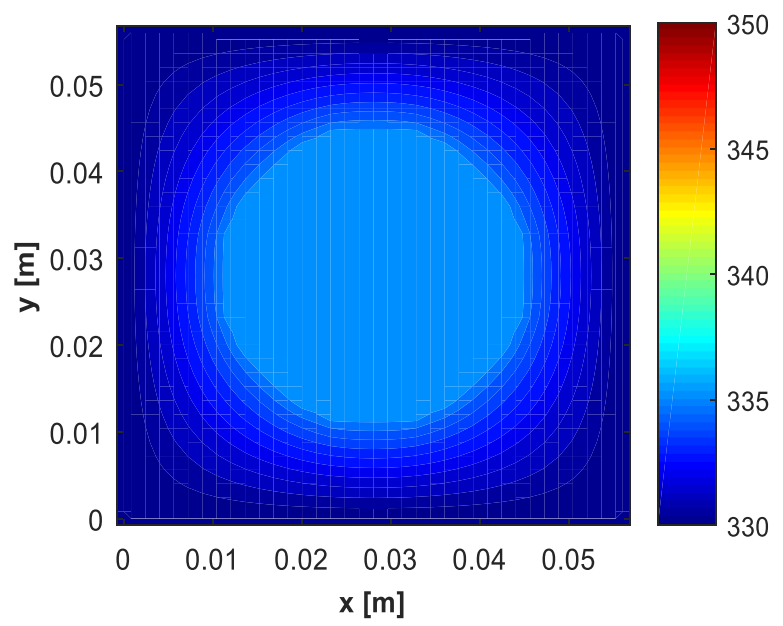

(a)

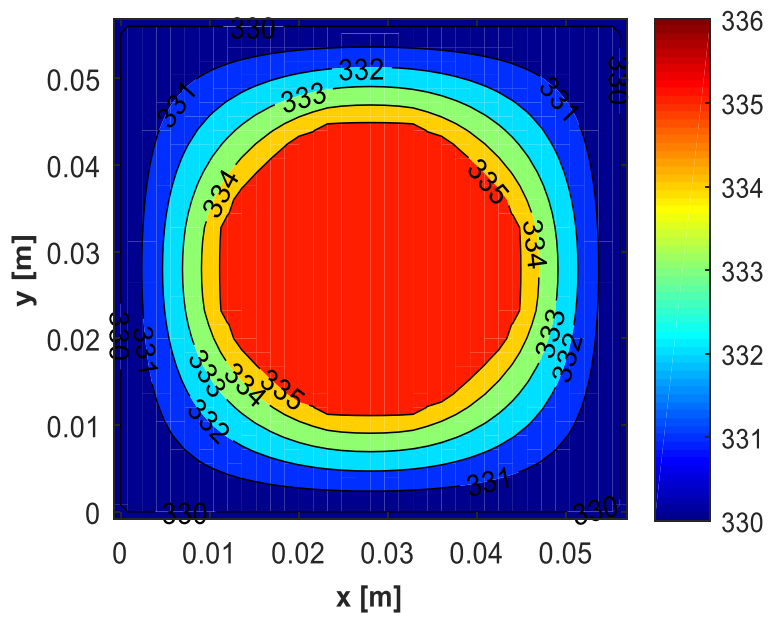

(b)

Figure 22 - Temperature contour in 2 hrs. of charging cycle when the gaps filled with sand (a) full scale (b) small scale. 


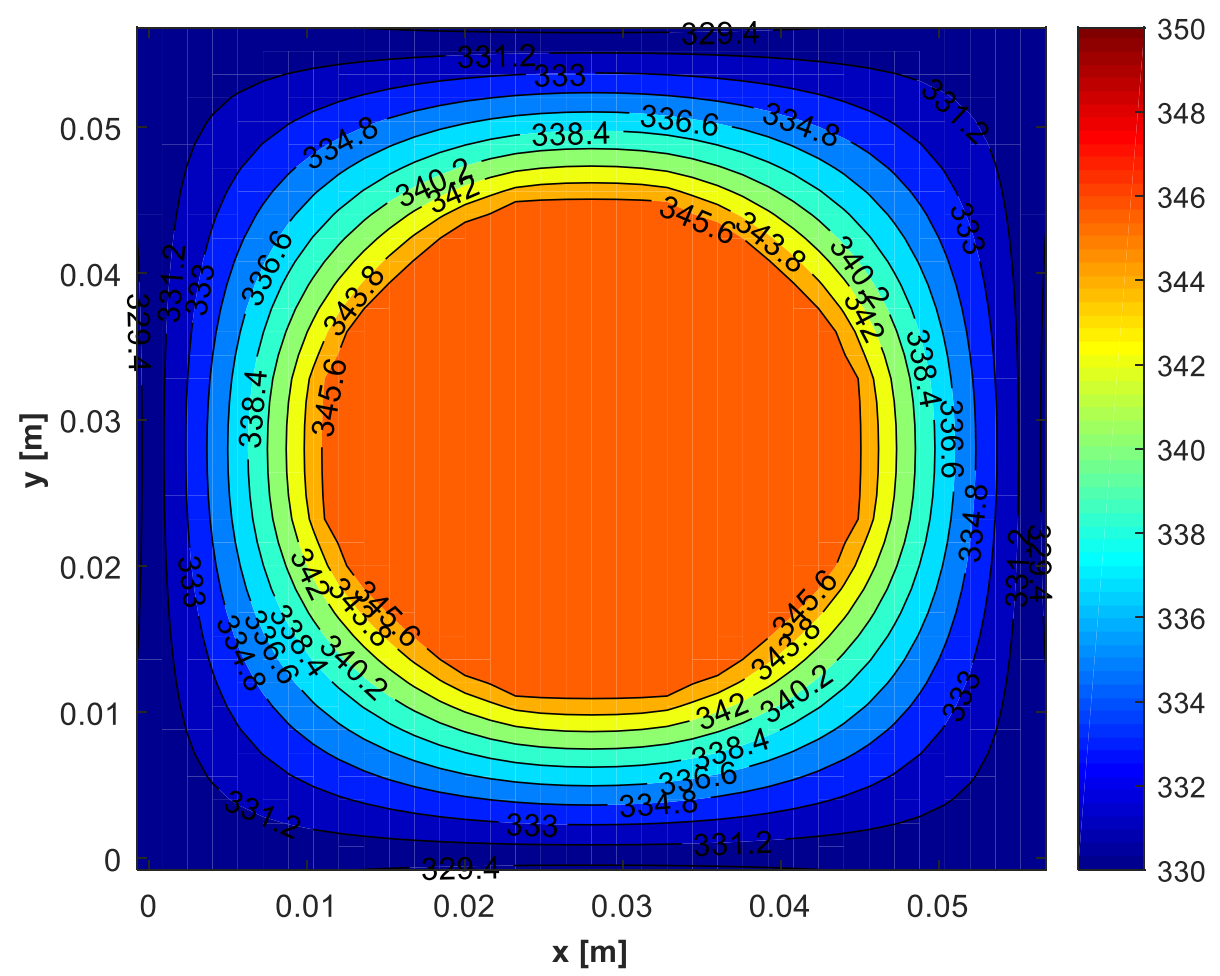

Figure 23 - Temperature contour in 2 hrs. of discharging cycle when the gaps filled with sand.

According to the results, there is not any significant change in temperature when the engineering sand is used $\left(\mathrm{SiO}_{2}\right)$. However, as it is indicated above it has some advantages in terms of safety, convenience and lifetime.

Also, in this model the battery is considered that it only used to perform experiments in laboratory however, in market applications the actual battery sizes are larger. Thus, the current model is extended to the real dimensions [9]. In 2007, Hussein, Cheung, Siam and Ismail charged and discharged the $\mathrm{NaS}$ battery as follows;

- 8 hours of constant power discharging at $84 \mathrm{~W}$

- 3 hours of constant power discharging at $136 \mathrm{~W}$

- 9 hours of constant power charging at $135 \mathrm{~W}$ 
Regarding to these conditions the present model is updated and summarized in Figures

24 and 25.
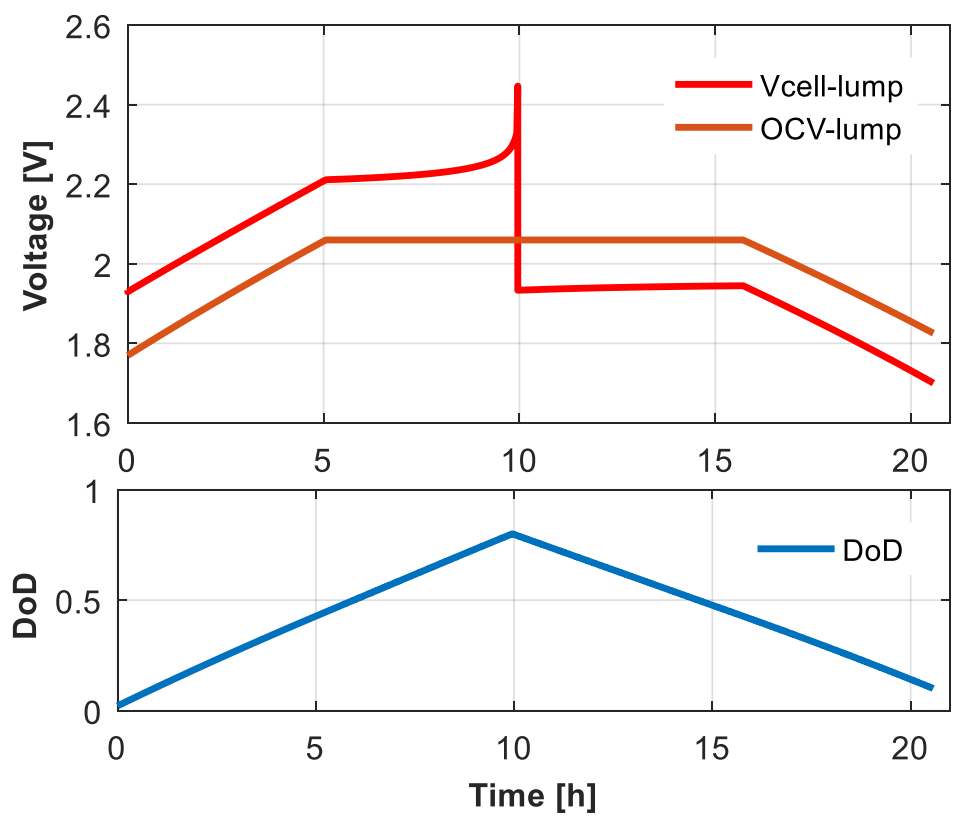

Figure 24 - Voltage and DoD for larger cell model.

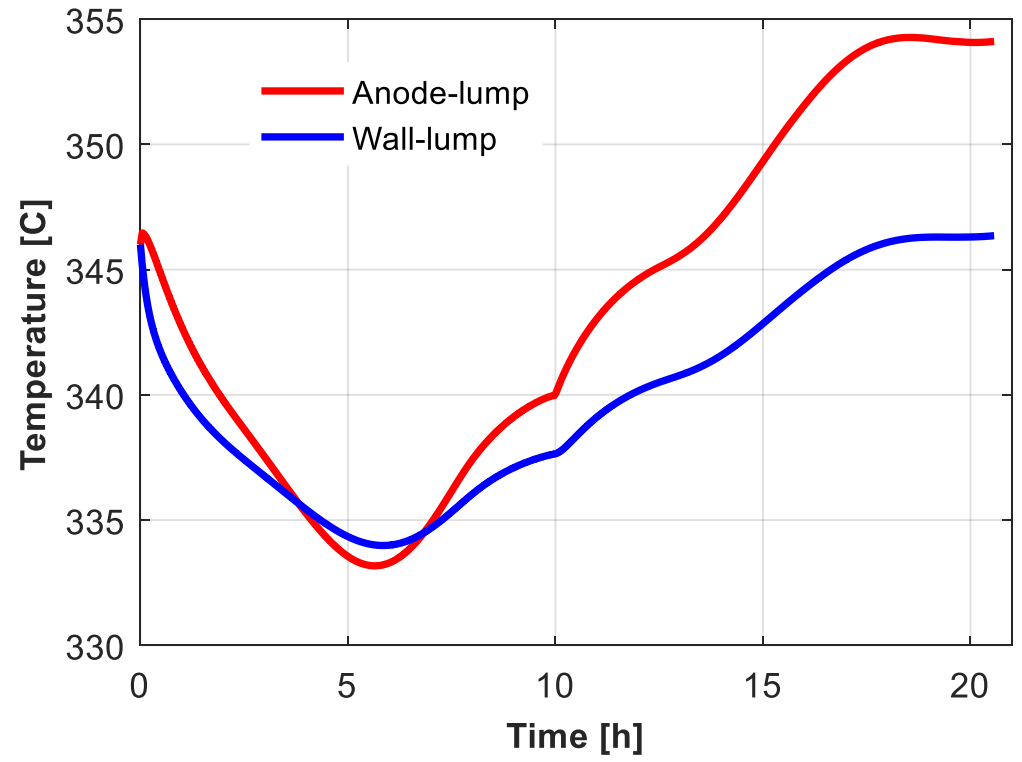

Figure 25 - Temperature profile for larger cell model. 
In the literature the one cycle of cell operation takes 20 hours. As it is seen in Figure 21 the present model completes one cycle approximately in 20 hours when the conditions are made same as in the literature. Similarly, for the temperature it can be concluded that the battery works in the range of operation temperatures (see Figure 25). It is also can be concluded that since the battery runs longer hours the chemical reaction increases the temperature of the battery more than it does in the previous model.

In the study, the number of the cells inside the battery block is user defined and it can be applied for any kind of cell configuration. Thus, the temperature can be easily predicted and this is highly convenient for researches who do experiments with different number of cells. In the following figures it is assumed that the NaS battery block contains 9 single cells which are arranged in 3 series and 3 parallel.

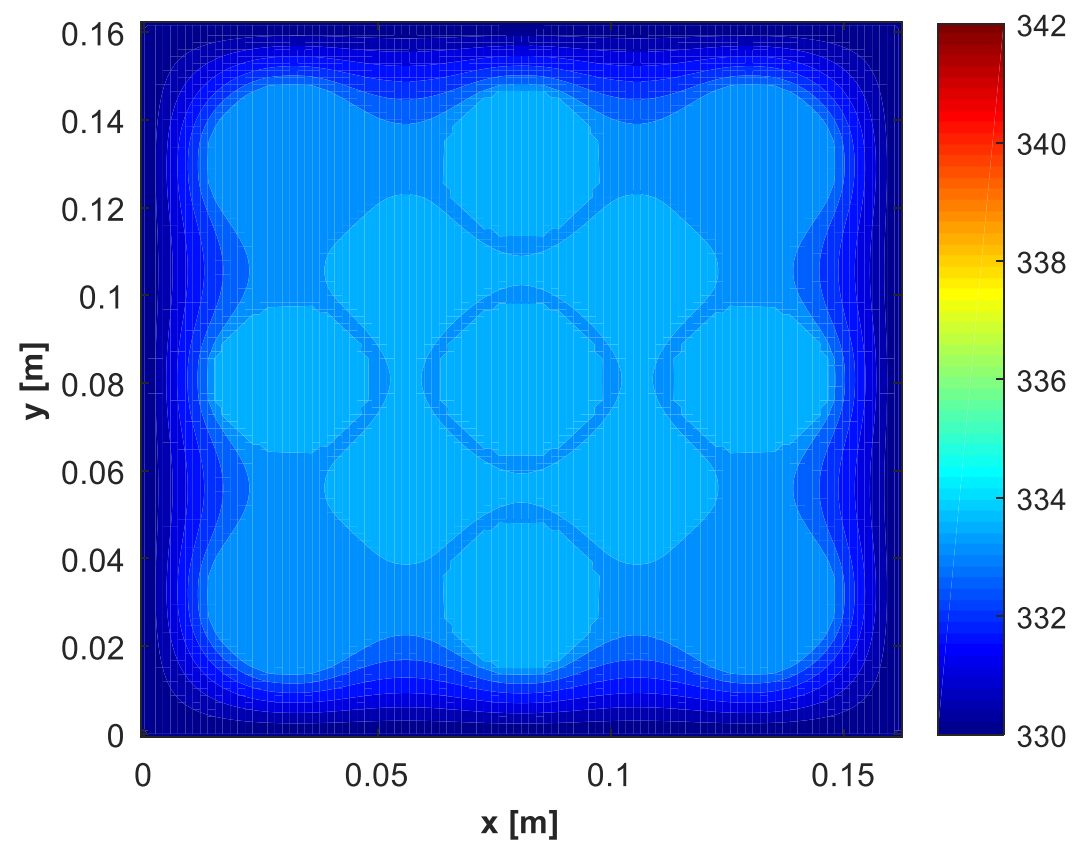

(a) 


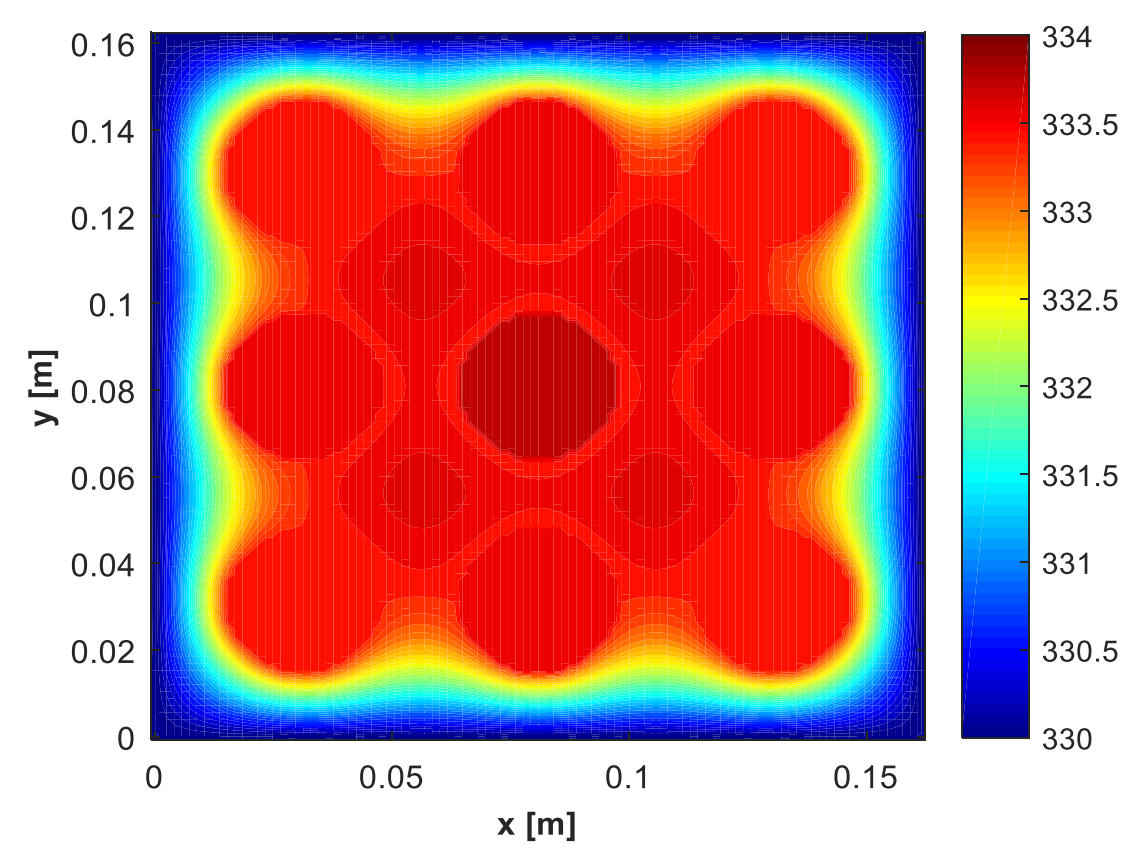

(b)

Figure 26 - Temperature contour in 2 hrs. of charging cycle for uniform boundary condition (a) full scale (b) small scale.

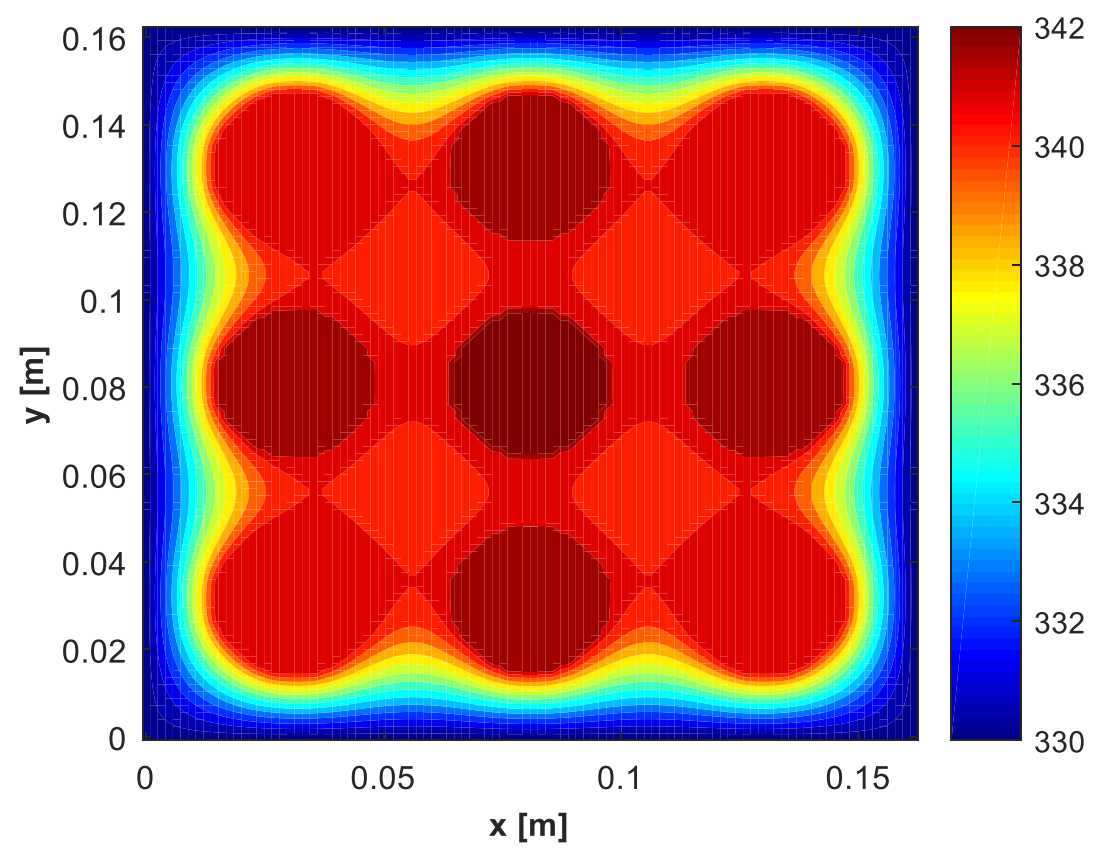

(a) 


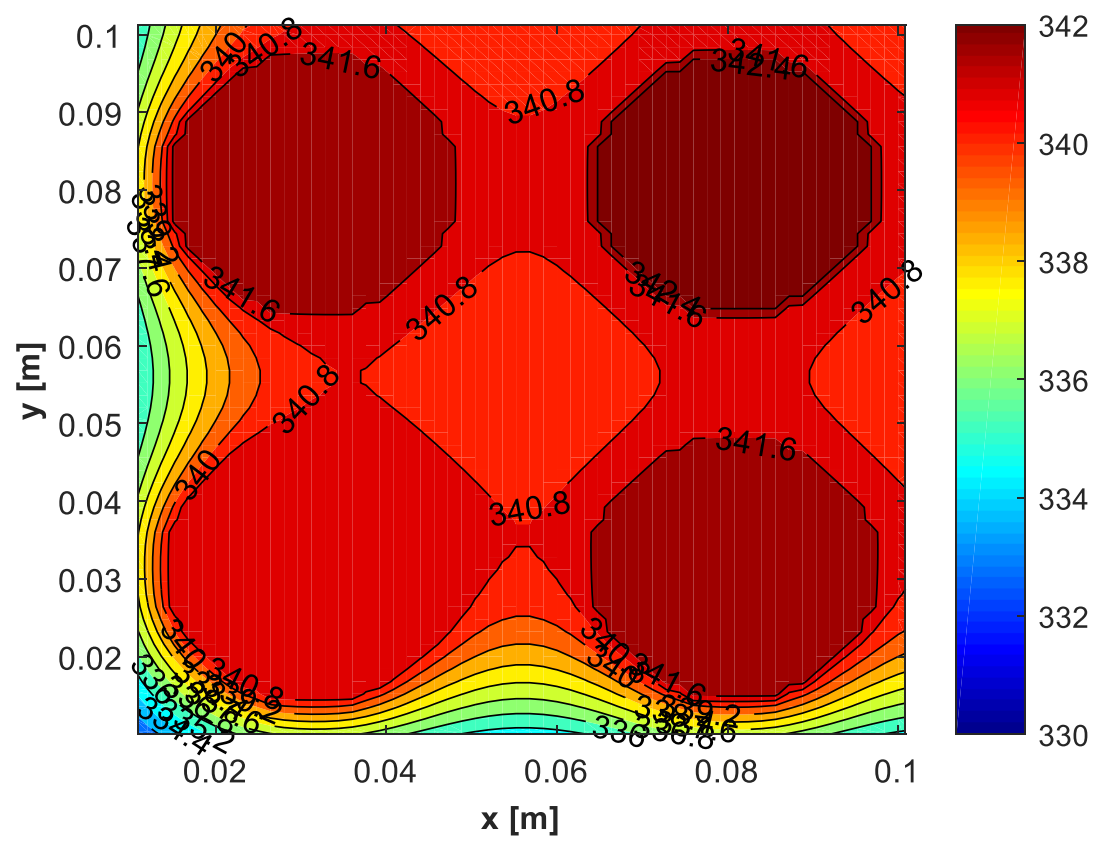

(b)

Figure 27 - Temperature contour in 2 hrs. of discharging cycle for uniform boundary condition (a) whole module (b) 4 cells in the bottom left-hand corner.

The temperature of the walls has been kept at $330{ }^{\circ} \mathrm{C}$ (Figure 26 and Figure 27). It is explained in the previous chapters that each individual cell takes the ambient temperature from its own defined boundary (see Figure 7). Based on that, in both charging and discharging cycles, it is expected that the cell in the middle should have highest temperature due to the less heat loss from surroundings. In the same manner, the corner cells should have the lowest temperature due to the heat loss from both walls (Figure 27b). 


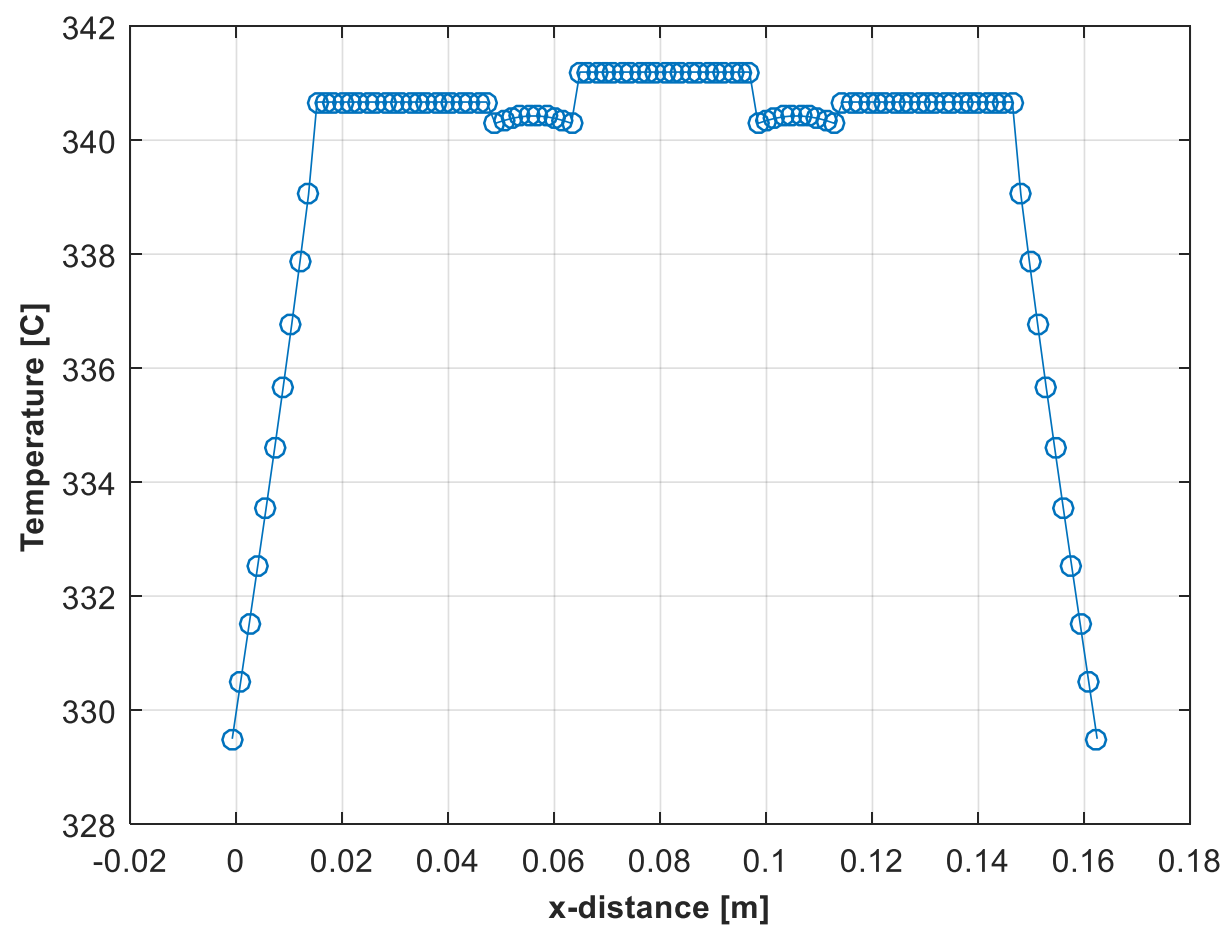

Figure 28 - Temperature profile along the x-axis for uniform boundary condition.

The temperature profile is obtained from middle points of the NaS battery block at the end of the discharge cycle (Figure 28). This figure illustrates the cells that are in the middle row. The cells are on the right and left are identically same because of the uniform boundary condition has been applied to the battery module (Figure 27a). Thus, it is expected from the cells to have the same temperature. In the same manner, the corner cells are identically same and all they have the same temperature value.

In the applications, it is difficult to have a uniform boundary condition around the battery module. The wind flow direction, the insulation, the sun, the heaters, the rain etc. might cause the boundary conditions to change easily. Therefore, a parametric study has been done and results are discussed below under the assumption of heating the west wall due to the environmental or technical effects. 


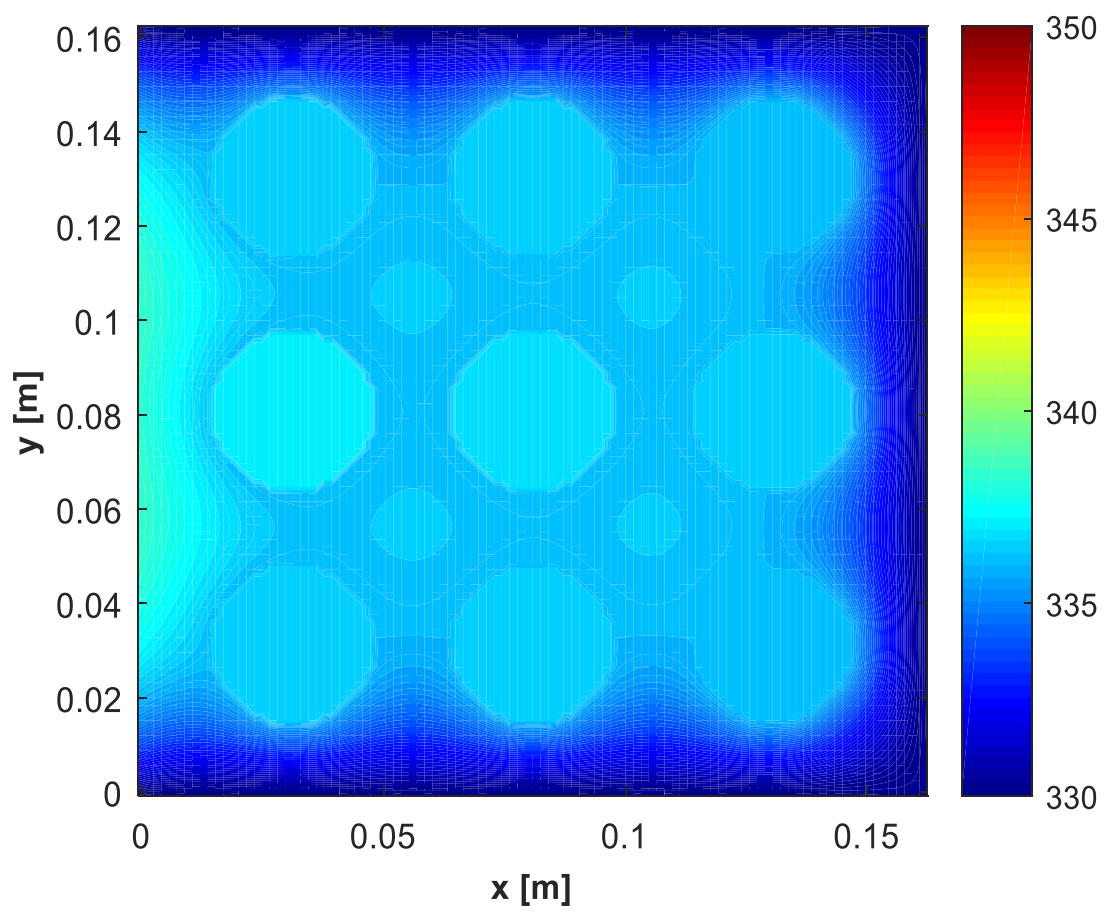

(a)

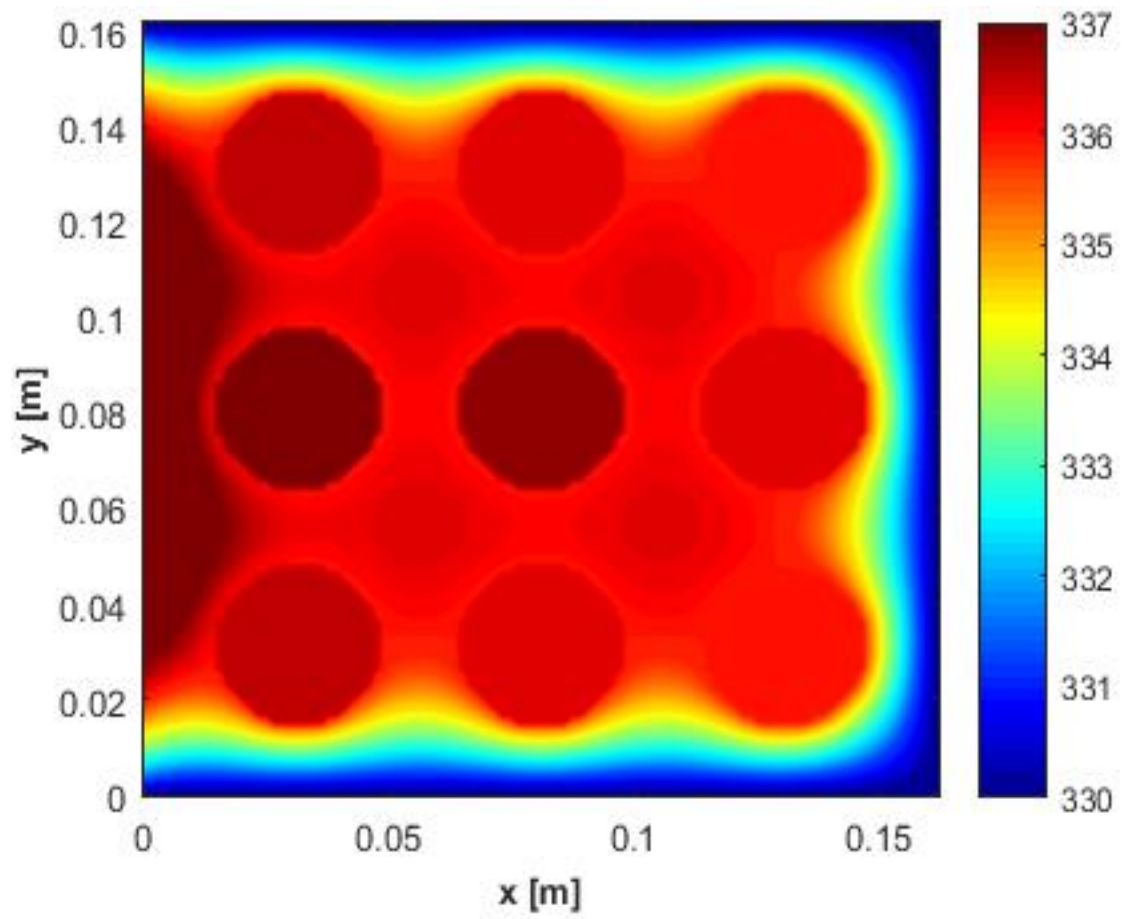

(b)

Figure 29 - Temperature profile in 2 hrs. of charging cycle for non-uniform boundary condition (a) full scale (b) small scale. 


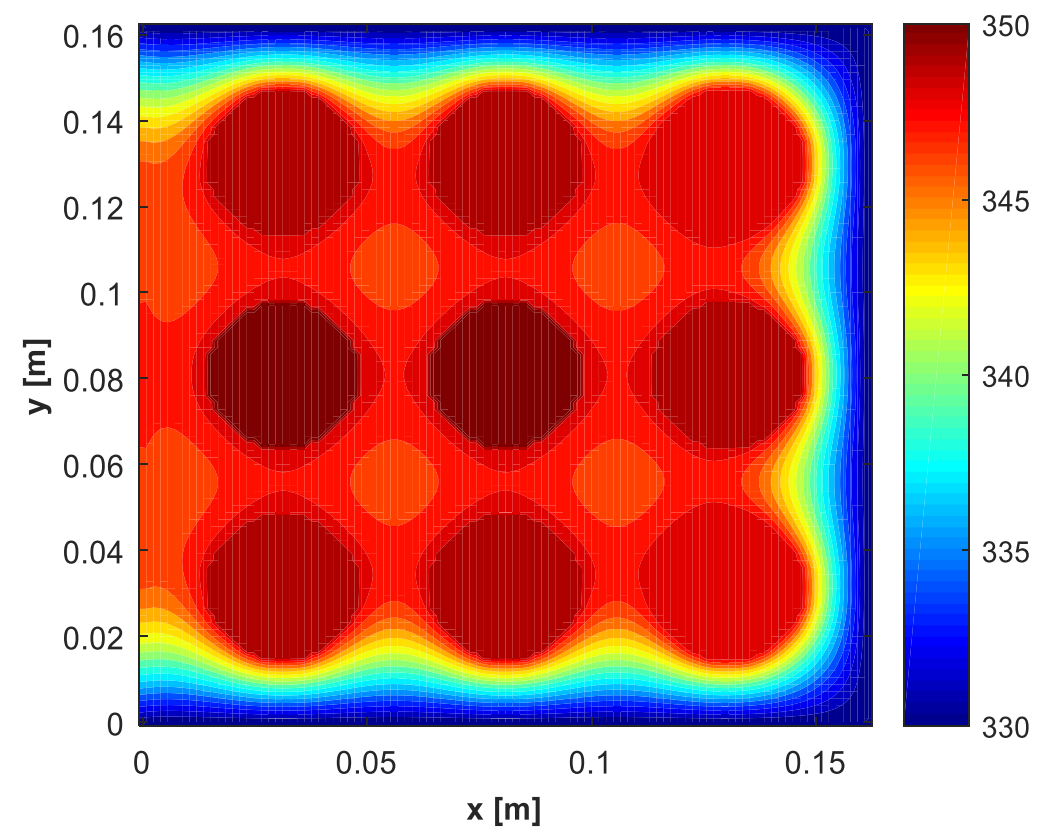

(a)

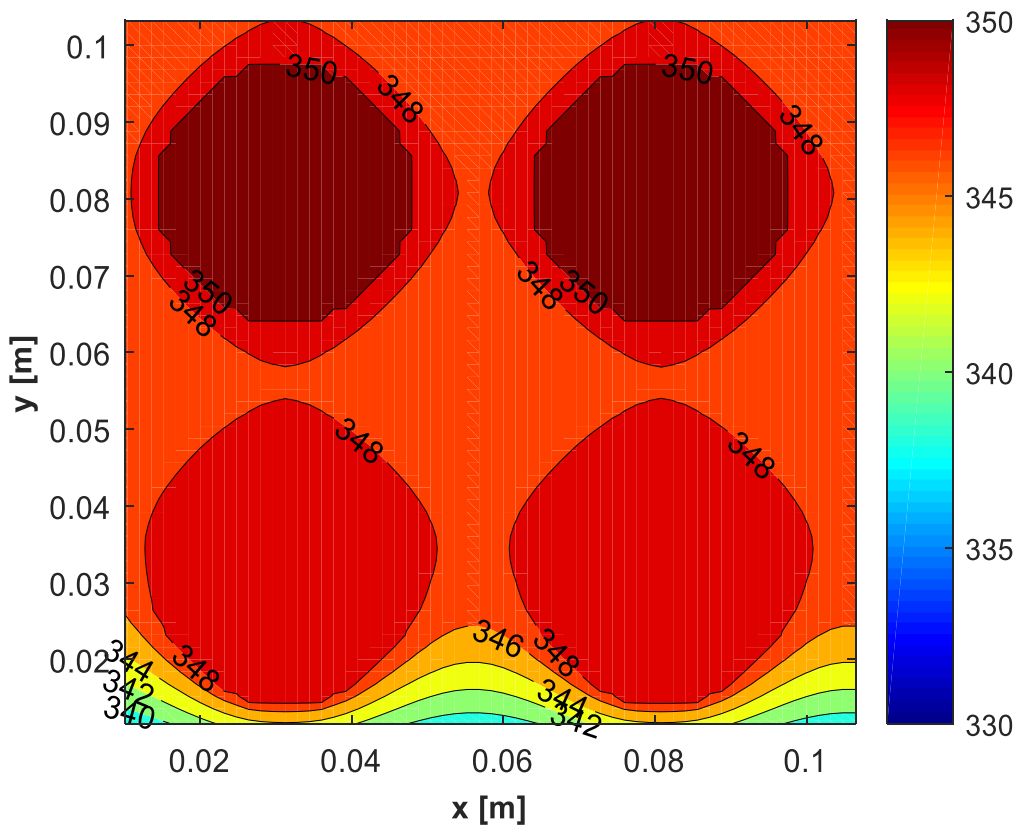

(b)

Figure 30 - Temperature contour in 2 hrs. of discharging cycle for non-uniform boundary condition (a) whole module (b) 4 cells in the bottom left-hand corner. 
In the Figure 29 and 30, the heat flux boundary condition is applied to the left wall and other walls are kept at $330^{\circ} \mathrm{C}$. Since the boundary condition is not uniform, the cells in the middle row are not identically same anymore. The cell on the left has higher temperature than the cell on the right. The reason is the cell on the left is closer to the heat source which heats it up. In previous case, when the boundary conditions were uniform, the cell in the middle had the highest temperature value. However, in this case it is not certain. In order to be sure of this, the temperature profile along the $\mathrm{x}$-axis should be observed.

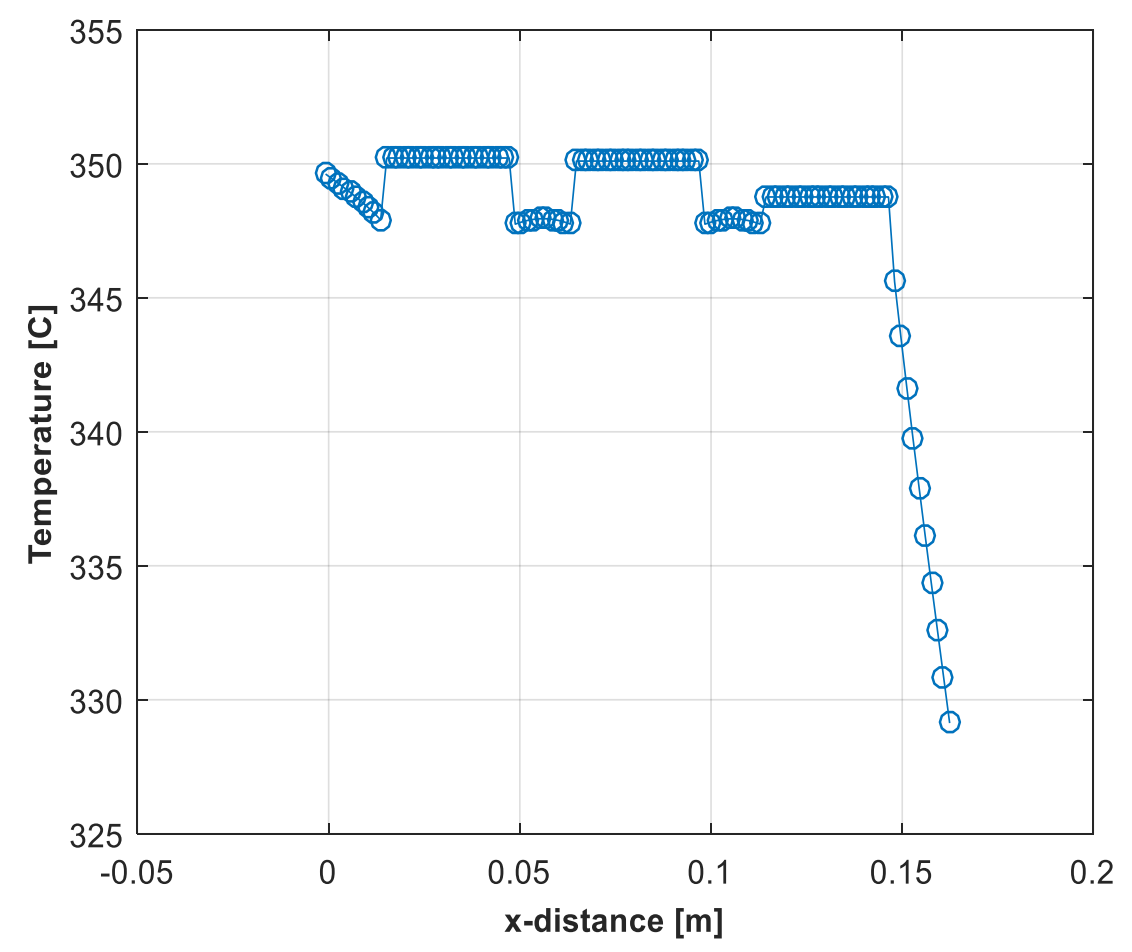

Figure 31 - Temperature profile along the x-axis with non-uniform boundary condition.

The temperature profile is obtained at the end of the discharge cycle for the middle row (Figure 31). The temperatures of the first two cells on the left can be considered the same (Figure 30b). However, they can be different from each other as well. On the other hand, the 
cell on the right has the lowest temperature value due to the heat loss. Also, the cell in the corner does not have the lowest temperature as it has in uniform boundary condition case due to the heat source (compare Figure 30b with Figure 27b).

In the industrial application that is shown in Figure 3, a NaS battery module contains 320 cells in 8 blocks. Each block has 40 cells in it and cells are arranged in 8 series and 5 parallel. Even though the model is capable to produce the results for 320 cells, in this case it is assumed that the module contains only one block. Applying the boundary conditions which the walls are kept at $330^{\circ} \mathrm{C}$, the temperature results are obtained after 5 iterations as follows;

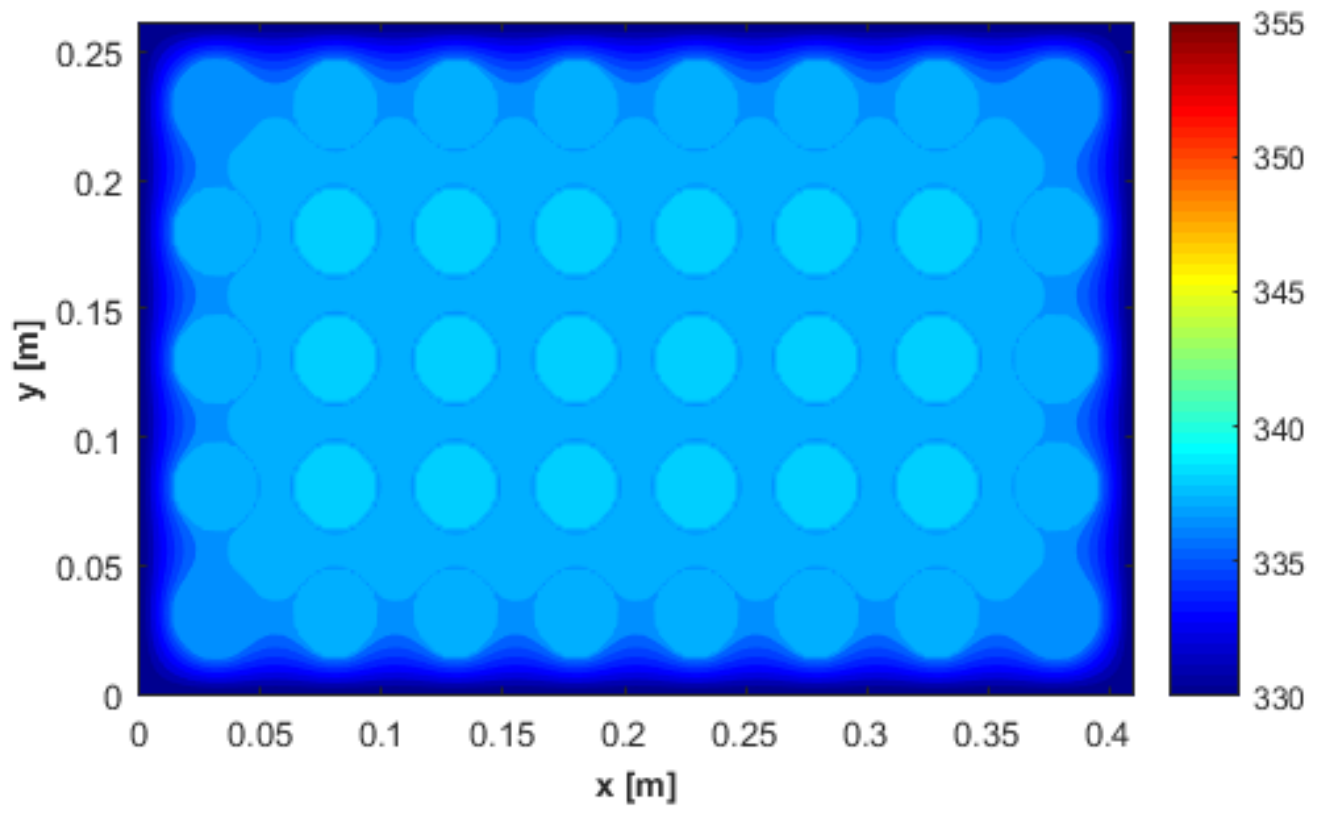

(a) 


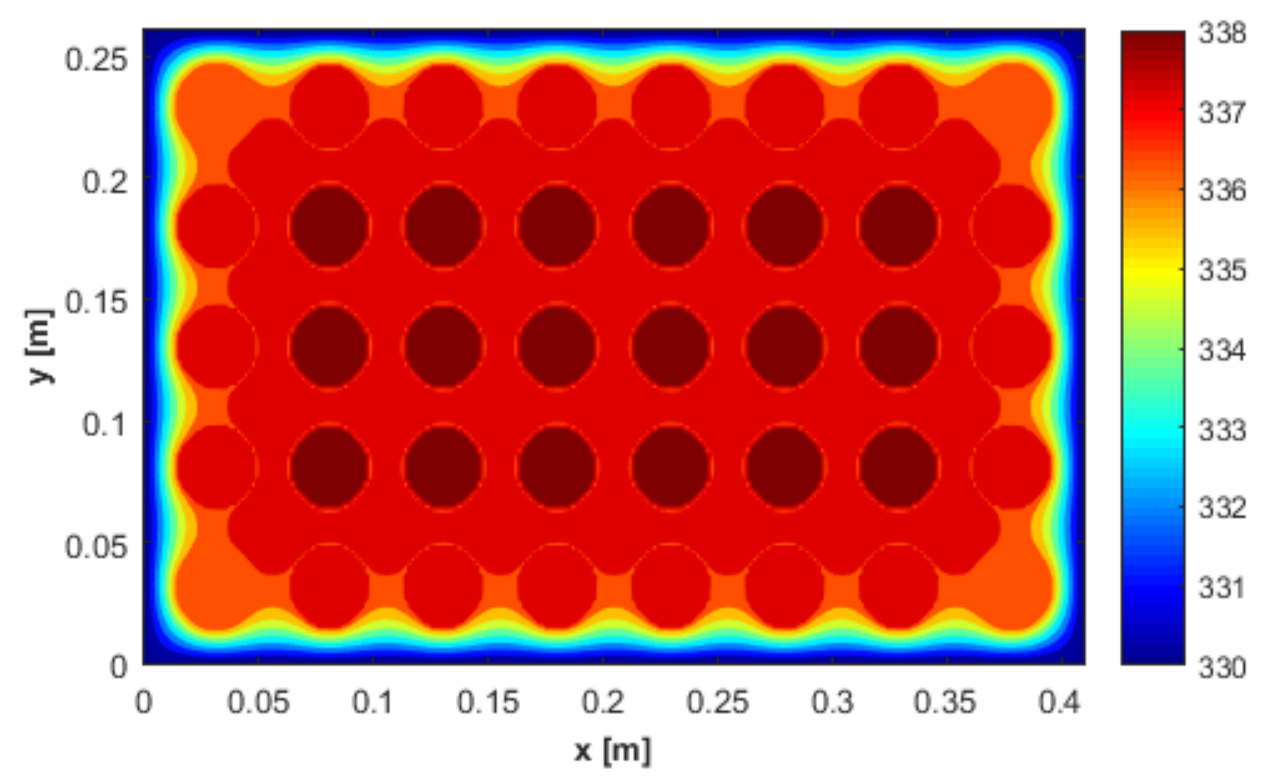

(b)

Figure 32 - Temperature profile in 2 hrs. of charging cycle for $8 \times 5$ battery module (a) full scale (b) small scale.

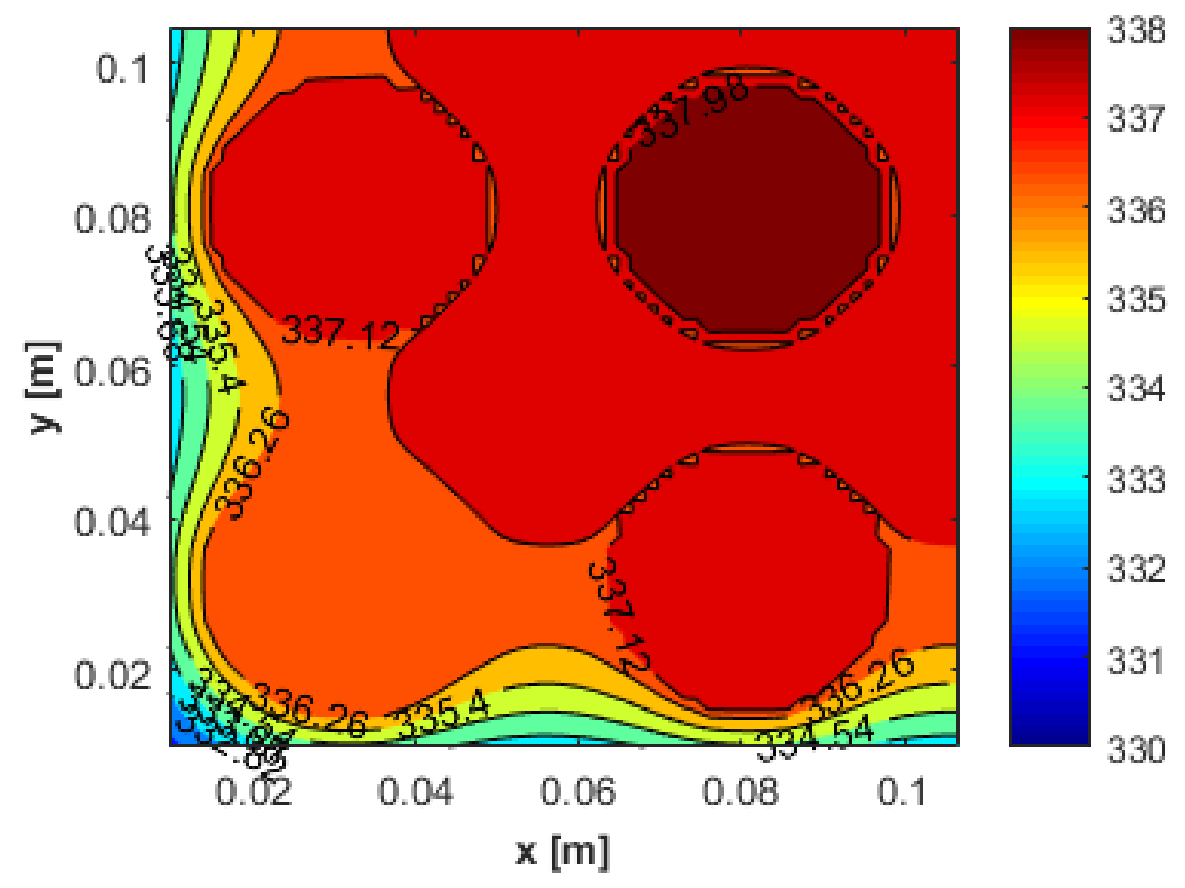

Figure 33 - Temperature profile in 2 hrs. of charging cycle for the 4 cells in bottom left-hand corner. 


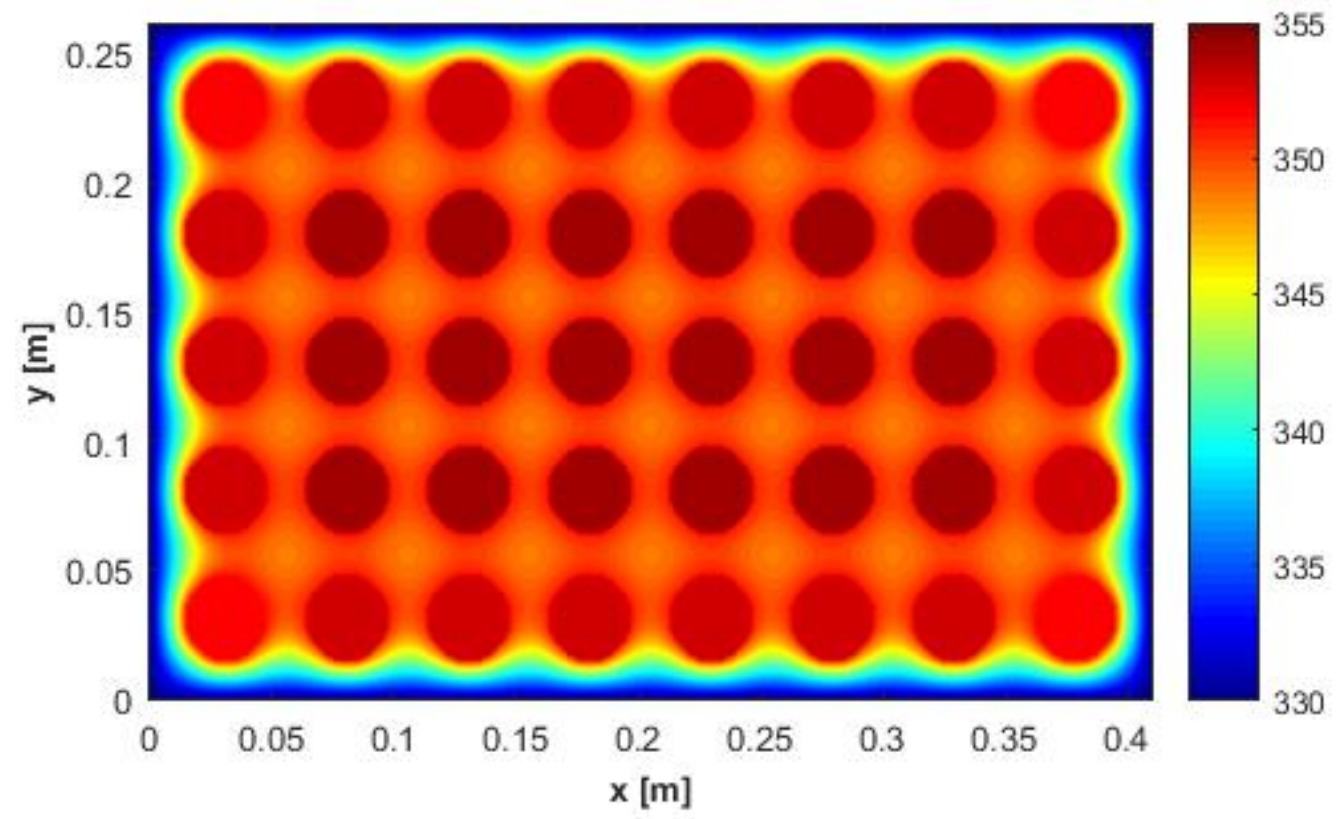

Figure 34 - Temperature profile in 2 hrs. of discharging cycle for $8 \times 5$ battery module.

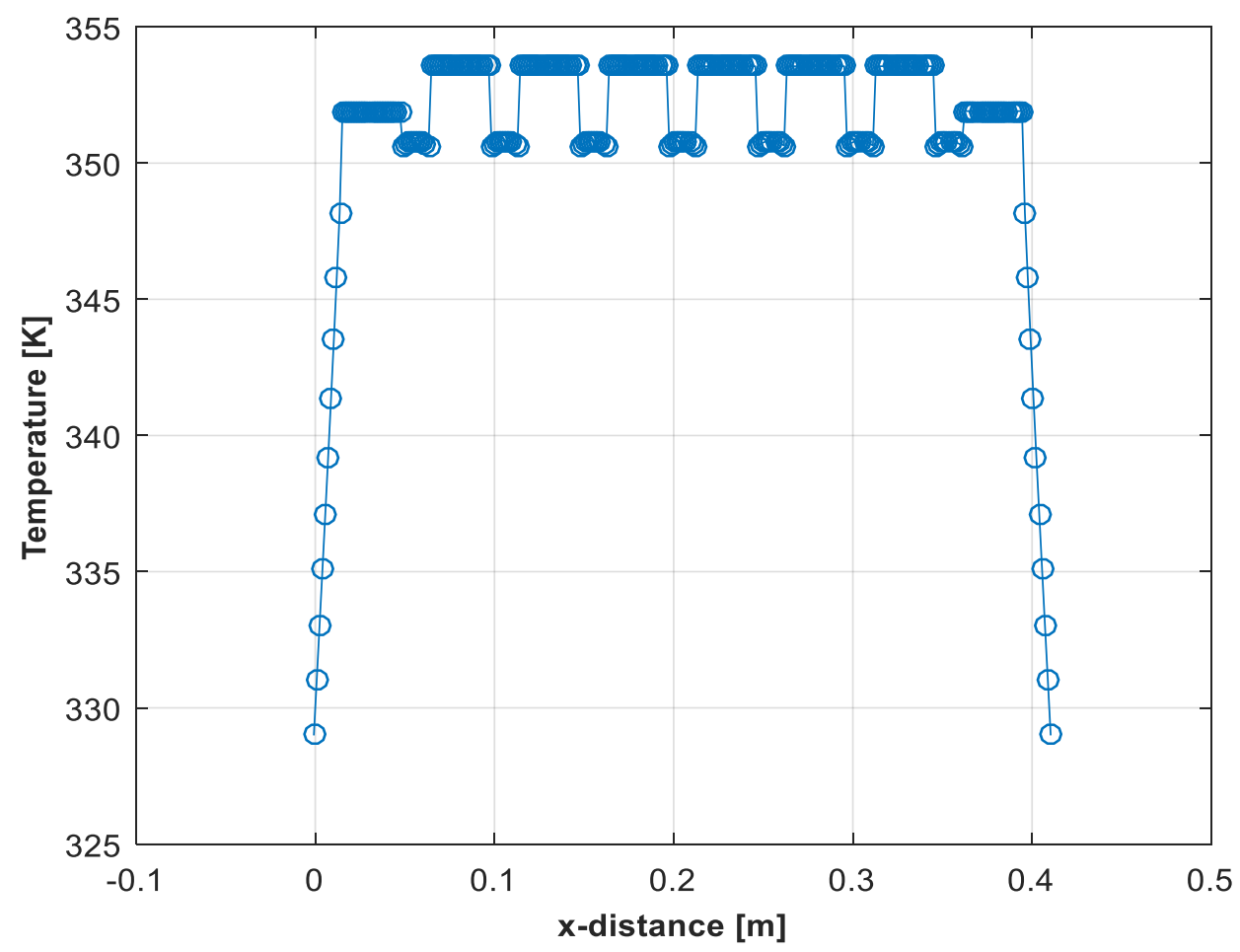

Figure 35 - Temperature profile of the middle row along the $\mathrm{x}$-axis for $8 \times 5$ cell configuration. 
Due to the uniform boundary conditions the cell temperatures are so close to each other in some rows and columns (Figure 32 and Figure 34). However, in order to see that the temperatures change with regard to position, the cells that are in the corner and near the walls can be observed (Figure 33).

\subsection{Mesh Convergence Analysis}

Numerical studies cannot produce exact solutions however; they can converge to the exact solution. In order to converge to the exact solution, mesh sizes of the domain must be small enough. If the result changes with large amount when the mesh size is finer, that means the solution has not converged yet. If the solutions are nearly similar, that means the first mesh size is good enough for the particular geometry. On the other hand, finer meshes come with a cost such as more computational time and large memory requirements. Therefore, it is desired to find the minimum number of elements that give you a converged solution. The number of the grids are shown in the table below.

Table 7 - Grid numbers for mesh convergence analysis.

\begin{tabular}{|c|c|}
\hline Mesh & Number of the grids \\
\hline 1 & $41 \times 41 \times 10$ \\
\hline 2 & $61 \times 61 \times 10$ \\
\hline 3 & $81 \times 81 \times 10$ \\
\hline
\end{tabular}




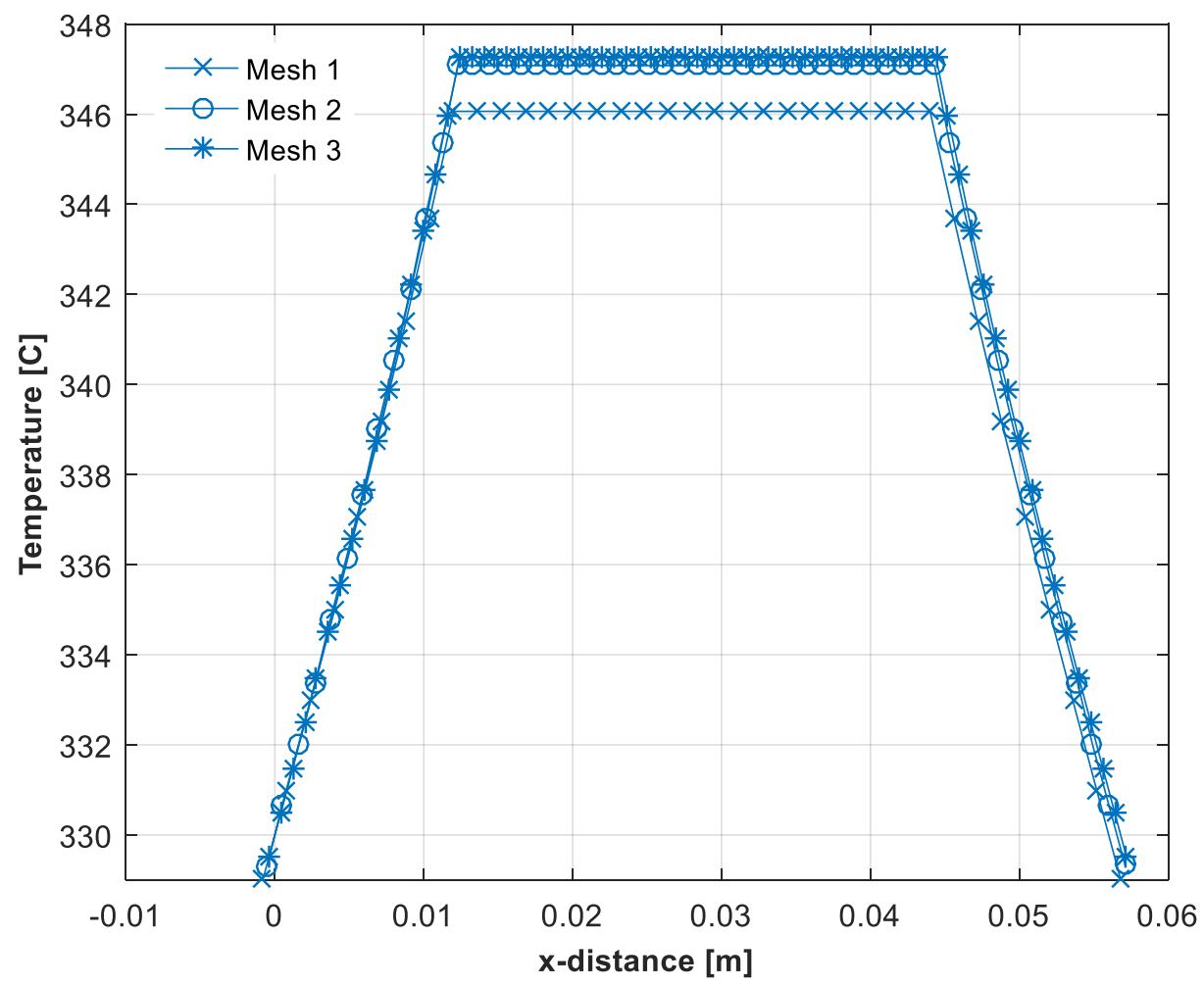

Figure 36 - Temperature profiles along the $\mathrm{x}$-axis for the grid numbers defined in Table 7 at the end of the discharge cycle.

The temperature does not change in large amount when the grid number increases. Thus, the numerical model results can be considered to be nearly grid independent.

For the larger cell, the mesh converge analysis is shown below in Figure 37. It can be easily seen that the grid numbers are enough to converge even though the cell dimensions are larger. 


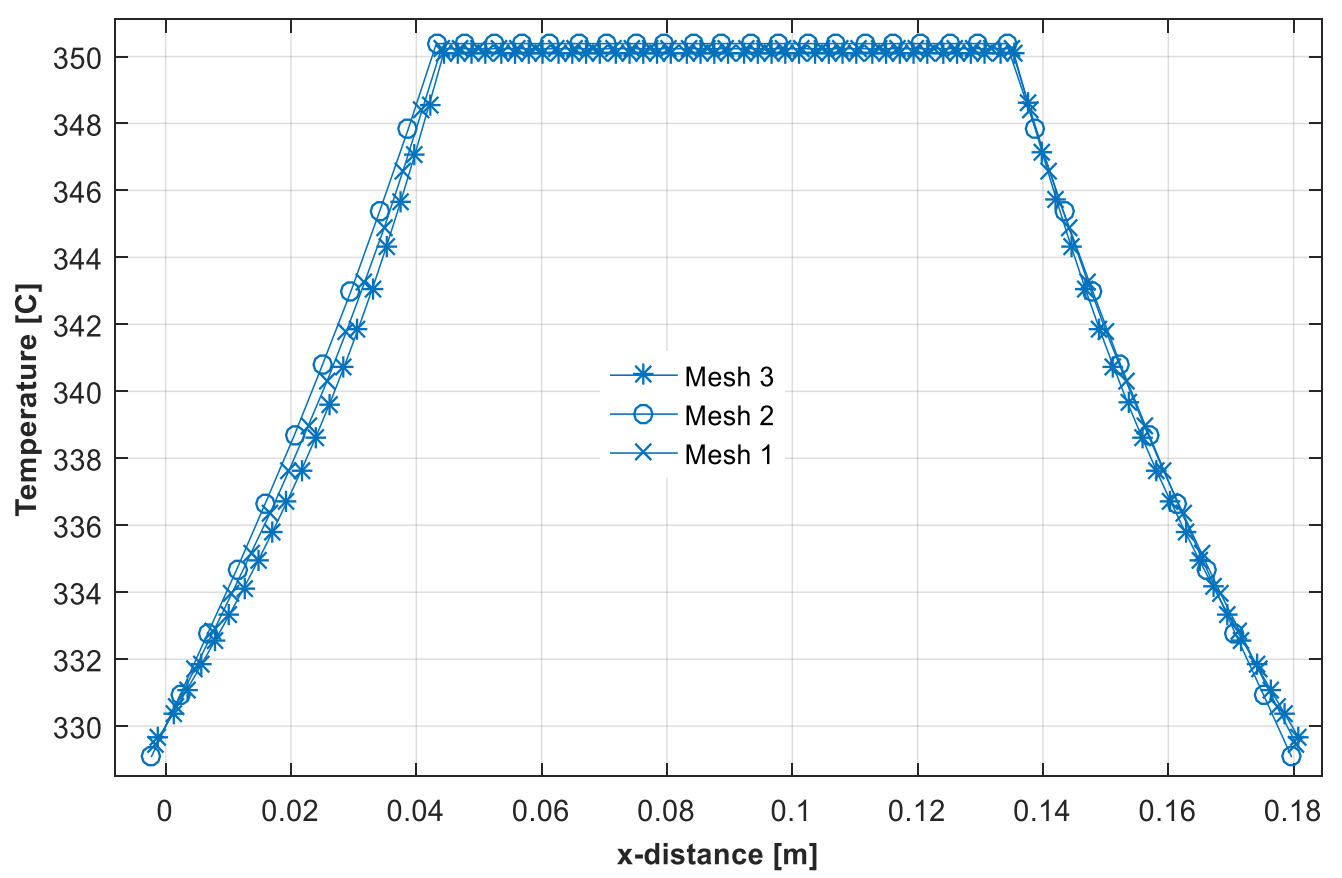

Figure 37 - Temperature profiles along the $\mathrm{x}$-axis for the grid numbers defined in Table 7 at the end of the discharge cycle for larger cell model. 


\section{Chapter 7: Conclusions}

In this study, a three-dimensional heat transfer model has been developed to simulate the temperature behaviors inside a NaS battery block. Also, a lumped model has been developed and incorporated into the 3D thermal model by using the governing equations of charge, energy and species conservation. The equations have been solved numerically and the results have been validated using published experimental and numerical data taken from the literature.

It is demonstrated the temperature distribution within the module can be predicted and variations from the required temperature range can be discerned. The model was run under several type of conditions. Thus, the temperature change in the enclosure and its effect on efficiency can be illustrated. Also, a fatigue analysis can be done for electrolyte regarding to the temperature change. The temperature change during the charging and discharging cycles is discussed in Appendix A.

The 3D thermal model when used with the lump electrochemistry model is robust and fast. It is also versatile such that more complex stack geometries and cell arrangements can be simulated. Hence, it can be concluded that a useful computation design tool has been developed for the NaS batteries in particular. The same model can be extended to other type of batteries without much difficulty. 


\section{References}

[1] Ohki, Y., "Recent Progress in Energy Storage by a NAS Battery System," IEEE Electrical Insulation Magazine, vol. 26, no. 3, 2008.

[2] Wen, Z., "Study on Energy Storage Technology of Sodium Sulfur Battery and its Application in Power System," in International Conference on Power System Technology, 2006.

[3] Jeffrey, W. B. and William, L. A., "Sodium Beta Batteries," Sandia National Laboratories, 1993.

[4] Bito, A., "Overview of the Sodium-Sulfur Battery for the IEEE Stationary Battery Committee," in IEEE, 2005.

[5] Kodama, E. and Kurashima, Y., "Development of a Compact Sodium-Sulphur Battery," Power Engineering Journals, 1999.

[6] Wen, Z., Cao, J., Gu, Z., Xu, X., Zhang, F. and Lin, Z., "Research on Sodium Sulfur Battery for Energy Storage," Solid State Ionics, vol. 179, pp. 1697-1701, 2008.

[7] Kawamoto, H. and Kusakabe, Y., "Performance and Thermal Behavior of Sodium Sulfur Cell under High Current Density Operations," Journal of Electrochemistry Society, vol. 136, no. 5, pp. 1355-1361, 1989.

[8] Iba, K., Ideta, R. and Suzuki, K., "Analysis and Operational Records of NAS Battery," Meisei University, Japan, 2006.

[9] Zahrul F. H., Lee W. C., Mohd F. M. S. and Amir B. I., "Modeling of Sodium Sulfur Battery for Power System Applications," Elektrika, vol. 9, no. 2, pp. 66-72, 2007.

[10] Sarasua, A. E., Molina, M. G., Pontoriero, D. E. and Mercado, P. E., "Modelling of NaS Energy Storage System for Power System Applications," Sao Paulo, 2010.

[11] Min, J. K. and Lee, C. H., "Numerical Study on the Thermal Management Sysyem of a Molten Sodium-Sulfur Battery Module," Journal of Power Sources, vol. 210, pp. 101$109,2012$.

[12] Gibson, J. G., "The Distribution of Potential and Electrochemical Reaction Rate in Molten Polysulphide Electrodes," Journal of Applied Electrochemistry, vol. 4, pp. 125134, 1973.

[13] Breiter, W. and Dunn, B., "Potential Distribution Model for Rechargeable Sulphur Electrodes in Sodium-Sulfur Cells," journal of Applied Electrochemistry, vol. 9, pp. 291-299, 1979. 
[14] Kawamoto, H., "Dynamic Simulation of the Charge-Discharge Characteristics of the Sodium-Sulfur Cell," Journal of Applied Electrochemistry, vol. 21, pp. 409-414, 1990.

[15] Kawamoto, H. and Wada, M., "Two-Dimensional Distribution of Electrochemical Reaction Rate in Porous Sulfur Electrodes of Sodium-Sulfur Cells," Journal of Electrochemical Society, vol. 134, no. 2, pp. 280-285, 1987.

[16] Kawamoto, H., "Two-Dimensional Distribution of Sodium Polysulfide Composition in Sulfur Electrodes of Sodium-Sulfur Cells," Journal of Electrochemical Society, vol. 136, no. 7, pp. 1851-1860, 1989.

[17] Bankal, W., Knodler, R. and Kuhn, W. H., "Sodium-Sulfur Battery and Process for its Production," United States Patent, 1977.

[18] Gotou, T., Kawamure, F., Sagawa, N. and Yusa, H., "Power Storage System Using Sodium Sulfur Batteries," United States Patent, 1986.

[19] Sernka, R. P. and Taenaka, R. K., "Planar Sodium-Sulfur Electric Storage Cell," Unites States Patent, 1991.

[20] Divya, K. C., and Ostergaard, J., "Battery Energy Storage Technology for Power Systems-An overview," Electric Power System Research, vol. 79, pp. 511-520, 2009.

[21] Rydh, C. J. and Sanden, B. A., "Energy analysis of batteries in photovoltaic systems. Part I:Performance and energy requirements," Energy Coversion\&Management, pp. 1957-1979, 2005.

[22] Sudworth, J. L. and Tiley, A., "Sodium Sulfur Battery," Springer Science\&Business Media, 1985.

[23] Oshima, T. and Kajita, M., "Development of Sodium-Sulfur Batteries," Journal of Applied Seramic Technology, vol. 1, no. 3, pp. 269-276, 2004.

[24] Lu, X., Xia, G., Lemmon, J. P. and Yang, Z., "Advanced Materials for Sodium-Beta Alumina Batteries," Journal of Power Sources, vol. 195, pp. 2431-2442, 2010.

[25] Bohnke, O., Ronchetti, S. and Mazza, D., "Conductivity Measurements on Nasicon and Nasicon-Modified Materials," Solid State Ionics, vol. 122, pp. 127-136, 1999.

[26] Fuentes, R. O., Figueiredo, F. M., Marques, F. M. B. and Franco, J. I., "Processing and Electrical Properties of NASICON Prepared from Yttria-Doped Zirconia Precursors," Journal of the European Ceramic Society, vol. 21, pp. 737-743, 2001.

[27] Ignaszak, A., Pasierb, P., Gajerski, R. and Komornicki, S., "Synthesis and Properties of Nasicon-Type Materials," Thermochimica Acta, vol. 426, pp. 7-14, 2005. 
[28] Wu, F., "A Lumped Model for Sodium Sulfur Battery Analysis," Master Thesis, 2014.

[29] Berera, G. P., "Lead-Acid Storage Cell," 2006.

[30] Wang, S., "Entropy and heat generation of lithium cells/batteries," Chinese Physical Society, vol. 25, no. 1, pp. 1-6, 2016.

[31] Subbarao, R., Vadivel, V. U. S. and Subbarao, P. M. V., "Mathematical Modeling of Activation Overpotential in High Temperature Fuel Cells," in BSME-ASME International Conference of Thermal Engineering, 2006.

[32] Mason, J. H., "Multiphysics Modelling of Sodium Sulfur Battery," 2016.

[33] Tu, J., Yeoh, G. H. and Liu, C., Computational Fluid Dynamics, ButterworthHeinemann, 2008.

[34] Patankar, S. V., Numerical Heat Transfer and Fluid Flow, McGraw-Hill Books, 1980.

[35] Shewchuk, J. R., "An Introduction to the Conjugate Gradient Method Without the Agonozing Pain," Carnegie Mellon University, Pittsburgh, 1994.

[36] Xiao, B., Wang, G., Wang, Q., Manizruzzaman, M. and Rong, Y., "An Experimental Study of Heat Transfer During Forced Air Convection," ASM International, vol. 20, pp. 1264-1270, 2010.

[37] Briant, J. L. and Farrington, G. C., "Ionic conductivity in Lithium and Lithium-Sodium Beta Alumina," Journal of Electrochemical Society, vol. 128, no. 9, pp. 1830-1834, 1981. 


\section{Appendix A}

\section{A.1 Parameters}

The other parameters that used in the NaS battery model is shown below.

Table 8 - Parameters used in the model.

\begin{tabular}{|c|c|}
\hline Thermal conductivity of air $[\mathrm{W} / \mathrm{mK}]$ & 0.0485 \\
\hline Thermal conductivity of sand $[\mathrm{W} / \mathrm{mK}]$ & 0.15 \\
\hline Density of air $\left[\mathrm{kg} / \mathrm{m}^{3}\right]$ & 0.566 \\
\hline Density of sand $\left[\mathrm{kg} / \mathrm{m}^{3}\right]$ & 1600 \\
\hline Heat capacity of air $[\mathrm{J} / \mathrm{kgK}]$ & 1055 \\
\hline Heat capacity of sand $[\mathrm{J} / \mathrm{kgK}]$ & 800 \\
\hline Porosity & 0.9 \\
\hline Universal gas constant $(\mathrm{R})$ & 8.314 \\
\hline Faraday constant $[J]$ & 96485 \\
\hline Molar mass of sulfur $[\mathrm{g} / \mathrm{mol}]$ & 32.06 \\
\hline Molar mass of sodium $[\mathrm{g} / \mathrm{mol}]$ & 22.99 \\
\hline Molar mass of sodium-polysulfide $[\mathrm{g} / \mathrm{mol}]$ & 174.22 \\
\hline Convection heat transfer coefficient $\left[\mathrm{W} / \mathrm{m}^{2} \mathrm{~K}\right]$ & 5 \\
\hline Radius of anode [m] & 0.0063 \\
\hline Radius of electrolyte [m] & 0.0075 \\
\hline Radius of cathode $[\mathrm{m}]$ & 0.032 \\
\hline Height of single $\mathrm{NaS}$ cell $[\mathrm{m}]$ & 0.18 \\
\hline
\end{tabular}




\section{A.2 Fatigue Analysis}

Fatigue is the weakening of a material caused by cyclic applied loads or stresses; in our case thermal stresses arising from temperature gradients. Since the anode and cathode materials are liquid only the solid electrolyte is exposed to cyclic temperature differences during the charging and discharging states. Considering the cycle life of a NaS battery (approximately 3000 cycles) is very long, the fatigue analysis becomes crucial. The temperature change in the electrolyte can be seen for the 5 complete cycles in Figure A.1 and the fatigue analysis can be done based on the temperature change inside the cell. In applications the NaS battery systems have a standby time before starting each iteration. Thus, it can be assumed that the battery has the same starting temperature in each iteration.

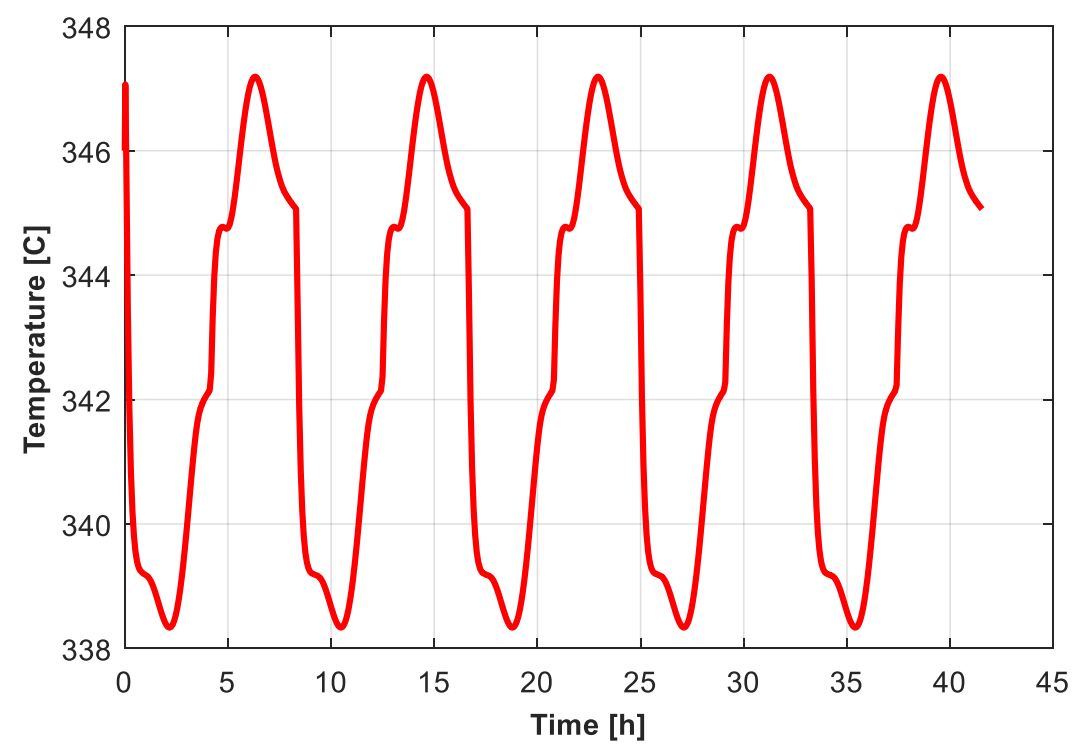

Figure A.2 Temperature profile of the electrolyte during the 5 full cycles. 